Portland State University

PDXScholar

\title{
A New Method for Calculating the Economic Benefits of Varying Degrees of Power Factor Correction for Industrial Plant Loads
}

Mohammed Ishaque

Portland State University

Follow this and additional works at: https://pdxscholar.library.pdx.edu/open_access_etds

Part of the Power and Energy Commons

Let us know how access to this document benefits you.

\section{Recommended Citation}

Ishaque, Mohammed, "A New Method for Calculating the Economic Benefits of Varying Degrees of Power Factor Correction for Industrial Plant Loads" (1992). Dissertations and Theses. Paper 4322.

https://doi.org/10.15760/etd.6206

This Thesis is brought to you for free and open access. It has been accepted for inclusion in Dissertations and Theses by an authorized administrator of PDXScholar. Please contact us if we can make this document more accessible: pdxscholar@pdx.edu. 
AN ABSTRACT OF THE THESIS OF Mohammed Ishaque for the Master of Science in Electrical and Computer Engineering presented January 31,1992.

Title: A New Method for Calculating the Economic Benefits of Varying Degrees of Power Factor Correction for Industrial Plant Loads

APPROVED BY THE MEMBERS OF THE THESIS COMMITTEE:

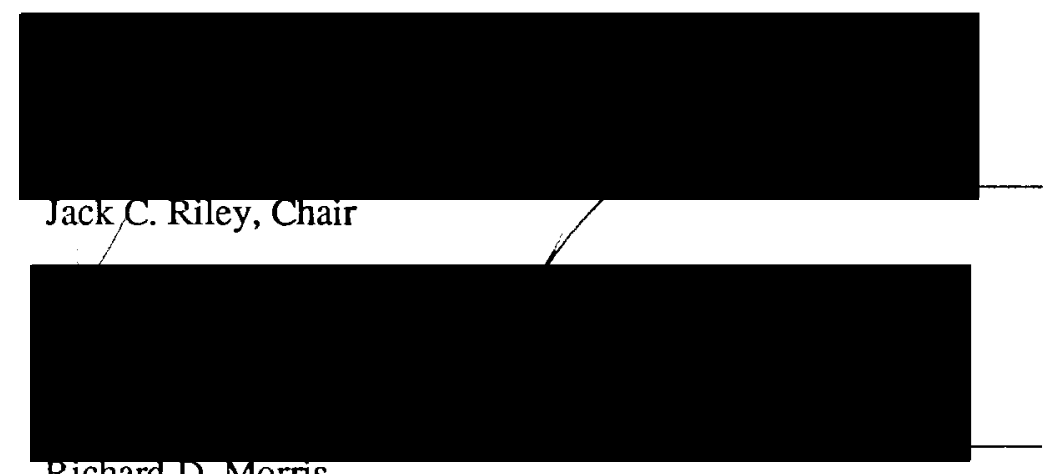

Richard D. Mortis

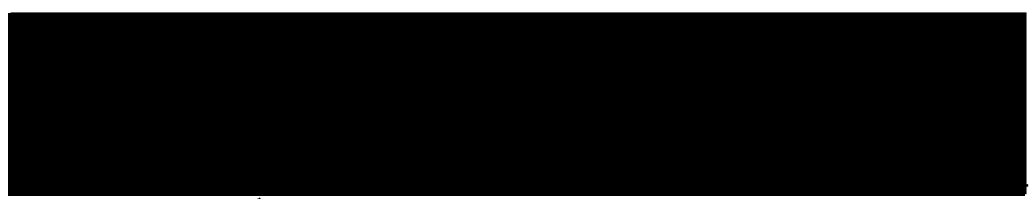

Faryar Etesami

A comparative study of the economic benefits that can be obtained from different degrees of power factor correction for medium and small scale industrial installations is shown. A new approach for precise calculation of $k w s$ and kvars required at different power factors is presented. These calculated values are used to find the retum on investments for the capacitors needed for power factor correction. The developed method is easy to use, cost effective, accurate and will help electrical engineers with minimum knowledge of power systems to precisely determine the savings available by improving the power factor of an industrial load. 
A NEW METHOD FOR CALCULATING THE ECONOMIC BENEFITS OF VARYING DEGREES OF POWER FACTOR CORRECTION FOR INDUSTRIAL PLANT LOADS

$$
\text { by }
$$

MOHAMMED ISHAQUE

A thesis submitted in partial fulfillment of the

requirements for the degree of

\section{MASTER OF SCIENCE}

in

ELECTRICAL AND COMPUTER ENGINEERING

Portland State University

1992 


\section{TO THE OFFICE OF GRADUATE STUDIES:}

The members of the Committee approve the thesis of Mohammed Ishaque presented January 31, 1992.

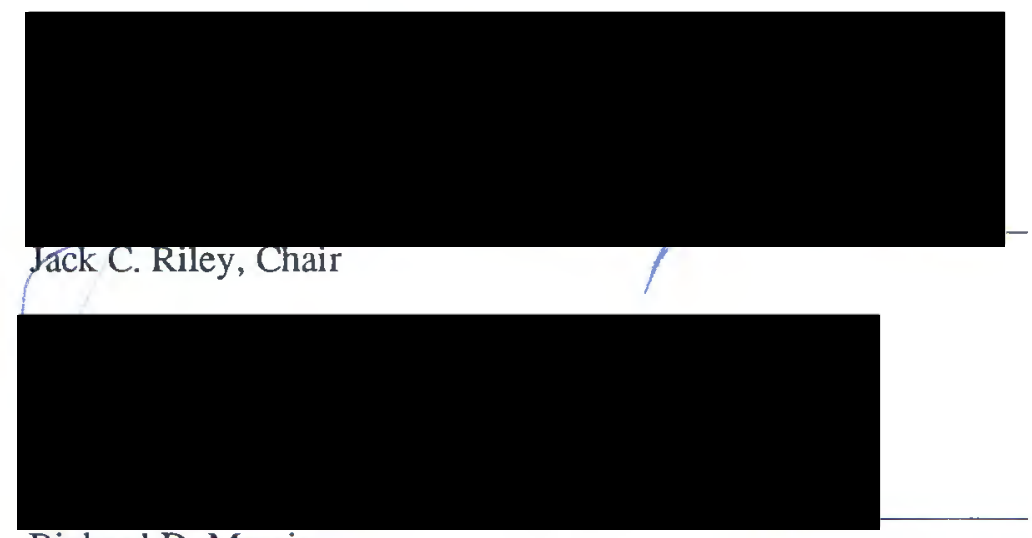

Richard D. Morris

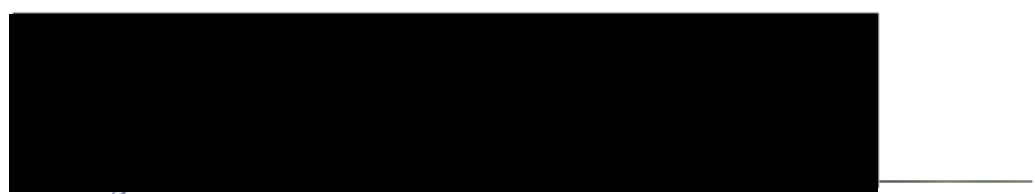

Faryär Etesami

APPROVED:

Rolf Schaumann, Chair, Department of Electrical Engineering

C. Whiliam Savery, vice Provost for Graduate ytudres and Research 


\section{ACKNOWLEDGEMENTS}

I wish to express my profound gratitude to Mr. Barry W. Kennedy of Bonneville Power Administration who patiently guided me through this endeavor. He certainly deserves much credit.

I also wish to thank my academic adviser, Professor Jack C. Riley for his constant support and encouragement in completing this thesis. Prof. Riley's creative suggestions and comments were valuable resources which made this thesis possible. I am grateful for the unbelievable time he spent for my thesis despite his busy schedule.

In addition, I express my appreciation to Cecilia H. Espinosa and Yousef A. Dandach for their support and assistance in swimming through this difficult endeavor.

Finally, I appreciate the moral support of my parents, wife and sweet daughter during the whole course of my graduate study at the Portland State University. May God bless them all.

Portland, Oregon

Mohammed Ishaque 


\section{TABLE OF CONTENTS}

PAGE

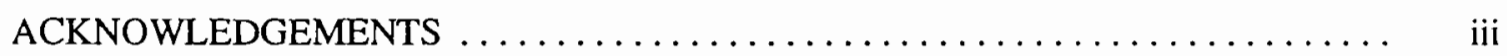

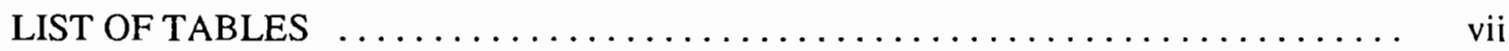

LIST OF FIGURES $\ldots \ldots \ldots \ldots \ldots \ldots \ldots \ldots \ldots \ldots \ldots \ldots \ldots \ldots \ldots \ldots \ldots \ldots \ldots$ viii

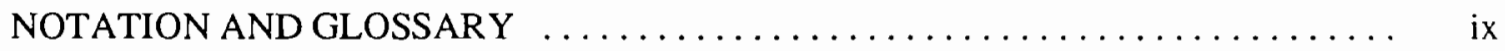

\section{CHAPTER}

I INTRODUCTION $\ldots \ldots \ldots \ldots \ldots \ldots \ldots \ldots \ldots \ldots \ldots \ldots \ldots \ldots \ldots, 1$

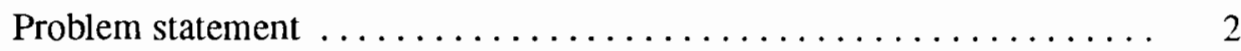

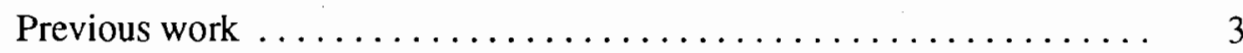

Solution approach $\ldots \ldots \ldots \ldots \ldots \ldots \ldots \ldots \ldots \ldots \ldots \ldots \ldots \ldots \ldots \ldots$

Significance and contributions $\ldots \ldots \ldots \ldots \ldots \ldots \ldots \ldots \ldots \ldots \ldots \ldots \ldots \ldots$

Organization of the thesis $\ldots \ldots \ldots \ldots \ldots \ldots \ldots \ldots \ldots \ldots \ldots \ldots \ldots$

II POWER FACTOR $\ldots \ldots \ldots \ldots \ldots \ldots \ldots \ldots \ldots \ldots \ldots \ldots \ldots \ldots \ldots \ldots \ldots$

Leading and lagging power factor $\ldots \ldots \ldots \ldots \ldots \ldots \ldots \ldots \ldots, \quad 9$

The effects of low power factor $\ldots \ldots \ldots \ldots \ldots \ldots \ldots \ldots \ldots \ldots \ldots$

Causes of low power factor $\ldots \ldots \ldots \ldots \ldots \ldots \ldots \ldots \ldots \ldots \ldots \ldots \ldots \ldots \ldots$

Methods of power factor measurement $\ldots \ldots \ldots \ldots \ldots \ldots \ldots \ldots, 13$

Practical methods of power factor improvement $\ldots \ldots \ldots \ldots \ldots \ldots$

Reasons for improving power factor $\ldots \ldots \ldots \ldots \ldots \ldots \ldots \ldots \ldots \ldots \ldots$ 


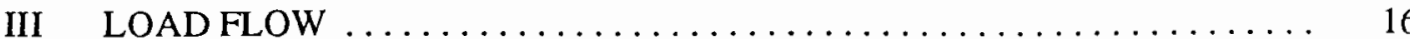

Glossary of load flow terms $\ldots \ldots \ldots \ldots \ldots \ldots \ldots \ldots \ldots \ldots \ldots$

Newton-Raphson method $\ldots \ldots \ldots \ldots \ldots \ldots \ldots \ldots \ldots \ldots \ldots$

Related programs $\ldots \ldots \ldots \ldots \ldots \ldots \ldots \ldots \ldots \ldots \ldots \ldots \ldots \ldots$

How to use the method $\ldots \ldots \ldots \ldots \ldots \ldots \ldots \ldots \ldots$

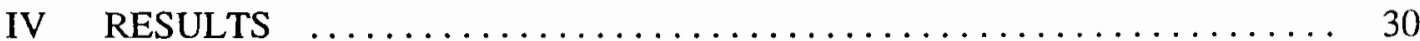

A power distribution model $\ldots \ldots \ldots \ldots \ldots \ldots \ldots \ldots \ldots \ldots \ldots$

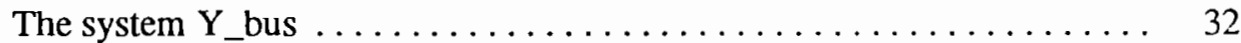

Simulation results at $95 \%$ power factor $\ldots \ldots \ldots \ldots \ldots \ldots \ldots \ldots$

Simulation results at $90 \%$ power factor $\ldots \ldots \ldots \ldots \ldots \ldots$

Simulation results at $85 \%$ power factor $\ldots \ldots \ldots \ldots \ldots$

Simulation results at $80 \%$ power factor $\ldots \ldots \ldots \ldots \ldots$

Summary of cost of energy and time of recovery $\ldots \ldots \ldots \ldots \ldots$

$\mathrm{V}$ CONCLUSIONS AND FUTURE WORK $\ldots \ldots \ldots \ldots \ldots \ldots \ldots \ldots \ldots$

REFERENCES $\ldots \ldots \ldots \ldots \ldots \ldots \ldots \ldots \ldots \ldots \ldots \ldots \ldots \ldots \ldots \ldots \ldots \ldots \ldots$

\section{APPENDICES}

A THE PROGRAM SOURCE CODE FOR THE CALCULATION OF

REAL AND REACTIVE POWER

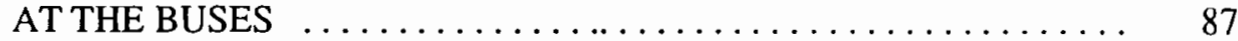

B THE PROGRAM SOURCE CODE FOR LOAD FLOW CALCULATION

USING THE NEWTON-RAPHSON METHOD . . . . . . . . . . 90

C THE PROGRAM SOURCE CODE FOR

LINE FLOW CALCULATIONS ................... 101 
D THE PROGRAM SOURCE CODE

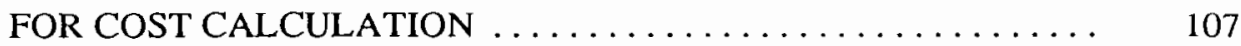




\section{LIST OF TABLES}

TABLE

PAGE

I Power Factor of Load and Source $\ldots \ldots \ldots \ldots \ldots \ldots \ldots \ldots \ldots, 10$

II Multipliers to Determine Capacitor Size for

pf Correction $\ldots \ldots \ldots \ldots \ldots \ldots \ldots \ldots \ldots \ldots \ldots \ldots \ldots \ldots \ldots \ldots$

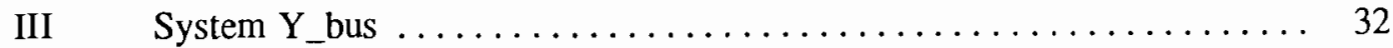

IV Load Flow Output at $\mathrm{pf}=95 \% \ldots \ldots \ldots \ldots \ldots \ldots \ldots \ldots \ldots \ldots \ldots$

V Partial compensation at the Load Buses at $\mathrm{pf}=95 \% \ldots \ldots \ldots \ldots \ldots$

VI Compensation at Buses at $\mathrm{pf}=95 \% \ldots \ldots \ldots \ldots \ldots \ldots \ldots \ldots \ldots \ldots \ldots \ldots \ldots$

VII Load Flow Output at $\mathrm{pf}=90 \% \ldots \ldots \ldots \ldots \ldots \ldots \ldots \ldots \ldots \ldots \ldots$

VIII Partial compensation at the Load Buses at $\mathrm{pf}=90 \% \ldots \ldots \ldots \ldots \ldots$

IX Compensation at Buses at $\mathrm{pf}=90 \% \ldots \ldots \ldots \ldots \ldots \ldots \ldots \ldots \ldots \ldots \ldots \ldots$

$\mathrm{X} \quad$ Load Flow Output at $\mathrm{pf}=85 \% \ldots \ldots \ldots \ldots \ldots \ldots \ldots \ldots \ldots \ldots \ldots \ldots \ldots$

XI Partial compensation at the Load Buses at $\mathrm{p} f=85 \% \ldots \ldots \ldots \ldots \ldots$

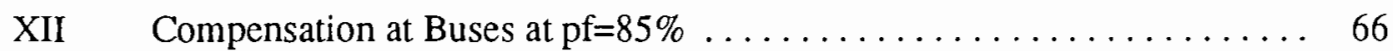

XIII Load Flow Output at $\mathrm{pf}=80 \% \ldots \ldots \ldots \ldots \ldots \ldots \ldots \ldots \ldots \ldots \ldots \ldots \ldots \ldots \ldots$

XIV Partial compensation at the Load Buses at $\mathrm{pf}=80 \% \ldots \ldots \ldots \ldots$

$\mathrm{XV} \quad$ Compensation at Buses at $\mathrm{pf}=80 \% \ldots \ldots \ldots \ldots \ldots \ldots \ldots \ldots \ldots$

XVI Summary of Cost of Energy $\ldots \ldots \ldots \ldots \ldots \ldots \ldots \ldots \ldots \ldots$

XVII Cost Effective and Time of Recovery $\ldots \ldots \ldots \ldots \ldots \ldots \ldots \ldots, 81$ 


\section{LIST OF FIGURES}

FIGURE

PAGE

1. Right Triangle Relationship of Current and Power $\ldots \ldots \ldots \ldots \ldots$

2. Effects of Low Power Factor on Altemators and Transformers . . . . . 12

3. Flow Chart of Newton-Raphson Algorithm $\ldots \ldots \ldots \ldots \ldots \ldots \ldots$

4. Flow chart of Pfactor.c $\ldots \ldots \ldots \ldots \ldots \ldots \ldots \ldots \ldots \ldots \ldots \ldots$

5. Flow chart of Lineflow.c $\ldots \ldots \ldots \ldots \ldots \ldots \ldots \ldots \ldots \ldots \ldots \ldots \ldots$

6. Flow chart of CostCalc.c . . . . . . . . . . . . . . . . 29

7. A Power Distribution Model $\ldots \ldots \ldots \ldots \ldots \ldots \ldots \ldots \ldots \ldots \ldots \ldots$

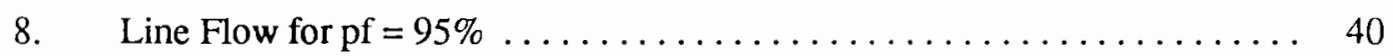

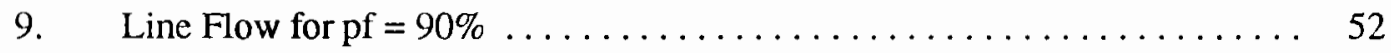

10. Line Flow for $\mathrm{pf}=85 \% \ldots \ldots \ldots \ldots \ldots \ldots \ldots \ldots \ldots \ldots \ldots$

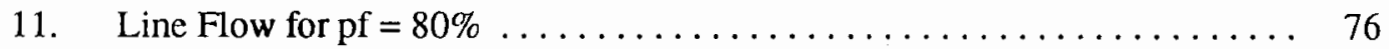




\section{NOTATION AND GLOSSARY}

\begin{tabular}{|c|c|}
\hline$\theta$ & Phase angle in degrees \\
\hline$\eta$ & Efficiency in proportion parts \\
\hline$h p$ & Horse power in proportion parts \\
\hline$p f, \mathrm{PF}$ & Power factor \\
\hline APFCS & Automatic Power Factor Controllers \\
\hline$k w h r$ & Kilowatt hours \\
\hline kvarhr & Reactive kilovolt ampere hours \\
\hline $\mathrm{kw}$ & Kilo watts \\
\hline kva & Kilo volt amperes \\
\hline ACSR & Aluminium Conductor Steel Reinforced \\
\hline Kws & Kilo watts \\
\hline Kvar & Reactive kilo volt amperes \\
\hline KV & Kilo volts \\
\hline$G_{1}$ & Generator_1 or Substation_1 \\
\hline$G_{2}$ & Generator_2 or Substation_2 \\
\hline gen & Generator \\
\hline $\mathrm{V}$ & Voltage in volts \\
\hline$G$ & conductance in siemens \\
\hline$B$ & susceptance in siemens \\
\hline lag & Lagging power factor \\
\hline lead & Leading power factor \\
\hline
\end{tabular}




$\begin{array}{ll}\text { W } & \text { Watt } \\ \mathrm{R} & \text { Resistance in ohms } \\ X_{c} & \text { Current in amperes } \\ \mathrm{rpm} & \text { Capacitive reactance in Farads } \\ \propto & \text { Revolution per minute } \\ \mathrm{X} & \text { proportional to } \\ \varepsilon & \text { Reactance in ohms } \\ Y_{k m} & \text { error check } \\ V_{m} & \text { Admittance between bus k and bus } \mathrm{m} \text { in siemens } \\ P_{k} & \text { Voltage at bus } \mathrm{m} \\ Q_{k} & \text { Real power at bus k } \\ G_{k m} & \text { Reactive power at bus k } \\ B_{k m} & \text { Conductance between bus k and } \mathrm{m} \text { in siemens } \\ P_{k}(V, \theta) & \text { Susceptance between bus k and } \mathrm{m} \text { in siemens } \\ Q_{k}(V, \theta) & \text { Real power at bus k as a function of voltage and phase } \\ \mathrm{H}, \mathrm{N}, \mathrm{M}, \mathrm{L} & \text { Partition of Jacobian matrix }\end{array}$




\section{CHAPTER I}

\section{INTRODUCTION}

This thesis presents a new way of addressing the economic problems resulting from the expensive supply of unnecessary reactive power to industrial loads. A set of computer programs have been developed which address the financial merits of power factor correction plans. These programs can be used to test the anticipated savings of proposed power factor improvement strategies. To illustrate the use of these programs a reactive compensation scheme for a typical industrial load has been studied.

The cost of system losses due to the kilovar flow of reactive power is an important economic factor [2] which should not be overlooked. Modem industries are continually increasing their inductive loads thus requiring ever larger amounts of reactive power. Typical reactive loads are induction motors, (especially those operated at less than full load), transformers, arc welders, rectifiers, arc fumaces, fluorescent lamps and various types of electronic equipment [1]. Unless reactive power is dealt with locally a reactive burden results which is expensive for the utility system to supply. The most common devices used to improve poor power factors are capacitors, synchronous motors and synchronous capacitors. Improving the power factor leads to both important savings in power cost and improved plant efficiency.

The choice of the best power factor improvement plan depends on the cost of correcting the original combined power factor of the loads and the details of utility rate structures. Each of these factors should be individually studied before reaching any decision.

A suitable computer model for analyzing power factor economics has been developed. Programs have been written which calculate the influence of such items as plant power factors, 
reactive power losses, demand charges, and power factor penalties. These programs can be used to find the effects of various degrees of power factor correction.

A model representing a medium size industrial load has been analyzed to demonstrate the application of the method. The cost saving strategies suggested by the example are discussed.

\section{PROBLEM STATEMENT}

Every year, millions of dollars are wasted in industrial plants because of the difficulty of determining the economic benefits of power factor improvement. An industrial plant operating at a low power factor will:

(1) Reduce system capacity and performance by overloading cables and transformers.

(2) Reduce line voltage levels, thus adversely affecting the efficiency of motor operation and decreasing incandescent lamp illumination.

(3) Increase power cost when utility power factor clauses are enforced.

(4) Introduce higher losses in generators, transformers and in the lines (copper loss) through which the reactive current flows.

(5) Overload generators and lines unnecessarily with reactive current, thus requiring larger generators and transformers, and heavier lines.

The cost of increased losses due to increased kilovar flow will be borne by the user, whether it be a private industry or a public institution. Not only that, but if the kilovar flow exceeds a certain minimum level, the power factor of the plant will be low and the utility will impose a "power factor penalty". In 1978 the major electrical power supplier in the Northwest initiated a penalty clause in its wholesale power rates for customers with a power factor less than $95 \%$. For each $0.5 \%$ decrement that the average monthly power factor is below $95 \%, 1 \%$ is added to the charge for peak power demand [32]. 
Millions of dollars are wasted in industrial plants because of the lack of understanding of the economic benefits of power factor improvement. On the one hand, because of the high cost of consulting services, medium and small size industries seldom seek technical assistance. On the other hand, no simple method exists for monitoring and analyzing the losses caused by reactive loads in industrial plants. Without this input it is difficult to determine the economic benefits of power factor improvement.

There has always been a need for a method of evaluating the economic benefits of power factor improvement for an existing system. Such a method should be fairly simple, reliable, and cost effective so that an electrical engineer with a minimum knowledge of power systems can determine the efficiency and cost situation of plant loads.

This dissertation presents a method and provides computer programs to implement it that can be used by a plant engineer to analyze and minimize the effects of electrical losses and power factor penalties.

\section{PREVIOUS WORK}

A search of the technical literature indicates that for medium and small scale industries very little attention has been paid to the economic benefits of accurate power factor correction analysis. No readily available methods for determining the cost savings for various amounts of power factor correction were found.

The literature did reveal two traditional methods for finding the combined power factor of a group of loads.

For the first method the combined power factor of the group is calculated using the name plate specifications of the individual loads. The calculations discussed in the literature are made by numerical, graphical or look-up table methods [33]. Name plate specifications can incorrectly predict the power factor at the generator or the substation since they typically have a 
$\pm 10 \%$ tolerance.

The second method uses portable kilowatt and power factor meters connected at load and motor control centers to determine the power factor at strategic locations [32]. Since there are no set rules to pinpoint where the worst power factors will be found, these locations are selected on a judgment basis depending on experience.

These traditional methods were still being used in a recent study of the economic benefits of power factor correction by Manolo E. Juguilon, R. Micheal Boger, and W. Dalos [32].

There are some methods available for dynamically adjusting power factor correcting devices. For example, Automatic Power Factor Controllers (APFCs) are used to switch power factor correcting capacitors in steps at load centers [31] to maintain a power factor within certain limits. APFCs operate in a window surrounding a power factor set point, and are usually used on systems under 600 volts [31]. Controlling all load centers in a complex industrial plants by a single APFC is not practical, especially when there are many load centers separated by considerable distances. Even if the controller is accurate, to $\pm 1 \%$ at a power factor of $95 \%$, the controller will work in a window from $94 \%-96 \%$. For power factor economics this difference can be significant.

Hopkin [3] suggested a completely different strategy from those of the traditional methods. He proposed that modified load flow calculations could be used to find the power factor at all load centers and generation sites. From these results the savings available from power factor correction could be determined. The only data required for his simulation are the ratings of the individual loads connected to the system. To the best of our knowledge his plan has not been used before. 


\section{SOLUTION APPROACH}

The work discussed here concerns the computer implementation of Hopkin's suggestion. The information obtained from this modified load flow study is the magnitude and phase angle of the voltage at each bus and the real and reactive power flowing in each line [16]. This gives all the necessary information for calculating power factor economics.

A set of four programs have been written to analyze the economic benefits of power factor improvement proposals. These benefits can be found by using the programs to compare the charges for uncorrected loads with those for various levels of power factor correction. To use the programs, first the bus loads are determined by the program Pfactor.c using motor data. Next the voltage and phase information for individual buses are found by the program Loadflow.c using the output of Pfactor.c and assumed initial values. The output from Loadflow.c is used by Powerflow.c to find the transmission line losses. Lastly, the program CostCalc.c calculates compensated and uncompensated cost using the output of Pfactor.c, Loadflow.c, Powerflow.c and the total hours of plant operation per month.

The program, Pfactor.c, calculates the total real and reactive power magnitudes at individual buses of the proposed model. The inputs to this program are the efficiency, power factor and horse power ratings of the motors. The documentation of this program is presented in appendix A.

The program, Loadflow.c, finds the bus admittance matrix, Y_bus, and the existing voltage and power factor at the individual buses. The inputs to this program are the output of Pfactor.c, the initial voltage and angle at the buses, and the resistance and reactance of the transmission lines. The documentation of this program is presented in appendix B.

The program, Powerflow.c, calculates the magnitude and direction of real and reactive power flow in individual transmission lines and buses. The inputs to this program are the Y_bus 
matrix, and the voltage and angle at the individual buses. The documentation of this program is presented in appendix $\mathrm{C}$.

The last program, CostCala.c, calculates the monthly power bills for both phase compensated and uncompensated systems and gives the potential monthly cost savings. The inputs to this program are the utility rate schedule, plant power factor, real and reactive power at the buses, days per month, shifts per day and hours per shift. The documentation of this program is presented in appendix D.

The results of a typical comparative study of power factor economics are presented in chapter IV.

\section{SIGNIFICANCE AND CONTRIBUTIONS}

The operating characteristics of power generation and transmission systems are available from load flow data [16]. To find the most cost effective operating mode for a plant all of the load centers and generating stations need to be studied as an integrated system. Cost savings can result from strict control of the generation angle which can be accomplished using a load flow analysis.

Hopkin [3] suggested that a modified load flow study computer program could be employed to determine the kilowatts and kilovars for an entire system operating at various power factors. The best part of Hopkins's idea is that his method yields a comparative evaluation of the economic benefits for different degrees of power factor correction. Traditional methods would be error prone, time consuming and difficult, if not impossible, to use.

A method similar ours is used to calculate voltage, angle and other parameters at different grids of power distribution systems for power scheduling and dispatching purposes. However, the idea of implementing the method in industrial plants to calculate power factor economics is completely new. 
The computer programs presented here have been written so that a plant engineer can make a practical analysis using readily available data.

\section{ORGANIZATION OF THE THESIS}

Chapter I is the introduction.

Chapter II provides the formal definitions of power factor and describes the effects of low power factor on electrical equipment, the causes of low power factor, the instruments required for power factor studies, the devices used for power factor improvement, the reasons for and benefits obtained from power factor correction.

Chapter III describes the algorithm used in the thesis for modified load flow study simulation.

Chapter IV presents the results of a computer analysis of a typical plant load, including the calculation of the economic benefits obtained from different degrees of power factor correction.

Chapter V presents conclusions and directions for future work. 


\section{CHAPTER II}

\section{POWER FACTOR}

Active power in a single phase circuit can be expressed as:

$$
P=\left|V_{p}\right|\left|I_{p}\right| \cos \left(\theta_{v}-\theta_{i}\right)
$$

where

$\mathrm{P}=$ is the active power in watts

$\left|V_{p}\right|=$ is the phase voltage in ms volts

$\left|I_{p}\right|=$ is the phase current in rms amperes

$\theta_{v}=$ is the phasor angle of the phase voltage in radians

$\theta_{I}=$ is the phasor angle of the phase current in radians

$\left|V_{p}\right|\left|I_{p}\right|=$ is the apparent power in volt-amperes

$p f=\cos \left(\theta_{v}-\theta_{I}\right)=$ is the power factor in proportional parts

From the equation (2.1) the power factor can be expressed as:

$$
\text { power factor }=\frac{\text { active power }}{\text { apparent power }}
$$

In a similar manner for a single phase circuit reactive power can be defined as:

$$
Q=\left|V_{p}\right|\left|I_{p}\right| \sin \left(\theta_{v}-\theta_{i}\right)
$$

where

$\mathrm{Q}=$ is the reactive power in vars (reactive volt amperes)

$Q f=\sin \left(\theta_{v}-\theta_{I}\right)=$ is the reactive factor in proportional parts

from the equation (2.3) the reactive factor can be expressed as: 


$$
\text { reactive factor }=\frac{\text { reactive power }}{\text { apparent power }}
$$

For polyphase circuits it can be shown that these definitions of power factor and reactive factor in terms of apparent, active and reactive power still hold.

Apparent power, $S$, (complex power) is made up of both active and reactive power.

Active Power, $P$, (or working power) is the power that is read on a power meter. Active power does useful work such as tuming a lathe, heating the metal for making a weld, or heating and lighting a plant. Some loads, such as incandescent lights and resistive heaters require only active power.

Reactive power, $Q$, (nonworking power) is the power required to produce the magnetic flux necessary for the operation of induction devices. Reactive power energizes the magnetic circuits of transformers and motors, and the dielectrics of capacitors.

Active power and reactive power add in quadrature as shown in Figure 2(a).

$$
|S|=\sqrt{P^{2}+Q^{2}}
$$

Figure 2(b) shows the significant increase in loss at lower power factors.

\section{LEADING AND LAGGING POWER FACTOR}

The power factor may be either leading or lagging. The power factor is lagging if the load requires kilovars and leading if the load furnishes kilovars. Thus, an induction motor has a lagging power factor because its magnetizing requirements must be supplied by the power source. On the other hand, a capacitor or an over excited synchronous motor can supply kilovars and therefore has a leading power factor.

Table I shows the power factor for common operating conditions for both loads and generators, based on the direction of kilowatt and kilovar flow. 

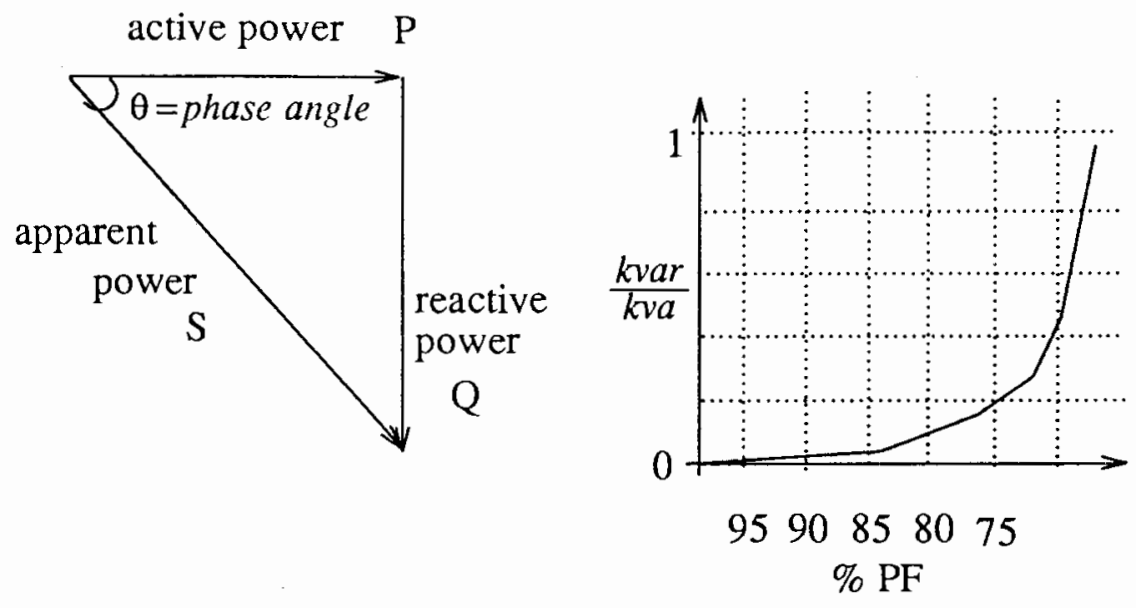

(a) power components in an a.c circuit

(b) increase in loss with PF.

Figure 1. Right triangle relationship of current and power.

TABLE I

POWER FACTOR OF LOAD AND SOURCE

\begin{tabular}{|c|c|c|c|c|c|c|}
\hline \multirow{2}{*}{$\begin{array}{l}\text { load type } \\
\text { motor }\end{array}$} & \multicolumn{3}{|c|}{ load } & \multicolumn{3}{|c|}{ generator } \\
\hline & $\overline{\mathrm{Kw}}$ & Kvar & $p f^{*}$ & $\overline{\mathrm{Kw}}$ & Kvar & $p f^{* *}$ \\
\hline Induction & in & in & lag & out & out & lag \\
\hline $\begin{array}{l}\text { Sync. motor } \\
\text { (over excited) }\end{array}$ & in & out & lead & out & in & lead \\
\hline $\begin{array}{l}\text { Sync. motor } \\
\text { (under excited) }\end{array}$ & in & in & lag & out & out & lag \\
\hline
\end{tabular}

* Power factor measured at the load.

** Power factor measured at the generator. 


\section{THE EFFECTS OF LOW POWER FACTOR}

At low power factors the total current flowing through conductors, lines and windings is greater than it needs to be. Since the power loss increases as the square of the current, a relatively small increase in current will cause a much larger increase in the loss.

Poor power factor reduces the output from an alternator, the performance of a transmission line, the regulation of transformers and the operating efficiency of the plant equipment. Figure 3 shows what happens at low power factor for typical loads.

For a typical alternator the amount of this reduction is shown in Figures 2(a) and 2(b). It is rather startling to observe that the kilowatt capacity of this altemator will drop from 1100 at unity power factor to 320 at $40 \%$ power factor. From the equation,

$$
V_{t}=E_{t}-I_{a}\left(R_{a}+j X_{s}\right)
$$

Where for the altemator,

$V_{t}=$ terminal voltage in $\mathrm{ms}$ volts

$E_{t}=$ No-load voltage in rms volts

$I_{a}=$ armature current in rms amperes

$R_{a}=$ armature resistance in ohms

$X_{s}=$ synchronous reactance in ohms

So if $I_{a}$ increases (for low PF) there is a voltage drop due to $R_{a}$ and $X_{s}$ causing reduced terminal voltage $V_{t}$. This reduction of $V_{t}$ will cause a reduced output capacity from the altemator.

For a typical transformer the performance reduction is shown in Figures 2(c) and 2(d). Not only does the power handling capacity of the transformer fall off badly, but the regulation gets much poorer.

$$
\text { regulation }=\frac{\text { no load voltage }- \text { full load voltage }}{\text { full load voltage }}
$$




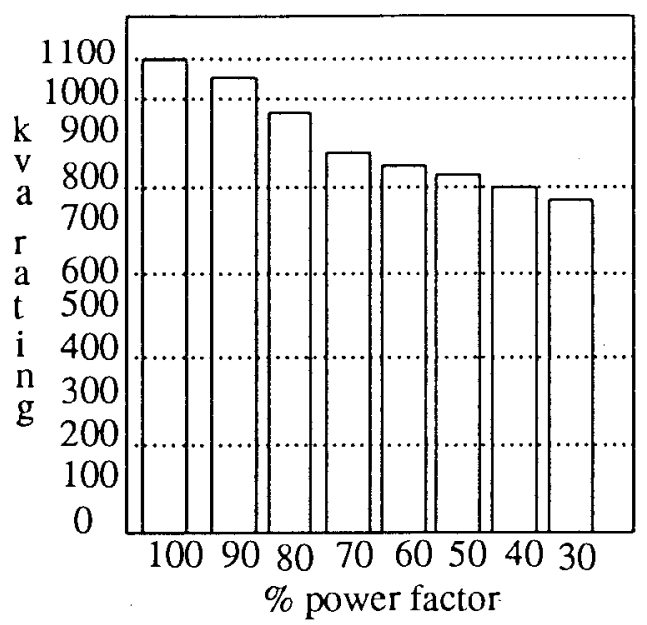

(a) small reduction of kva capacity of an alternator at lower pf

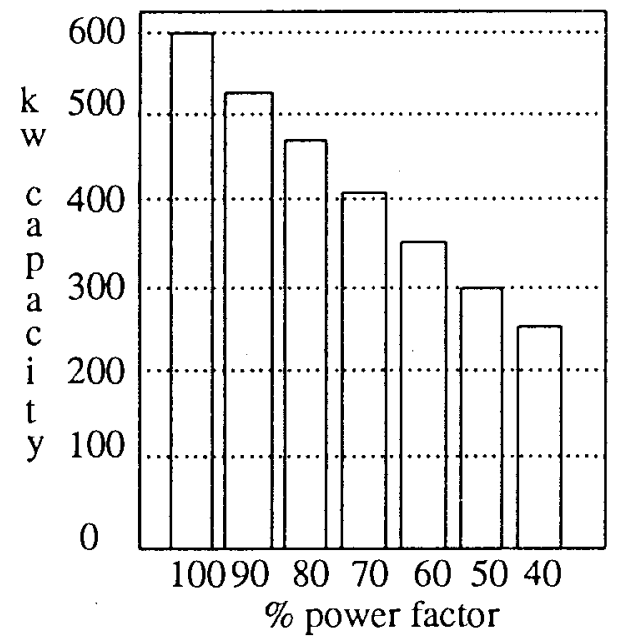

(c) reduction of $\mathrm{kw}$ capacity of a transformer at lower pf

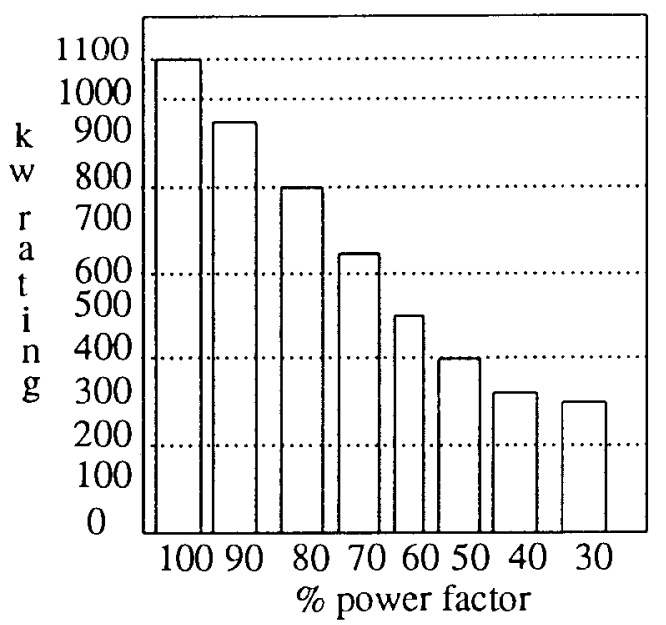

(b) drastic reduction of $\mathrm{kw}$ rating of an alternator at lower $\mathrm{pf}$

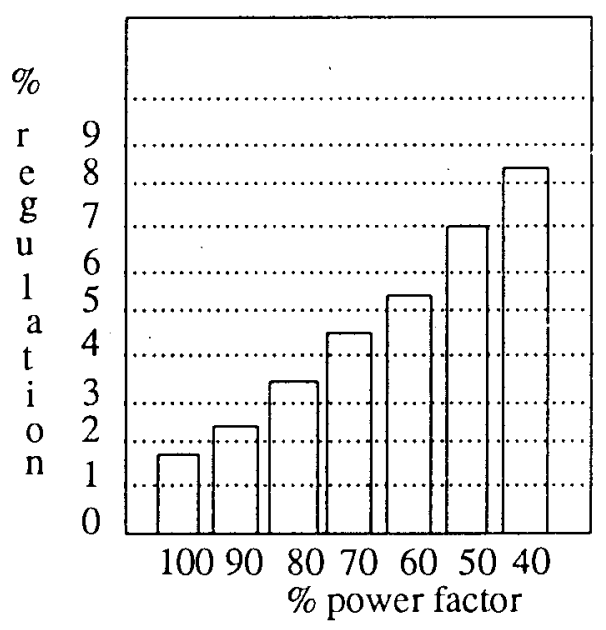

(d) drastic increase of regulation of a transformer at lower pf

Figure 2. Effects of low power factor on alternators and transformers. 


\section{CAUSES OF LOW POWER FACTOR}

Many types of electrical equipment can reduce the power factor [5]. Chief among these, and by far the most widely used, is the induction motor. Also electric welding equipment, electric induction fumaces, transformers, neon signs, and other types of inductive equipment installed in a plant tend to lower the power factor.

\section{METHODS OF POWER FACTOR MEASUREMENT}

Power factor may be measured direclly or computed from other measurements [7]. There are two convenient methods of finding the power factor of a plant by knowing the individual load ratings including their power factors.

The power factors of individual loads are usually specified. These power factors can be used to calculate the power factor for the combined load by summing the kws and kvars separately. The two results are then combined vectorially to find the total kva. The power factor is then given as the ratio of kw to kva.

The second method uses a tedious graphical approach which will not be discussed here.

\section{PRACTICAL METHODS OF POWER FACTOR IMPROVEMENT}

Reactive power is necessary for the operation of many types of electrical equipment and it must be supplied from some source. Since the transmission of reactive current through lines and transformers results in unnecessary expensive losses, it is desirable to generate reactive power near where it is required.

Static capacitors and switched capacitors offer a practical method of producing reactive power for medium size motors and other equipment [8]. Such capacitors are usually connected in shunt across the line. For example, a $30 \mathrm{kw}$ load with an $80 \%$ power factor can be corrected 
to $90 \%$ power factor by adding an $8 \mathrm{kvar}$ capacitor $(3 \mathrm{kw} \times 0.266)$ as shown in table II.

Synchronous motors and synchronous capacitors may also be used to control the power factor. They can be adjusted to supply either lagging or leading power or to operate at unity power factor.

\section{REASONS FOR IMPROVING POWER FACTOR}

(1) Reduce Total Power Loss in the Plant

(2) Improve Voltage performance

(3) Improve the Power Capacity of the Plant

(4) Improve the Transmission and Distribution Systems capacity

(5) Reduce power cost and avoid penalties 
TABLE II

MULTIPLIERS TO DETERMINE CAPACITOR SIZE FOR PF CORRECTION

$$
C_{k v a r}=P_{k w}\left(\tan \left(\cos ^{-1}\left(p f_{\text {old }}\right)\right)-\tan \left(\cos ^{-1}\left(p f_{n e w^{\prime}}\right)\right)\right)
$$

\begin{tabular}{|c|c|c|c|c|c|c|c|c|c|c|c|c|c|c|c|c|c|c|c|c|c|}
\hline \multirow{2}{*}{ 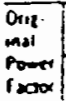 } & \multicolumn{21}{|c|}{ corrected } \\
\hline & 0.80 & 0.81 & 02 & $0.8 \mathrm{~J}$ & 0.4 & OEs & 0.6 & 0.87 & 0.88 & 0.89 & 0.90 & 0.91 & 0.92 & 093 & 09 & 0.95 & 0.96 & 0.97 & 0.8 & 0.9 & 10 \\
\hline 0.50 & 0.282 & 1008 & 1.034 & 1.060 & 1.086 & 1.112 & 1.19 & 1.165 & 1.192 & 1.220 & 1.24 & 1.276 & 1,506 & 1.331 & 1.369 & 1.003 & $1 \mathrm{cos}$ & $\mid 481$ & 1.59 & $15 \times 9$ & 1732 \\
\hline osi & 0.937 & 0.52 & 0.908 & 1.015 & 1.041 & 1.067 & 1.09 & 1.120 & 1.147 & 1.175 & 1.203 & 1.231 & $1 . x 1$ & 1.292 & 1324 & 1.358 & 1.35 & 1.06 & 1.48 & 1.54 & 1.687 \\
\hline 0.52 & 0.93 & 0.919 & 0.45 & 0991 & 0591 & 1.023 & 1.050 & 1.076 & 1.103 & 1.131 & 1.159 & $|181|$ & $\mid . m$ & 1.248 & 1.200 & 1.314 & 1.351 & 130 & 1.00 & 1.500 & 1643 \\
\hline os & 0.850 & 0.876 & 0.902 & 0.978 & $0.958 \mid$ & 0.900 & 1.001 & 1.033 & 1.060 & 1008 & 1.116 & 1.141 & 1.171 & 1.205 & $\mid 1.231$ & $\mid 1.2 n 1\}$ & 1.308 & $13 \times 9$ & $|\mathrm{~s}|$ & 1.451 & 1.600 \\
\hline oss & 0.209 & 0.035 & 0.861 & 0.881 & 0.913 & 0.939 & 0.966 & 0.992 & 1.019 & 1007 & 1075 & 1.103 & 1.133 & 1161 & $1.1 \%$ & 1.230 & 1260 & 1.00 & 1.56 & 1416 & 1.559 \\
\hline oss & 0.769 & 0 .rss & 0.221 & 0.817 & 0.813 & 0899 & 0.26 & 0.952 & 0.979 & 1.007 & 1.035 & $1.06 \mathrm{~s}$ & 1003 & 1.124 & 1.158 & 1.190 & 1.222 & 1201 & 1316 & $1.3 \%$ & 1.519 \\
\hline 0.56 & 010 & 0.566 & 0.782 & $0.008 \mid$ & 0.234 & 0.860 & 0.831 & 0.913 & 0.920 & 10.968 & 0.966 & 1.024 & 1.054 & 1.005 & 1.111 & (1.15i & 1.188 & 128 & $1.2 n$ & 1.33 & 1.400 \\
\hline 0.51 & 0.692 & 0.718 & 0.74 & $0.7 r \mid$ & 0.186 & 0.822 & 0.49 & 0.215 & 0.907 & 0.930 & 0.988 & 0.586 & 1.016 & $|.01|$ & $1.0 \mathrm{~g}$ & 1.113 & 1.150 & 1.191 & 129 & 1258 & 1.42 \\
\hline 0.48 & 0.655 & 0.081 & 0.201 & 0.133 & $\mid 0.259$ & $0.7 \mathrm{ss}$ & 0.812 & 0.238 & 0.865 & 0.893 & 0.921 & 0.969 & 0.979 & 1.010 & 1.022 & 1076 & 1.i13 & $1.15 x$ & 1200 & $\mid x 2$ & $1.40 \mathrm{~s}$ \\
\hline OSS & 0619 & o.us & 0.671 & 0.691 & $0 . n 3$ & 0.219 & 0.176 & 0.802 & 0.229 & 0.851 & 0.825 & 0.913 & $0.9 \times 3$ & 0.914 & 1.006 & 1.020 & 1.071 & 1.118 & 1.165 & 1276 & 1.369 \\
\hline 060 & 0.583 & 0600 & 0.635 & 0.551 & 0.681 & 0.713 & 070 & 0.766 & 0.293 & 0.821 & 0.499 & $0.8 \mathrm{n}$ & 0.901 & 0.938 & 0.920 & 1001 & $1.041 \mid$ & 1.00 & 1.130 & 1.100 & 1.333 \\
\hline 0.61 & 0.549 & 0.575 & 0.001 & 0.621 & O 653 & 0659 & 0.706 & 0.72 & 0.159 & $0 . n)$ & 0.815 & $\left.\begin{array}{llll}0 & 0 & 4\end{array}\right)$ & 0.873 & 0.901 & 0.936 & 0.95 & $(1.00)$ & 1004 & 1000 & 1.156 & 1299 \\
\hline .2 & 0.516 & 0.42 & 0.568 & 0.599 & 0.620 & $0466^{\circ}$ & 0.673 & 0.699 & 0.726 & 0.58 & 0.78 & $0.810 \mid$ & 0840 & 0.871 & 0.903 & $|0.237|$ & $0.974 \mid$ & 1015 & {$[. \infty]$} & 1.120 & 1.266 \\
\hline 0.03 & 0.483 & 0.509 & 0.535 & 0.561 & 0.581 & 0.613 & 0.600 & 0.656 & 0.693 & 0.71 & 0.719 & $0 . \mathrm{mi}$ & 0.201 & 0.838 & 0.20 & 0.504 & 0.91 & $0 . x 0$ & 1000 & 1000 & 1.233 \\
\hline O.H & 0.451 & 0.114 & 0.503 & 0.529 & 0.555 & 0.381 & 0.608 & 0.634 & 0.661 & 0.609 & 0.717 & 0.725 & $0 . \mathrm{ns}$ & 0.006 & $0.038 \mid$ & 0.872 & 0.509 & 0.559 & 0.58 & 1.004 & 1.201 \\
\hline 0.05 & 0419 & 0.45 & 0.471 & 0.491 & $|0.523|$ & 0.549 & $0.5 \pi$ & 0.00 & 0.029 & 0.657 & 0.685 & 0.113 & 0.143 & 0.71 & 0.006 & $|0.200|$ & $0.8 n$ & 0.91 d & exce & $100 \times$ & 1.169 \\
\hline 0.65 & 0.388 & 0,414 & 0.40 & 0.468 & 0.092 & 0.518 & 0.545 & $0.5 \mathrm{~N}$ & 0.58 & $0.0 \times 6$ & 0.654 & $0.608 \mid$ & 0.712 & $0.743\}$ & $0 . \mathrm{ns}$ & $|0.009|$ & 0.246 & $0 \mathrm{an}$ & 0.935 & 0.955 & 1.138 \\
\hline 0.01 & 0.58 & 0.328 & 0.410 & 0.436 & 0.462 & 0.458 & 0.515 & 0.54 & 0.568 & 0.596 & 0.04 & 0.652 & 0.60 & 0.713 & 0.745 & $0.189^{7}$ & 0.816 & 0.00 & $10 \operatorname{ses} \mid$ & $0.95 \mid$ & 1.108 \\
\hline 1.4 & 0.328 & 0.354 & 0.300 & 0.406 & 0.432 & 0.458 & 0.085 & 0.511 & 0.538 & 0.566 & 0.59 & 0.622 & 0.652 & 0.683 & 0.715 & 0.219 & 0.788 & 0.21 & oves & 0.25 & $1.0 \pi$ \\
\hline is & $0 \times 99$ & 0.355 & 0.351 & $0.3 n 1$ & $\mid 0.03\}$ & 0.429 & 0.456 & 0.48 & 0.509 & 0.531 & 0.565 & 0.593 & 0.623 & 0.658 & 0.626 & $0.720_{1}$ & $0.7 \mathrm{sI}$ & $\left|\begin{array}{lll}0 & 0\end{array}\right|$ & 0.245 & 0.506 & 1049 \\
\hline $1 . x$ & 0.25 & 0.756 & 0.322 & 348 & 0.314 & $0 . \infty \infty$ & 0.427 & 0.453 & 0.400 & 0.508 & 0.536 & $0.561 \mid$ & 0.59 & 0.625 & $0.657 \mid$ & $0.691 \mid$ & 0.728 & $0 . \mathrm{Kg}$ & 0.811 & $0.8 n$ & 1.020 \\
\hline $0 . n$ & 0.212 & 0.258 & 0.29 & $0.320 \mid$ & 0.346 & $0.3 n$ & 0.399 & 0.425 & 0.452 & 0.480 & 0.508 & 0.536 & 0.566 & 0.597 & 0.628 & $0.663 \mid$ & 0.700 & 0.241 & $0 . \pi \omega$ & ons & 1092 \\
\hline$\theta n$ & 0.214 & 0.240 & 0.285 & $|0.292|$ & 0.318 & $0.3 m$ & $0.3 m$ & 0.397 & $|0.424|$ & 0.452 & 0.400 & 0.508 & 0.538 & 0.569 & $|0.601|$ & 0.635 & $\mid 0.672$ & 0.51 & $0 . x 1$ & 0.21 & 0.566 \\
\hline$n$ & 0.186 & 0.212 & 0.238 & $|0.261|$ & 0.290 & 0.316 & 0.343 & 0.369 & 0.396 & 0.124 & 0.452 & $0.40 \mid$ & o.sio & $0.5+1$ & $0.573 \mid$ & 0.608 & 0.64 & $0 . \cos$ & 0.733 & $0.7 \mathrm{D}$ & 0.936 \\
\hline 018 & 0.159 & 0.185 & 0.211 & 0.231 & $0.263\}$ & 0.269 & 0.316 & 0.342 & 0.369 & 0.391 & 0.28 & {$[0.45]$} & 0.483 & 0.514 & 0.546 & 0.580 & 0.611 & 0.658 & 0.006 & 0.1666 & 0.909 \\
\hline $0 x$ & 0.13 & 0.158 & 0.184 & 0.210 & 0.236 & 0.262 & 0.289 & 0.315 & 0.342 & 0.370 & 0.398 & 0.426 & 0.456 & 0.481 & $|0.519|$ & $|0.553|$ & $0.590 \mid$ & 0.631 & $0.6 \times 9$ & 0.759 & 0.828 \\
\hline 026 & 0.105 & 0.131 & $\begin{array}{llll}0 & 151\end{array}$ & 0.183 & $0.209 \mid$ & 0.235 & 0.252 & 0.288 & $|0.315|$ & 10.43 & 0.371 & $0.599 \mid$ & $0<29$ & $0.460)$ & $(0.492)$ & $|0.528|$ & $|0.563|$ & $|0.00 \times|$ & 0.652 & $0 . \mathrm{n} 2$ & 0.855 \\
\hline 0.11 & 0.019 & 0.105 & 0.131 & 0.151 & 0.18 & 02091 & 0.256 & 0.262 & 0.289 & 0.317 & $\longdiv { 0 . 3 0 5 }$ & 0.373 & 0.003 & 0.434 & 0466 & 0.500 & 0.530 & $0.5 \pi$ & 0.62 & $|0.05|$ & 0.009 \\
\hline$n$ & 0.052 & 0.078 & 0104 & 0,130 & 0.156 & 0.182 & 0.209 & 0.235 & $0.262 \mid$ & 0.780 & 0.318 & 0.346 & 0.376 & 0.401 & $\mid \begin{array}{lll}0 & 2\end{array}$ & 0.67 & 0.510 & 0.551 & 0.59 & 0.65 & 10.802 \\
\hline 09 & 0.026 & 0.022 & 0.018 & 104 & 0.130 & 0.156 & 0.18 & 0.209 & 0.236 & 0.760 & 0.298 & 0.320 & 0.350 & 0.381 & $\left|\begin{array}{lll}0 & 4\end{array}\right|$ & $|0.4|$ & 0.484 & 0.58 & 0.523 & 0.60 & 0.716 \\
\hline 0.0 & 0.000 & 0.026 & 0.052 & 0018 & 0.100 & 0.130 & 0.151 & C 183 & 0.210 & 0.238 & 0.266 & 0.29 & 0.32 & 0 uss & 0.387 & $0.421 \mid$ & 0.458 & 0.099 & 0.581 & $0 \cos \mid$ & 0.150 \\
\hline 211 & & 0.000 & 0026 & 10.052 & 0.018 & 0101 & 0.131 & $0 .(s)$ & $0.1 \mathrm{~m}$ & 0.212 & 0.200 & 0.268 & 028 & $0.3 \times 9$ & 0.361 & $0 . x 95 \mid$ & $\mid \begin{array}{lll}0 & 432\end{array}$ & 0.473 & 0.521 & 0.581 & 10.24 \\
\hline 12 & & & 0000 & 0.028 & 0.052 & 0018 & 0105 & 0.131 & 0.158 & 0.186 & 0.214 & $0.242 \mid$ & $02 \pi$ & 0.303 & 0.335 & $\mid 0.369$ & 0.406 & $\mid 0.41$ & 0.058 & 0.555 & 0.696 \\
\hline S.13 & & & & 0000 & 0.076 & $\cos 2$ & 0.079 & 0.105 & 0.132 & 0.160 & 0.188 & $|0.216|$ & 0.246 & $0.2 \mathrm{~m}$ & 0.009 & $|0.343|$ & 0.300 & 0.011 & $|0.469|$ & $0 \sin \mid$ & 0.67 \\
\hline $\boldsymbol{I \mu}$ & & & & & 0.000 & 0.026 & 0 os 3 & 0.079 & 0.106 & 0.134 & 0.162 & 0.190 & 0.2701 & 0.81 & 0.200 & 0.311 & 0.356 & 0.595 & $\left|\begin{array}{lll}0 & 4\end{array}\right|$ & $|0.503|$ & 0.646 \\
\hline ors & & & & & & 00001 & 0021 & $\begin{array}{lll}0 & 0 \times 3\end{array}$ & $|0.050|$ & 0.108 & 0.136 & $|0.161|$ & 0.191 & 0.275 & $|0.251|$ & $|0.291|$ & 0.328 & $0 . x+1$ & 0.47 & 0.011 & 0.620 \\
\hline O & & & & & & & $0 \propto \infty$ & 0.028 & 0.053 & 0.081 & 0.109 & | & 0161 & $\mid \begin{array}{lll}0 & 188\end{array}$ & 0.230 & 10.261 & $|0.301|$ & 0.302 & 0.550 & 0.400 & 10.583 \\
\hline$\Delta v$ & & & & & & & & 0.000 & 0.021 & o.0ss & 0.003 & O.III & $0.1+1$ & 0 in & 10201 & $\left|\begin{array}{ll}0 & 238\end{array}\right|$ & 10.25 & $|0.316|$ & $0 . x+1$ & 0.46 & 0.567 \\
\hline 10 & & & & & & & & & 0.000 & 0028 & 0.056 & 0 oosi & 0.1141 & o.1as & $0.5 \mathrm{~m}$ & $\mid 0.211\}$ & $|0.248|$ & $10 \pi 5$ & $|0.33 ;|$ & 0.59 & 0.56 \\
\hline On & & & & & & & & & & 0,000 & 0.028 & 00581 & 0.006 & 0111 & $|0.819|$ & $|0.183|$ & 0.220 & $0 . x 1$ & $0 \begin{array}{lll}0.09\end{array}$ & 0.307 & 0.512 \\
\hline 0.00 & & & & & & & & & & & 0,000 & 0.0281 & 0.0 & 1.009 & $0 \begin{array}{lll}0 & 121\end{array}$ & $0.15 s$ & 0.192 & 0.23 & 0.281 & 0.311 & 0.48 \\
\hline 09 & & & & & & & & & & & & 0,00 & 0000 & 00061 & {$\left[\begin{array}{lll}0 & 093\end{array}\right.$} & $\left|\begin{array}{llll}0 & 1 & 12\end{array}\right|$ & $|0.164|$ & 10205 & $0 \times 53$ & 0.313 & 0.156 \\
\hline 0.22 & & & & & & & & & & & & & 0000 & 100311 & 00063 & 0081 & $\mid 0136$ & $0.1 \%$ & $0.2 \mathrm{~m}$ & 0.220 & 0.62 \\
\hline 0.3 & & & & & & & & & & & & & & 00001 & $\begin{array}{lllll}0 & 0 & 032\end{array}$ & 10066 & {$\left[\begin{array}{lll}0 & 103\end{array}\right]$} & 014 & 0.122 & 0.222 & 0.395 \\
\hline 0.96 & & & & & & & & & & & & & & & $|0000|$ & $\mid 0.036$ & 0.011 & 0.112 & 0.160 & 0.50 & 10.363 \\
\hline $0 x$ & & & & & & & & & & & & & & & & 0.000 & 0.031 & $00 \mathrm{rg}$ & 0.126 & 0.18 & 10.529 \\
\hline $0 x$ & & & & & & & & & & & & & & & & & 0.000 & $00<1$ & 000 & 0 oins & 0.252 \\
\hline 0.91 & & & & & & & & & & & & & & & & & & 0000 & o.ass & 0.108 & 0.751 \\
\hline $8 x$ & & & & & & & & & & & & & & & & & & & 0.000 & 0060 & 0.203 \\
\hline Ay & & & & & & & & & & & & & & & & & & & & 0000 & $0.14]$ \\
\hline & & & & & & & & & & & & & & & & & & & & & 10.000 \\
\hline
\end{tabular}




\section{CHAPTER III}

\section{LOAD FLOW}

Under normal conditions electrical transmission systems operate in a steady state mode. The characteristics of this state can be found by a load flow (or power flow) calculation.

The objective of load flow calculations is to determine the steady state operating characteristics of the power generation and transmission system for a given set of bus loads. Active power generation is normally specified according to the least expensive dispatching practice and the generator voltage magnitude is nomally maintained at a specified level by the automatic voltage regulator acting on the machine excitation. Loads are normally specified by their constant active and reactive power requirement and are assumed to be unaffected by the small variations of voltage and frequency expected during normal steady state operation.

The load flow solution is expected to provide the bus voltage magnitudes and angles, the active and reactive power flow in the individual transmission units, the losses and the reactive power generated or absorbed at voltage controlled buses.

The load flow problem is formulated in its basic analytical form in this chapter with the network represented by linear, bilateral and balanced lumped parameters. However, the power and voltage constraints make the problem non linear and an iterative numerical solution is required. For the iterative process an arbitrary set of initial values of the inputs are selected. After first iteration the results are tested and if they match the initial values within the specified tolerance, a solution has been obtained. If the calculated values differ from the initial ones, a new selection must be tried. The calculated values obtained in the first trial become a new set of initial values. The process then repeats. Finally, when calculated values agree with the initial 
values within the specified tolerance, a solution has been found.

The first practical digital solution methods for load flow were the $\mathrm{Y} \_$matrix iterative methods [14]. These were suitable because of the low storage requirements, but had the disadvantage of converging slowly or not at all. Z_matrix methods were developed which overcame the reliability problem but at a sacrifice of storage and speed for large systems. The NewtonRaphson method was developed at this time and was found to have very strong convergence and reasonable computing requirements.

\section{GLOSSARY OF LOAD FLOW TERMS}

The complete power flow solution requires the determination of four variables at each bus $\mathrm{k}$ in the system.

$P_{k}=$ real power

$Q_{k}=$ reactive power

$V_{k}=$ voltage magnitude

$\theta_{k}=$ voltage phase angle

When two of these variables are given at each bus the aim of the load flow analysis is to solve for the remaining two.

We define three different bus conditions based on the steady state assumptions of constant system frequency and constant voltages.

Voltage controlled bus ( $P V$ bus) The total injected active power $P_{k}$ is specified, and the voltage magnitude $V_{k}$ is maintained at a specified value by reactive power injection. This type of bus generally corresponds to a generator where $P_{k}$ is fixed by a turbine governor setting and $V_{k}$ is fixed by automatic voltage regulators acting on the machine excitation.

Nonvoltage controlled bus (Load bus) The total injected power, $P_{k}+j Q_{k}$, is specified at this bus. In the physical power system this corresponds to a load center such as a city or an 
industry, where the consumer receives his power requirements. Both $P_{k}$ and $Q_{k}$ are assumed to be unaffected by small variations in bus voltage.

Slack (swing) bus This bus is required because the system losses are not known precisely in advance of the load flow calculation. Therefore, the total injected power cannot be specified at all of the buses. The slack bus voltage is usually assigned as the system phase reference, and its complex voltage $V_{s}=f(V, \theta)$ is therefore specified. The analogy in a practical power system is the generating station which has the responsibility of system frequency control.

\section{NEWTON-RAPHSON METHOD}

A load flow calculation solves a set of simultaneous nonlinear algebraic power equations for the unknown variables at each node in a system [15]. For this study the Newton-Raphson method was chosen for analysing the load flow.

The generalized Newton-Raphson method is an iterative algorithm for solving a set of simultaneous analytic nonlinear equations in an equal number of unknowns. At each iteration of the Newton-Raphson method, the nonlinear problem is approximated by a linear matrix equation. Given a set of non-linear equations,

$$
\begin{aligned}
& f_{1}\left(x_{1}, x_{2}, \ldots \ldots ., x_{n}\right)=y_{1} \\
& f_{2}\left(x_{1}, x_{2}, \ldots \ldots ., x_{n}\right)=y_{2} \\
& f_{3}\left(x_{1}, x_{2}, \ldots \ldots . ., x_{n}\right)=y_{3} \\
& \ldots \ldots \ldots \ldots \ldots \ldots \ldots \ldots \ldots \ldots \ldots \ldots \\
& f_{n}\left(x_{1}, x_{2}, \ldots \ldots \ldots, x_{n}\right)=y_{n}
\end{aligned}
$$

and the initial estimate for the solution vector

$$
x p, x_{2}^{0}, \ldots \ldots \ldots, x_{n}^{0}
$$

Assume $\Delta x_{1}, \Delta x_{2}, \ldots \ldots, \Delta x_{n}$ are the total corrections for $x \rho^{\rho}, x_{2}, \ldots \ldots \ldots, x_{n}^{0}$ respectively, so that the equations (3.1) are solved, i,e., 


$$
\begin{aligned}
& f_{1}\left(x \rho+\Delta x_{1}, x_{2}^{\rho}+\Delta x_{2}, x_{n}^{0}+\Delta x_{n}\right)=y_{1} \\
& f_{2}\left(x \rho+\Delta x_{1}, x \rho+\Delta x_{2}, x_{n}^{0}+\Delta x_{n}\right)=y_{2} \\
& f_{3}\left(x \rho+\Delta x_{1}, x \rho+\Delta x_{2}, x_{n}^{0}+\Delta x_{n}\right)=y_{3} \\
& \ldots \ldots \ldots \ldots \ldots \ldots \ldots \ldots \ldots \ldots \ldots \ldots \ldots \ldots \ldots \ldots \ldots \ldots \ldots \ldots \ldots \ldots \ldots \ldots \ldots \ldots \ldots \ldots \ldots \ldots \ldots \ldots \\
& f_{n}\left(x \rho+\Delta x_{1}, x \rho+\Delta x_{2}, x_{n}^{0}+\Delta x_{n}\right)=y_{n}
\end{aligned}
$$

Each equation of the set (3.2) can be expanded by Taylor's theorem for a function of two or more variables. For example, the following is obtaimed for the first equation:

$$
\begin{gathered}
f_{1}\left(x_{\rho}^{\rho}+\Delta x_{1,} x_{2}+\Delta x_{2}, \ldots, x_{n}^{0}+\Delta x_{n}\right)=f_{1}\left(x \rho, x \rho, \ldots \ldots ., x_{n}^{0}\right)+\left.\Delta x_{1} \frac{\partial f_{1}}{\partial x_{1}}\right|_{0}+ \\
\left.\Delta x_{2} \frac{\partial f_{1}}{\partial x_{2}}\right|_{0}+\ldots \ldots . .+\left.\Delta x_{n} \frac{\partial f_{1}}{\partial x_{n}}\right|_{0}+\phi_{1}
\end{gathered}
$$

where $\phi_{1}$ is a function of $\Delta x_{1}, \Delta x_{2}, \ldots \ldots, \Delta x_{n}$ and second, third, etc., derivatives of the function $f_{1}$. If the initial estimate for the $x_{i} s$ is near the solution value, the $\Delta x_{i} s$ will be relatively small and all terms of higher powers can be neglected. The linear set of equations resulting is as follows:

$$
\begin{gathered}
f_{1}\left(x \rho, x_{2}, \ldots ., x_{n}^{0}\right)+\left.\Delta x_{1} \frac{\partial f_{1}}{\partial x_{1}}\right|_{0}+\left.\Delta x_{2} \frac{\partial f_{1}}{\partial x_{2}}\right|_{0}+\ldots .+\left.\Delta x_{n} \frac{\partial f_{1}}{\partial x_{n}}\right|_{0}=y_{1} \\
f_{2}\left(x \rho, x \rho, \ldots ., x_{n}^{0}\right)+\left.\Delta x_{1} \frac{\partial f_{2}}{\partial x_{1}}\right|_{0}+\left.\Delta x_{2} \frac{\partial f_{2}}{\partial x_{2}}\right|_{0}+\ldots .\left.\Delta x_{n} \frac{\partial f_{2}}{\partial x_{n}}\right|_{0}=y_{2} \\
f_{n}\left(x \rho, x \rho, \ldots ., x_{n}^{0}\right)+\left.\Delta x_{1} \frac{\partial f_{n}}{\partial x_{1}}\right|_{0}+\left.\Delta x_{2} \frac{\partial f_{n}}{\partial x_{2}}\right|_{0}+\ldots .+\left.\Delta x_{n} \frac{\partial f_{n}}{\partial x_{n}}\right|_{0}=y_{n}
\end{gathered}
$$

In matrix form, equations (3.4) are

$$
\left[\begin{array}{l}
{\left[\begin{array}{l}
y_{1}-f_{1}\left(x \rho, x \rho, \ldots, x_{n}^{0}\right) \\
y_{2}-f_{2}\left(x \rho, x \rho, \ldots ., x_{n}^{0}\right) \\
y_{n}-f_{n}\left(x \rho, x \rho, \ldots . ., x_{n}^{0}\right)
\end{array}\right]=} \\
\left.\left.\frac{\partial f_{1}}{\partial x_{1}}\right|_{0} \frac{\partial f_{1}}{\partial x_{2}}\right|_{0} \ldots .\left.\frac{\partial f_{1}}{\partial x_{n}}\right|_{0} \\
\left.\left.\frac{\partial f_{2}}{\partial x_{1}}\right|_{0} \frac{\partial f_{2}}{\partial x_{2}}\right|_{0} \ldots .\left.\frac{\partial f_{2}}{\partial x_{n}}\right|_{0} \\
\left.\left.\frac{\partial f_{n}}{\partial x_{1}}\right|_{0} \frac{\partial f_{n}}{\partial x_{2}}\right|_{0} \ldots . .\left.\frac{\partial f_{n}}{\partial x_{n}}\right|_{0}
\end{array}\right]\left[\begin{array}{c}
\Delta x_{1} \\
\Delta x_{2} \\
\Delta \ddot{x}_{n}
\end{array}\right]
$$




$$
D=J C
$$

Where $J$ is the jacobian for the functions $f_{i}$ and $C$ is the change vector $\Delta x_{i}$. The elements of the matrices $D$ and $J$ are evaluated by substituting the current values of the $X_{i}$ s. Hence a solution for the $\Delta x_{i}$ can be obtained by the application of any method for the solution of a system of linear equations. The new values for $X_{i}$ 's are calculated from

$$
x_{i}^{1}=x_{i}^{0}+\Delta x_{i}
$$

The process is repeated untill two successive values for each $x_{i}$ differ only by a specified tolerance. In this process the elements of $J$ can be reevaluated each iteration, or only every $K$ th iteration provided the $\Delta x_{i}$ are changing slowly.

The Newton-Raphson algorithm will converge quadratically if the functions have continuous first derivatives in the neighborhood of the solution, the Jacobian matrix is nonsingular, and the initial approximations of $x$ are close to the actual solutions. However the method is sensitive to the behavior of the functions $f_{n}\left(x_{1}, x_{2}, \ldots \ldots ., x_{n}\right)$ and hence to their formulation. The more linear they are, the more rapidly and reliably Newton's method converges.

\section{$\underline{\text { Equations Relating to Newton-Raphson Load Flow Analysis }}$}

The load flow problem can be solved by the Newton-Raphson method using a set of Nonlinear equations to express the specified real and reactive power in terms of bus voltages. The derivation of the fundamental equations starts with the formulation of the nodal network equations, chosing the buses as the nodes,

$$
I_{k}=\sum_{m=1}^{n} Y_{k m} V_{m}, \quad k=1 \rightarrow n, \text { and } m=1 \rightarrow n
$$

Where,

$I_{k}=$ the current flowing into bus $\mathrm{k}$ in amperes.

$V_{m}=$ the voltage at bus $m$ in volts 
$Y_{k m}=$ the admittance between bus $\mathrm{k}$ and bus $\mathrm{m}$ in siemens

The power at the $k^{\text {th }}$ bus is then given by

$$
S_{k}=P_{k}+j Q_{k}=V_{k} I_{k}^{*}
$$

by equation (3.8) and (3.9) we get,

$$
P_{k}+j Q_{k}=V_{k} \sum_{m=1}^{n} Y_{k m}^{*} V_{m}^{*}
$$

Mathematically speaking, the complex load flow equations are nonanalytic, and cannot be differentiated in complex form. In order to apply Newton's method, equation (3.10) is separated into its real and imaginary components with $V_{k}=\left|V_{k}\right| L \theta_{k}, \quad V_{m}=\left|V_{m}\right| L \theta_{m}$, and $Y_{k m}=\left|Y_{k m}\right| L \theta_{k m}$. Using polar coordinates we calculate $P_{k}(V, \theta)$ and $Q_{k}(V, \theta)$ as,

$$
\begin{aligned}
& P_{k}=\sum_{m=1}^{n} V_{k} V_{m}\left(G_{k m} \operatorname{Cos} \theta_{k m}+B_{k m} \operatorname{Sin} \theta_{k m}\right) \\
& Q_{k}=\sum_{m=1}^{n} V_{k} V_{m}\left(G_{k m} \operatorname{Sin} \theta_{k m}-B_{k m} \operatorname{Cos} \theta_{k m}\right)
\end{aligned}
$$

where, $\theta_{k m}=\theta_{k}-\theta_{m}$

For the PQ buses i.e., the load buses, the equations used are (3.11 and (3.12)

For the PV buses only equation (3.11) is used, since $Q_{k}$ is not specified.

For the slack buses no equations are used because both voltage and angle are specified at this bus.

After specifying $\mathrm{P}$ and $\mathrm{Q}$ for all buses except the slack bus, $\Delta P_{k}$ and $\Delta Q_{k}$ are calculated as follows,

$$
\begin{aligned}
\Delta P_{k} & =P_{k, \text { speci }}-P_{k, \text { calcu }} \\
\Delta Q_{k} & =Q_{k, \text { speci }}-Q_{k, \text { calcu }}
\end{aligned}
$$


After finding $\Delta P$ and $\Delta Q$ the jacobian, consisting of the partial derivatives of $P_{k}$ and $Q_{k}$ with respect to the variables $(V, \theta)$, is calculated, the jacobian matrix looks like,

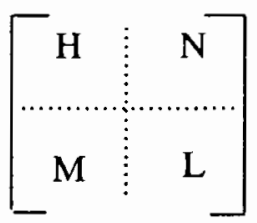

where the elements are

for $m \neq k$

$$
\begin{gathered}
H_{k m}=\frac{\partial P_{k}}{\partial \theta_{m}}=V_{k} V_{m}\left(G_{k m} \operatorname{Sin} \theta_{k m}-B_{k m} \operatorname{Cos} \theta_{k m}\right) \\
N_{k m}=V_{m} \frac{\partial P_{k}}{\partial V_{m}}=V_{k} V_{m}\left(G_{k m} \operatorname{Cos} \theta_{k m}+B_{k m} \operatorname{Sin} \theta_{k m}\right) \\
M_{k m}=\frac{\partial Q_{k}}{\partial \bar{\theta}_{m}}=-V_{k} V_{m}\left(G_{k m} \operatorname{Cos} \theta_{k m}+B_{k m} \operatorname{Sin} \theta_{k m}\right) \\
L_{k m}=V_{m} \frac{\partial Q_{k}}{\partial V_{m}}=V_{k} V_{m}\left(G_{k m} \operatorname{Sin} \theta_{k m}-B_{k m} \operatorname{Cos} \theta_{k m}\right)
\end{gathered}
$$

for $m=k$

$$
\begin{gathered}
H_{k k}=\frac{\partial P_{k}}{\partial \theta_{k}}=Q_{k}-B_{k k} V_{k}^{2} \\
N_{k k}=V_{k} \frac{\partial P_{k}}{\partial V_{k}}=P_{k}+G_{k k} V_{k}^{2} \\
M_{k k}=\frac{\partial Q_{k}}{\partial \theta_{k}}=P_{k}-G_{k k} V_{k}^{2} \\
L_{k k}=V_{k} \frac{\partial Q_{k}}{\partial V_{k}}=Q_{k}-B_{k k} V_{k}^{2}
\end{gathered}
$$

As an example for $\Delta P_{2}, \Delta P_{3}, \Delta Q_{2}$ and $\Delta Q_{3}$, the matrix is: 


$$
\left[\begin{array}{l}
\Delta P_{2} \\
\Delta P_{3} \\
\Delta Q_{2} \\
\Delta Q_{3}
\end{array}\right]=\left[\begin{array}{llll}
\frac{\partial P_{2}}{\partial \theta_{2}} & \frac{\partial P_{2}}{\partial \theta_{3}} & \frac{\partial P_{2}}{\partial V_{2}} & \frac{\partial P_{2}}{\partial V_{3}} \\
\frac{\partial P_{3}}{\partial \theta_{2}} & \frac{\partial P_{3}}{\partial \theta_{3}} & \frac{\partial P_{3}}{\partial V_{2}} & \frac{\partial P_{3}}{\partial V_{3}} \\
\frac{\partial Q_{2}}{\partial \theta_{2}} & \frac{\partial Q_{2}}{\partial \theta_{3}} & \frac{\partial Q_{2}}{\partial V_{2}} & \frac{\partial Q_{2}}{\partial V_{3}} \\
\frac{\partial Q_{3}}{\partial \theta_{2}} & \frac{\partial Q_{3}}{\partial \theta_{3}} & \frac{\partial Q_{3}}{\partial V_{2}} & \frac{\partial Q_{3}}{\partial V_{3}}
\end{array}\right]\left[\begin{array}{l}
\Delta \theta_{2} \\
\Delta \theta_{3} \\
\Delta V_{2} \\
\Delta V_{3}
\end{array}\right]
$$

after inverting the jacobian equation (3.16) becomes,

$$
\left[\begin{array}{l}
\Delta \theta_{2} \\
\Delta \theta_{3} \\
\Delta V_{2} \\
\Delta V_{3}
\end{array}\right]=\left[J^{-1}\right]\left[\begin{array}{l}
\Delta P_{2} \\
\Delta P_{3} \\
\Delta Q_{2} \\
\Delta Q_{3}
\end{array}\right]
$$

Solving equation (3.17) we get,

$$
\left[\begin{array}{c}
\Delta_{2} \\
\Delta \theta_{3}^{1} \\
\Delta V_{2}^{1} \\
\Delta V_{3}^{1}
\end{array}\right]=\left[\begin{array}{c}
\text { incremental } \\
\text { valuesof } \\
\Delta \theta \\
\Delta V
\end{array}\right]
$$

The values found for $\Delta \theta_{k}$ and $\Delta V_{k}$ are added to the previous values of voltage magnitude and angle to obtain new values for $V_{k}$ and $\theta_{k}$ for starting the next iteration, which is,

$$
\begin{aligned}
& V_{i+1}=V_{i}+\Delta V^{1} \\
& \theta_{i+1}=\theta_{i}+\Delta \theta^{1}
\end{aligned}
$$

This process is repeated until the precision index applied to the quantities in either column matrix is satisfied.

\section{RELATED PROGRAMS}

Apart from the Newton-Raphson load flow simulation program Loadflow.c, the procedure utilizes three other programs namely, Pfactor.c, Powerfiow.c and CostCalc.c.

(1) Pfactor.c calculates the real and reactive power magnitude at individual buses of the proposed model for input to Loadflow.c. A flow chart is shown in Figure 4 and the program is given in appendix $A$. 
(4) With the information obtained from the previous program the program "Powerflow.c" (appendix $\mathrm{C}$ ) is run to calculate the individual line losses resulting from the real and reactive power flow through the transmission lines.

(5) Knowing the line losses at different power factors (step 4), the partial reactive compensation required for drift in voltage and angle, and the real and reactive power required at the individual buses (step 3), we can find the cost of power at the individual buses. The program "CostCalc.c" is used to calculate the power bill and monthly savings. 


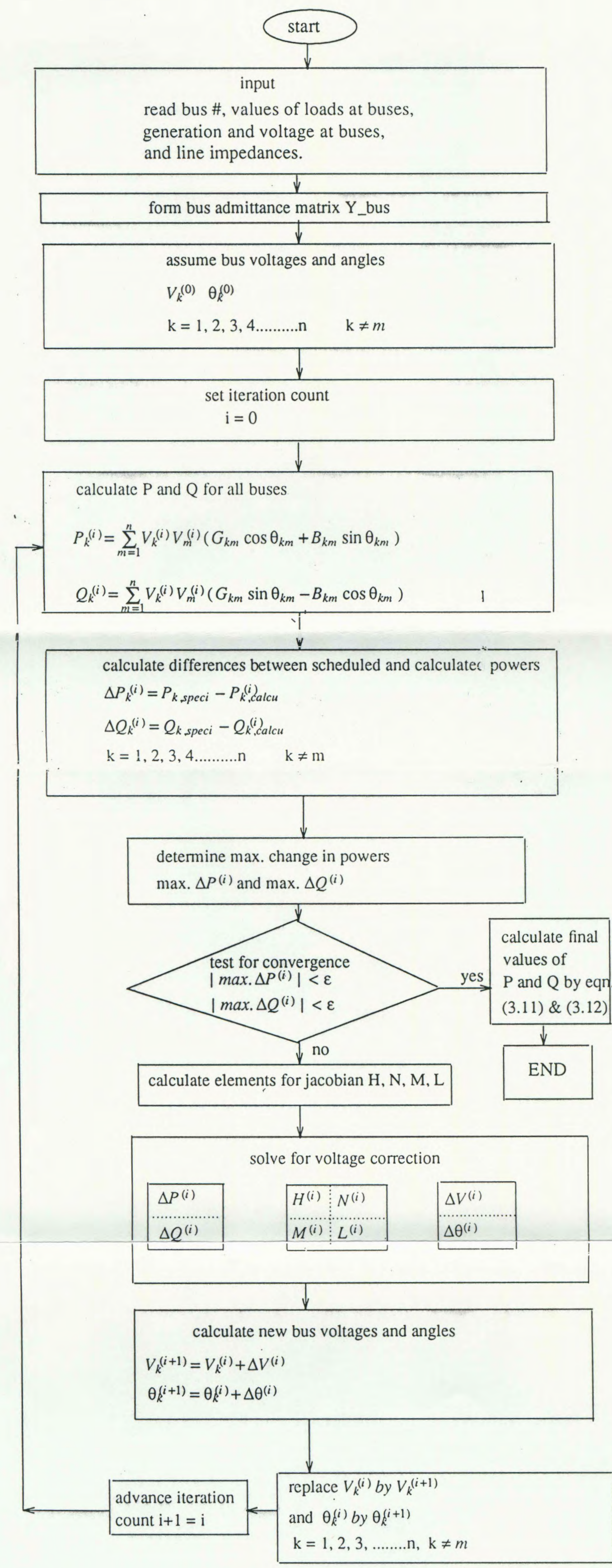

Figure 3. Flow chart of Newton-Raphson algorithm. 


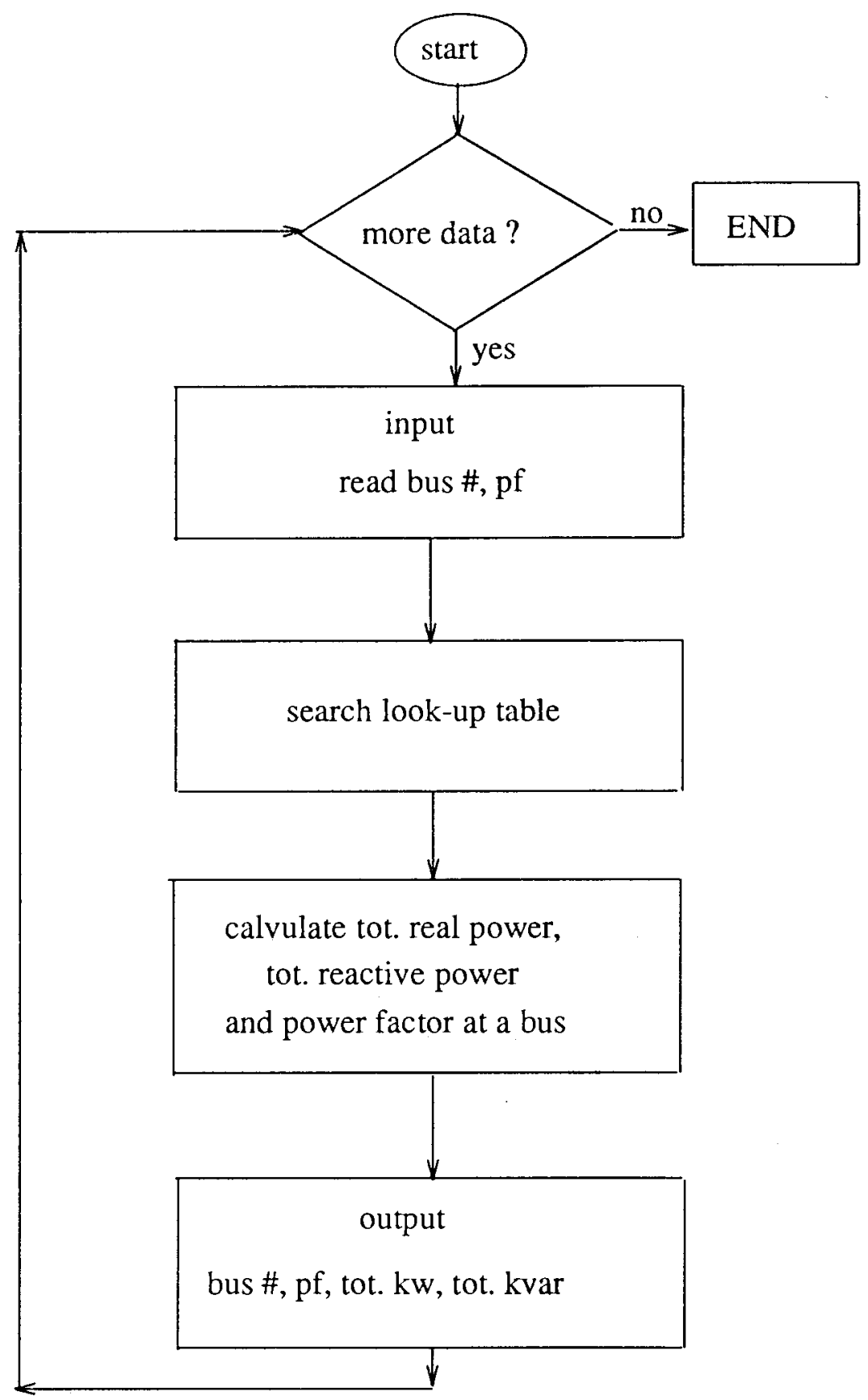

Figure 4. Flow chart of Pfactor.c. 


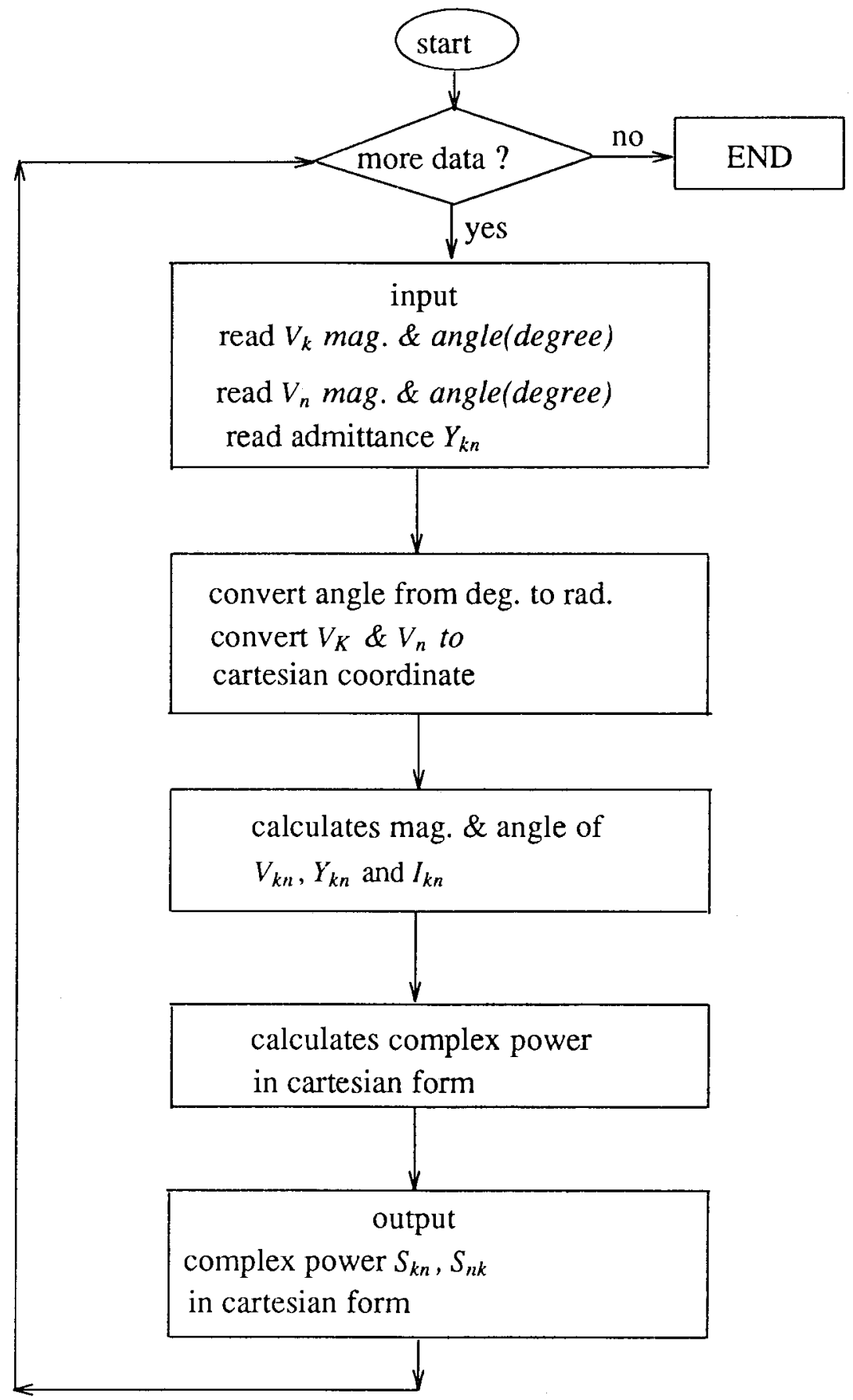

Figure 5. Flow chart of Lineflow.c. 


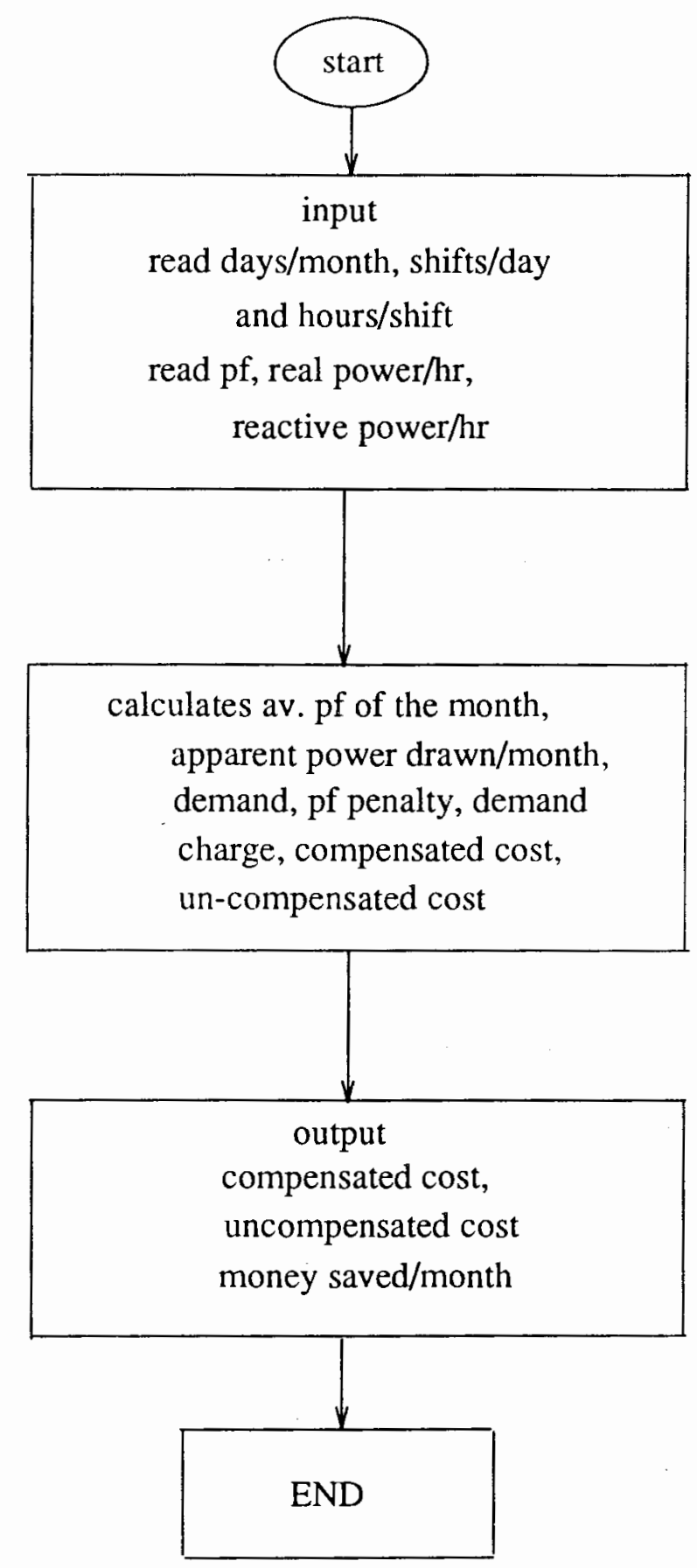

Figure 6. Flow chart of CostCalc.c. 


\title{
CHAPTER IV
}

\author{
RESULTS
}

\section{A POWER DISTRIBUTION MODEL}

The model, shown in Figure 7 representing a typical medium size industrial load was chosen to demonstrate the application of the method. Loads considered at individual load centers are shown in the model.

The Assumptions of the Model are:

(1) All lines are chosen to be one mile long. ACSR PENGUIN WSP H27 BUNDLE CONDUCTORS having $\mathrm{R}=0.456 \mathrm{ohms} / \mathrm{mile}$ and $\mathrm{X}=0.859 \mathrm{ohms} / \mathrm{mile}$ are used.

(2) A Single line diagram representing a balanced $3 \phi$ system is used to describe the model.

(3) The system may be considered to be connected to two substations or generators or to one substation and a generator for a constant power supply of greater reliability.

(4) Bus_4 of the system has small inductive loads and bus_6 has moderately high inductive loads. At times the power factor at bus_ 4 could automatically improve if fewer motors were in operation, in that case bus_6 could be directly benefited by linking bus_6 to bus_ 4 .

(5) Individual load centers are fed through separate transformers to isolate them from the main $13.8 \mathrm{kv}$ supply lines. This isolation has the advantage of confining faults to individual load centers so that they do not affect the others.

(6) Present day power transformers are highly efficient, thus loss incurred in the transformers are neglected. 


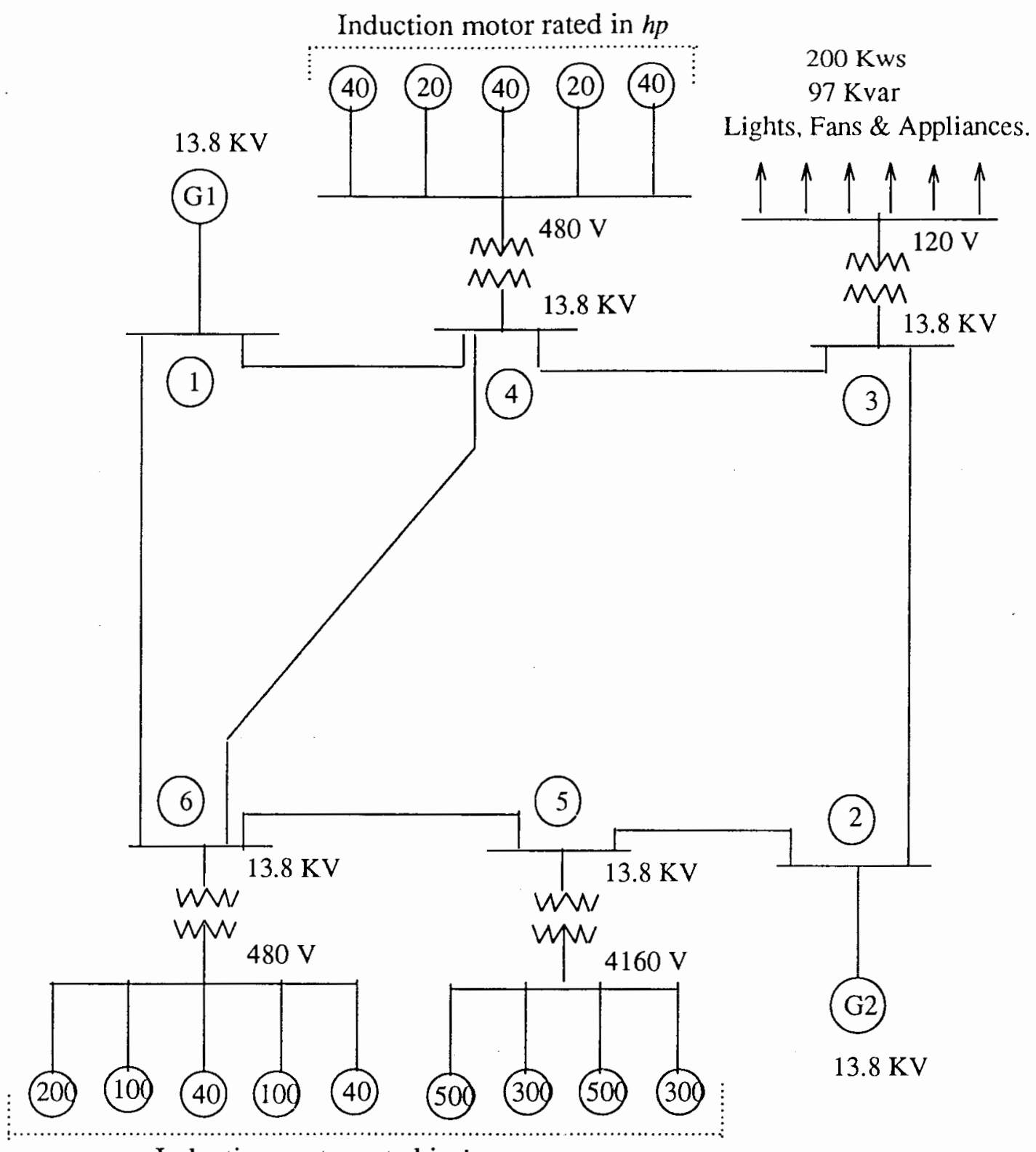

Induction motor rated in $h p$

Figure 7. A power distribution model.

(7) There are no constrains on the generators $G_{1}$ and $G_{2}$ to supply real or reactive power to the load buses when the load bus power factor falls below $95 \%$. 


\title{
THE SYSTEM Y_BUS
}

The system Y_bus data obtained from Loadflow.c is shown in the Table III below. The Y_bus data is used in the calculation of line flow at different power factors.

\author{
TABLE III
}

SYSTEM Y_BUS

\begin{tabular}{|c|c|c|c|c|c|c|}
\hline & 1 & 2 & 3 & 4 & 5 & 6 \\
\hline 1 & $\begin{array}{c}4.390 \\
-\mathrm{j} 8.331\end{array}$ & 0 & 0 & $\begin{array}{r}-2.432 \\
+\mathrm{j} 4.595\end{array}$ & 0 & $\begin{array}{r}-1.957 \\
+\mathrm{j} 3.737\end{array}$ \\
\hline 2 & 0 & $\begin{array}{r}3.915 \\
-\mathrm{j} 7.473\end{array}$ & $\begin{array}{r}-1.957 \\
+\mathrm{j} 3.737\end{array}$ & 0 & $\begin{array}{r}-1.957 \\
+\mathrm{j} 3.737\end{array}$ & 0 \\
\hline 3 & 0 & $\begin{array}{r}-1.957 \\
+\mathrm{j} 3.737\end{array}$ & $\begin{array}{r}3.915 \\
-\mathrm{j} 7.473\end{array}$ & $\begin{array}{r}-1.957 \\
+\mathrm{j} 3.737\end{array}$ & 0 & 0 \\
\hline 4 & -2.432 \\
$+\mathrm{j} 4.595$ & 0 & $\begin{array}{r}-1.957 \\
+\mathrm{j} 3.737\end{array}$ & $\begin{array}{r}6.347 \\
-\mathrm{j} 12.063\end{array}$ & 0 & $\begin{array}{r}-1.957 \\
+\mathrm{j} 3.737\end{array}$ \\
\hline 5 & 0 & $-\mathrm{j} 33.737$ & 0 & 0 & $\begin{array}{r}3.915 \\
-\mathrm{j} 7.473\end{array}$ & $\begin{array}{r}-1.957 \\
+\mathrm{j} 3.737\end{array}$ \\
\hline & -1.957 & & 0 & $\begin{array}{r}-1.957 \\
+\mathrm{j} 3.737\end{array}$ & $\begin{array}{r}-1.957 \\
+\mathrm{j} 3.737\end{array}$ & $\begin{array}{r}5.872 \\
-\mathrm{j} 11.210\end{array}$ \\
\hline
\end{tabular}

\section{SIMULATION RESULTS AT 95\% POWER FACTOR}

$\underline{\text { Real and Reactive Loads at Load Buses }}$

Given the $\eta, p f$. and the $h p$ of a motor the real and reactive power input of the motor can be calculated as shown below:

Real power input $(\mathrm{kw}$ input $)=\frac{h p \times 0.746}{\eta}$

Reactive power input (rkva input) $=k w$ input $\times \tan \left[\cos ^{-1}(p f)\right]$

BUS_6. At bus_6 we have $1 \times 200 \mathrm{hp}, 2 \times 100 \mathrm{hp}$ and $2 \times 40 \mathrm{hp}$ of $\eta=92 \%$. therefore, $k w$ input $=480 \times \frac{0.746}{0.92}=389.2174 \mathrm{kw}$ 
here, $\theta=\tan \left[\cos ^{-1}(0.95)\right]=0.3286$

and, $r k v a$ input $=389.2174 \times 0.3286=127.9295 \mathrm{kvar}$

BUS_5. At bus_5 we have $2 \times 500 \mathrm{hp}$, and $2 \times 300 \mathrm{hp}$ of $\eta=92 \%$.

Calculating the same way as shown above we get,

$k w$ input $=1297.3913 \mathrm{kw}$ and,

$r k v a$ input $=426.3189 \mathrm{kvar}$

BUS_4. At bus_4 we have $3 \times 40 \mathrm{hp}$, and $2 \times 20 \mathrm{hp}$ of $\eta=92 \%$.

Calculating the same way as shown above we get,

$k w$ input $=129.7391 \mathrm{kw}$ and,

$r k v a$ input $=42.6432 \mathrm{kvar}$

BUS_3. At bus_3 we have lights, fans, computers and other domestic and office usable appliances comprising a load of

$k w$ input $=200 k w s$

$r k v a$ input $=97$ kvars

Partial Compensation at the Load Buses

Results of the load flow simulation at $95 \%$ power factor and the partial compensation required at individual bus levels are shown in the Table IV and Table $V$ respectively.

It is seen from the Table IV that the

Total reactive power at the load end $=693.57139 \mathrm{kvars}$

Total real power at the load end $=2016.41747 \mathrm{kws}$

Total reactive power generated $=1016.76296 \mathrm{kvars}$

Total real power generated $=2189.1258 \mathrm{kws}$

Using Table II capacitor sizes for partial compensation at the load buses are, 
TABLE IV

LOAD FLOW OUTPUT AT PF $=95 \%$

\begin{tabular}{|c|c|c|c|c|c|c|}
\hline \multirow{2}{*}{$\begin{array}{c}\text { bus } \\
\# \\
\end{array}$} & \multirow{2}{*}{$\begin{array}{l}\text { volts } \\
\text { p.u }\end{array}$} & \multirow{2}{*}{$\begin{array}{c}\text { angle } \\
\text { degree }\end{array}$} & \multicolumn{2}{|c|}{ generation } & \multicolumn{2}{|c|}{ load } \\
\hline & & & $\mathrm{P}(\mathrm{kw})$ & Q(kvar) & $P(k w)$ & $\mathrm{Q}(\mathrm{kvar})$ \\
\hline 1 & 1.00000 & -18.099 & 933.22684 & 420.14783 & 0.00000 & 0.00000 \\
\hline 2 & 1.00000 & -18.066 & 1255.9017 & $5 \overline{96.61513}$ & 0.00000 & 0.00000 \\
\hline 3 & 0.96241 & -19.778 & 0.00000 & 0.00000 & 199.97647 & 96.98819 \\
\hline 4 & 0.95719 & -20.154 & 0.00000 & 0.00000 & 129.72434 & 42.63184 \\
\hline 5 & 0.85486 & -25.784 & 0.00000 & 0.00000 & 1297.5334 & 426.07247 \\
\hline 6 & 0.91739 & -22.225 & 0.00000 & 0.00000 & 389.18320 & 127.87889 \\
\hline
\end{tabular}

TABLE V

PARTIAL COMPENSATION AT THE LOAD BUSES AT PF $=95 \%$

\begin{tabular}{|c|c|c|c|c|c|}
\hline \hline BUS \# & KVA & PRE. PF\% & FIN. PF\% & CORREC. FAC & CAPA. SIZE(kvar) \\
\hline \hline 6 & 409.6542 & 92.57 & 95 & 0.07933 & 32.4978 \\
\hline 5 & 1365.6979 & 90.04 & 95 & 0.155 & 211.6832 \\
\hline 4 & 136.5499 & 93.87 & 95 & 0.039 & 5.3254 \\
\hline 3 & 222.255 & 94.10 & 95 & 0.0315 & 7.001 \\
\hline
\end{tabular}

$\underline{\text { Line Flow From Bus_1 to Bus_6 }}$

$$
\begin{gathered}
I_{16}=\left(V_{1}-V_{6}\right) \times Y_{16} \\
I_{16}=\left(1.0 e^{-18.099}-0.91739 e^{-22.22}\right)(-1.957+j 3.737) \\
I_{16}=-0.3336+j 0.3074 .
\end{gathered}
$$

therefore,

$S_{16}=\left(V_{1}\right) \times I_{16}^{*}$

$S_{16}=\left(1.0 e^{-18.099}\right)(-0.3336-j 0.3074)$

$S_{16}=-0.4127-j 0.1886$

again, 
$I_{61}=\left(V_{6}-V_{1}\right) \times Y_{61}$

$I_{61}=\left(0.91739 e^{-22.22}-1.0 e^{-18.099}\right)(-1.957+j 3.737)$

$I_{61}=0.3336-j 0.3074$

therefore,

$S_{61}=\left(V_{6}\right) \times I_{61}^{*}$

$S_{61}=\left(0.91739 e^{-22.22}\right)(0.3336+j 0.3074)$

$S_{61}=0.3900+j 0.1453$

Line loss between bus_ 1 and bus_6:

$S_{16}+S_{61}=-0.023-j 0.043$

\section{Line Flow From Bus_1 to Bus_4}

$$
I_{14}=\left(V_{1}-V_{4}\right) \times Y_{14}
$$

$I_{14}=\left(1.0 e^{-18.099}-0.9572 e^{-20.15}\right)(-2.432+j 4.595)$

$I_{14}=(-0.2143+j 0.1921)$

therefore,

$S_{14}=\left(V_{1}\right) \times I_{14}^{*}$

$S_{14}=\left(1.0 e^{-18.099}\right)(-0.2143-j 0.1921)$

$S_{14}=-0.2634-j 0.116$

again,

$I_{41}=\left(V_{4}-V_{1}\right) \times Y_{41}$

$I_{41}=\left(0.9572 e^{-20.15}-1.0 e^{-18.099}\right)(-2.432+j 4.595)$

$I_{41}=0.2143-j 0.1921$

therefore,

$S_{41}=\left(V_{4}\right) \times I_{41}^{*}$ 
$S_{41}=\left(0.9572 e^{-20.15}\right)(0.2143+j 0.1921)$

$S_{41}=0.2559+j 0.1019$

Line loss between bus_1 and bus_4:

$S_{14}+S_{41}=-0.008-j 0.014$

$\underline{\text { Line Flow From Bus_3 to Bus_ } 4}$

$$
I_{34}=\left(V_{3}-V_{4}\right) \times Y_{34}
$$

$I_{34}=\left(0.9624 e^{-19.78}-0.95719 e^{-20.15}\right)(-1.957+j 3.737)$

$I_{34}=-0.0293+j 0.01827$.

therefore,

$S_{34}=\left(V_{3}\right) \times I_{34}^{*}$

$S_{34}=\left(0.9624 e^{-19.78}\right)(-0.0293-j 0.01827)$

$S_{34}=-0.0325-j 0.007$

again,

$I_{43}=\left(V_{4}-V_{3}\right) \times Y_{43}$

$I_{43}=\left(0.95719 e^{-20.15}-0.9624 e^{-19.78}\right)(-1.957+j 3.737)$

$I_{43}=0.0293-j 0.01827$

therefore,

$S_{43}=\left(V_{4}\right) \times I_{43}^{*}$

$S_{43}=\left(0.95719 e^{-20.15}\right)(0.0293+j 0.01827)$

$S_{43}=0.03236+j 0.00675$

Line loss between bus_3 and bus_4:

$S_{34}+S_{43}=-0.00014-j 0.00025$ 
Line Flow From Bus_4 to Bus_6

$$
I_{46}=\left(V_{4}-V_{6}\right) \times Y_{46}
$$

$I_{46}=\left(0.95719 e^{-20.15-0.91739} e^{-22.22}\right)(-1.957+3.737)$

$I_{46}=(-0.1608+j 0.1507)$

therefore,

$S_{46}=\left(V_{4}\right) \times I_{46}^{*}$

$S_{46}=\left(0.95719 e^{-20.15)(-0.1608-j 0.1507)}\right.$

$S_{46}=-0.1942-j 0.0824$

again,

$I_{64}=\left(V_{6}-V_{4}\right) \times Y_{64}$

$I_{64}=\left(0.91739 e^{\left.-22.22-0.95719 e^{-20.15}\right)(-1.957+3.737)}\right.$

$I_{64}=-(-0.1608+j 0.1507)$

therefore,

$S_{64}=\left(V_{6}\right) \times I_{64}^{*}$

$S_{64}=\left(0.91739 e^{-22.22)(0.1608+j 0.1507)}\right.$

$S_{64}=0.1888+j 0.07223$

Line loss between bus_4 and bus_6:

$S_{46}+S_{64}=-0.005-j 0.010$

\section{Line Flow From Bus_2 to Bus_3}

$$
I_{23}=\left(V_{2}-V_{3}\right) \times Y_{23}
$$

$I_{23}=\left(1.0 e^{\left.-18.07-0.9624 e^{-19.78}\right)(-1.957+j 3.737)}\right.$

$I_{23}=(-0.1463+j 0.1379)$

therefore, 
$S_{23}=\left(V_{2)} \times I_{23}^{*}\right.$

$S_{23}=\left(1.0 e^{-18.07)(-0.1463-j 0.1379)}\right.$

$S_{23}=-0.1818-j 0.0858$

again,

$I_{32}=\left(V_{3}-V_{2}\right) \times Y_{32}$

$I_{32}=-\left(1.0 e^{-18.07-0.9624} e^{-19.78)(-1.957+j 3.737)}\right.$

$I_{32}=-(-0.1463+j 0.1379)$

therefore,

$S_{32}=\left(V_{3}\right) \times I_{32}^{*}$

$S_{32}=\left(0.96241 e^{-19.78)}\right)(0.1463+j 0.1379)$

$S_{32}=0.1774+j 0.07731$

Line loss between bus_2 and bus_3:

$S_{23}+S_{32}=-0.004-j 0.008$

$\underline{\text { Line Flow From Bus_2 to Bus_5 }}$

$$
I_{25}=\left(V_{2}-V_{5}\right) \times Y_{25}
$$

$I_{25}=\left(1.0 e^{-} 18.07-0.85486 e^{-25.78}\right)(-1.957+j 3.737)$

$I_{25}=(-0.5848+j 0.5554)$

therefore,

$S_{25}=\left(V_{2}\right) \times I_{25}^{*}$

$S_{25}=\left(0.85486 e^{-25.78)(-0.5848-j 0.5554)}\right.$

$S_{25}=-0.7282-j 0.3466$

again,

$I_{52}=\left(V_{5}-V_{2}\right) \times Y_{52}$ 
$I_{52}=-\left(1.0 e^{\left.-18.07-0.85486 e^{-25.78}\right)(-1.957+j 3.737)}\right.$

$I_{52}=-(-0.5848+j 0.5554)$

therefore,

$S_{52}=\left(V_{5}\right) \times I_{52}^{*}$

$S_{52}=\left(0.85486 e^{-25.78)(0.5848+j 0.5554)}\right.$

$S_{52}=0.6566+j 0.2100$

Line loss between bus_2 and bus_5:

$S_{25}+S_{52}=-0.072-j 0.137$

Line Flow From Bus_5 to Bus_6

$$
I_{56}=\left(V_{5}-V_{6}\right) \times Y_{56}
$$

$I_{56}=\left(0.85486 e^{-25.78-0.91739} e^{-22.22}\right)(-1.957-j 3.737$

$I_{56}=(0.2484-j 0.2484)$

therefore,

$S_{56}=\left(V_{5}\right) \times I_{56}^{*}$

$S_{56}=\left(0.85486 e^{-25.78)(0.2484+j 0.2484)}\right.$

$S_{56}=0.2835+j 0.0988$

again,

$I_{65}=\left(V_{6}-V_{5}\right) \times Y_{65}$

$I_{65}=-\left(0.85486 e^{-25.78-0.91739} e^{-22.22}\right)(-1.957-j 3.737)$

$I_{65}=-(0.2484-j 0.2484)$

therefore,

$S_{65}=\left(V_{6}\right) \times I_{65}^{*}$

$S_{65}=\left(0.91739 e^{-22.22}\right)(0.2484+j 0.2484)$

$S_{65}=-0.2971-j 0.1247$ 
Line loss between bus_5 and bus_6:

$S_{56}+S_{65}=-0.014-j 0.026$

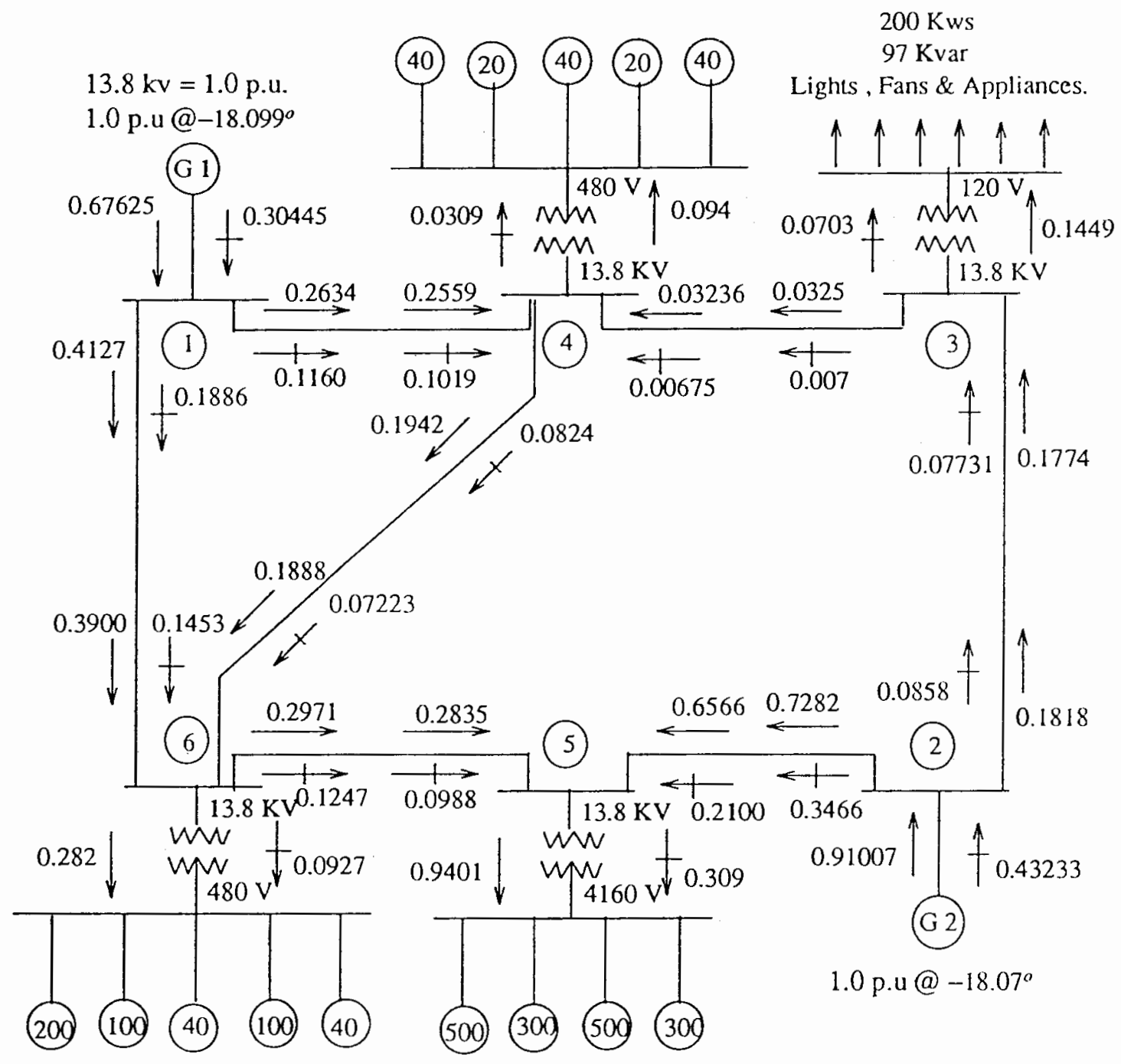

Figure 8. Line flow for $\mathrm{pf}=95 \%$. 
Reactive Power Loss in the Individual Lines Per Mile

Bus_1 to Bus_6 $=(0.1886-0.1453) \times 1380 \div 337=0.18 \mathrm{kvar}$

Bus_1 to Bus_4 $=(0.116-0.1019) \times 1380 \div 273=0.07 \mathrm{kvar}$

Bus_3 to Bus_4 $=(0.007-0.00675) \times 1380 \div 337=0.001 \mathrm{kvar}$

Bus_2 to Bus_3 $=(0.0858-0.07731) \times 1380 \div 337=0.035 \mathrm{kvar}$

Bus_6 to Bus_5 $=(0.1247-0.09788) \times 1380 \div 337=0.11 \mathrm{kvar}$

Bus_2 to Bus_5 $=(0.3466-0.21) \times 1380 \div 337=0.56 \mathrm{kvar}$

Bus_4 to Bus_ $6=(0.0824-0.07223) \times 1380 \div 337=0.042 \mathrm{kvar}$

Therefore total reactive power losses in the lines $=0.998 \mathrm{kvar}$

$\underline{\text { Real Power Loss in the Individual Lines Per Mile }}$

Bus_1 to Bus_6 $=(0.4127-0.39) \times 1380 \div 337=0.093 \mathrm{kw}$

Bus_1 to Bus_4 $=(0.2634-0.2559) \times 1380 \div 273=0.038 \mathrm{kw}$

Bus_3 to Bus_4 $=(0.0325-0.03236) \times 1380 \div 337=0.00057 \mathrm{kw}$

Bus_2 to Bus_3 $=(0.1818-0.1774) \times 1380 \div 337=0.018 \mathrm{kw}$

Bus_6 to Bus_5 $=(0.2971-0.2835) \times 1380 \div 337=0.055 \mathrm{kw}$

Bus_2 to Bus_5 $=(0.7282-0.6566) \times 1380 \div 337=0.29 \mathrm{kw}$

Bus_4 to Bus_6 $=(0.1942-0.1888) \times 1380 \div 337=0.022 \mathrm{kw}$

Therefore total real power losses in the lines $=0.516 \mathrm{kw}$

Total Capacitive Compensation at the Buses

From line flow data of $\mathrm{pf}=95 \%$ and from the reactive line losses we calculate the compensation required at the individual buses:

At Bus_ $5=0.309 \times 1380+0.56+0.11=427.09 \mathrm{kvar}$

At Bus_ $6=0.0927 \times 1380+0.18+0.042=128.15 \mathrm{kvar}$

Al Bus_4 $=0.0309 \times 1380+0.001+0.07=42.71 \mathrm{kvar}$ 
At Bus_3 $=0.0703 \times 1380+0.035=97.05 \mathrm{kvar}$

Therefore total bus compensation $=695.00 \mathrm{kvar}$

TABLE VI

COMPENSATION AT BUSES AT PF $=95 \%$

\begin{tabular}{|c|c|c|}
\hline bus \# & generator & capa. size (kvar) \\
\hline \hline 6 & - & 128.15 \\
\hline 5 & - & 427.09 \\
\hline 4 & - & 42.71 \\
\hline 3 & - & 97.05 \\
\hline
\end{tabular}

\section{Cost of Energy}

From the simulation result we see that,

Tot. kvar required per hour $=694.56 \mathrm{kvar} / \mathrm{hr}$

Tot. kws required per hour $=2016.933 \mathrm{kws} / \mathrm{hr}$

Considering a typical situation where the plant runs for two shifts, 8 hours per shift and 5 days in a week, we find,

Required generation of $\mathrm{kvar} / \mathrm{month}=694.56 \times 2 \times 8 \times 20=222259.20 \mathrm{kvar}$

Required generation of $\mathrm{kws} / \mathrm{month}=2016.933 \times 2 \times 8 \times 20=645418.56 \mathrm{kw}$

Using the formula,

$$
\begin{aligned}
& \text { Average } p f=\frac{\text { Tot } k w}{\sqrt{\left(\text { Tot } k w^{2}+\text { Tot } k v a r^{2}\right)}} \\
& p f=\frac{2016.933}{\sqrt{\left(2016.933^{2}+694.56^{2}\right)}} \\
& p f=94.55 \%
\end{aligned}
$$

$\underline{\text { Uncompensated Energy Bill }}$

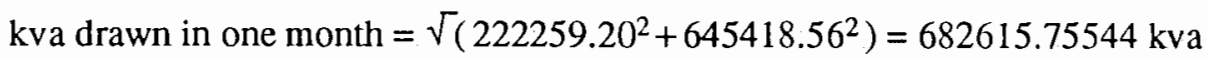

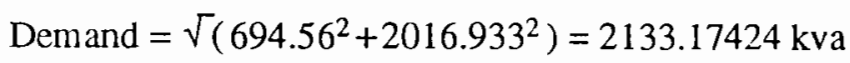

pf penalty of $=(95-94.55) \times 2=1 \%$ 
Energy $=682615.75544 \mathrm{kws}$

demand $=2133.17424 \mathrm{kws}$

pf penalty $=2133.17424 \times 0.01=21.33 \mathrm{kws}$

The total bill is $=682615.75544 \times 0.02+2133.17424 \times 4.14+21.33 \times 4.14=22571.97$ dollars .

where, energy charge $=0.02$ dollar $/ \mathrm{kwhr}$

demand charge $=4.14$ dollar $/ \mathrm{kwhr}$, and

pf penalty charge $=4.14$ dollar $/ \mathrm{kwhr}$

Compensated Energy Bill

By compensating the kvar keeping a pf $=95 \%$ to avoid the power factor penalty, the reactive power that can be drawn safely from the utility without paying a pf penalty can be calculated as,

$$
\begin{array}{r}
0.95=\frac{\text { Tot } k w}{\sqrt{\left(\text { Tot } k w^{2}+\text { Tot } k v a r^{2}\right)}} \\
0.95=\frac{645418.56}{\sqrt{\left(645418.56^{2}+\text { Tot } k v a r^{2}\right)}}
\end{array}
$$

The total kvar that could be safely drawn from the utility $=212138.82186 \mathrm{kvar}$ Therefore, the amount of kvar that needs to be compensated is = generated kvar - safe drawn kvar

The kvar to be compensated $=222259.20-212138.82186=10120.378$ kvar $\div 320=31.63$ $\mathrm{kvar} / \mathrm{hr}$

After compensation kva drawn/month $\left.=\sqrt{(} 645418.56^{2}+212138.82186^{2}\right)=679387.95789 \mathrm{kva}$

The new demand is $=\sqrt{\left(2016.933^{2}+(694.56-31.63)^{2}\right.}$

Demand $=2123.087 \mathrm{kva}$

Energy $=679387.95789 \mathrm{kws}$

Demand $=2123.087 \mathrm{kws}$ 
The total bill is $=679387.95789 \times 0.02+2123.087 \times 4.14=22377.34$ dollars.

where, the energy charge $=0.02$ dollar/kwhr, and

the demand charge $=4.14$ dollar $/ \mathrm{kwhr}$

Money saved/month $=$ Uncompensated bill - compensated bill $=22571.97-22377.34=194.63$

dollars.

Cost of Capacitor Compensation

Two separate costs are involved in capacitive compensation, namely,

- Installed costs (include site preparation, fence, relays,.. etc.), costs 6.00 dollars/kvar

- Cost of small banks of capacitors, costs 10.00 dollars/kvar

From the Table XII total kvar to be compensated is $694.56 \mathrm{kvar}$.

The total compensation cost $=$ the total kvar (to be compensated) $\times$ (the installed cost + the cost of capacitor banks)

The total compensation cost $=694.56 \times(6.00+10.00)=11112.96$ dollars.

Therefore, dividing compensation cost by monthly excess bill we get,

$11112.96 \div 194.63=57$ months

i.e., the total investment for capacitor compensation is equivalent to 57 months excess bill.

\section{SIMULATION RESULTS AT 90\% POWER FACTOR}

$\underline{\text { Real and Reactive Loads at Load Buses }}$

Given the $\eta, p f$ and the $h p$ of a motor the real and reactive power input of the motor can be calculated as shown below:

Real power input $(\mathrm{kw}$ input $)=\frac{h p \times 0.746}{\eta}$

Reactive power input (rkva input) $=k w$ input $\times \tan \left[\cos ^{-1}(p f)\right]$ 
BUS_6. At bus_6 we have $1 \times 200 \mathrm{hp}, 2 \times 100 \mathrm{hp}$ and $2 \times 40 \mathrm{hp}$ of $\eta=92 \%$.

therefore,

$k w$ input $=480 \times \frac{0.746}{0.92}=389.2174 \mathrm{kw}$

here, $\theta=\tan \left[\cos ^{-1}(0.90)\right]=0.4832$

Now, $r k v a$ input $=389.2174 \times 0.4832=188.5066 \mathrm{kvar}$

BUS_5. At bus_5 we have $2 \times 500 \mathrm{hp}$, and $2 \times 300 \mathrm{hp}$ of $\eta=92 \%$.

Calculating the same way as shown above we get,

$k w$ input $=1297.3913 \mathrm{kw}$ and,

rkva input $=628.3553 \mathrm{kvar}$

BUS_4. At bus_4 we have $3 \times 40 \mathrm{hp}$, and $2 \times 20 \mathrm{hp}$ of $\eta=92 \%$.

Calculating the same way as shown above we get,

$k w$ input $=129.7391 \mathrm{kw}$ and,

$r k v a$ input $=62.8355 \mathrm{kvar}$

BUS_3. At bus_3 we have lights, fans, computers and other domestic and office usable appliances comprising a load of

$k w$ input $=200 k w s$

rkva input $=97$ kvars

\section{Partial Compensation at the Load Buses}

Results of the load flow simulation at $90 \%$ power factor and the partial compensation required at individual bus levels are shown in the Table VII and Table VIII respectively. It is seen from the above Table VII that the,

Total reactive power at the load end $=975.85136 \mathrm{kvars}$

Total reactive power at the load end $=975.85136 \mathrm{kvars}$ 
TABLE VII

LOAD FLOW OUTPUT AT PF $=90 \%$

\begin{tabular}{|c|c|c|c|c|c|c|}
\hline \multirow{2}{*}{$\begin{array}{c}\overline{\text { bus }} \\
\#\end{array}$} & \multirow{2}{*}{$\begin{array}{l}\text { volts } \\
\text { p.u }\end{array}$} & \multirow{2}{*}{$\begin{array}{c}\text { angle } \\
\text { degree }\end{array}$} & \multicolumn{2}{|c|}{ generation } & \multicolumn{2}{|c|}{ load } \\
\hline & & & $\mathrm{P}(\mathrm{kw})$ & Q(kvar) & $\mathrm{P}(\mathrm{kw})$ & $\mathrm{Q}$ (kvar) \\
\hline 1 & 1.00000 & $\begin{array}{l}-18.099 \\
\end{array}$ & 937.09308 & 570.60622 & 0.00000 & 0.00000 \\
\hline 2 & 1.00000 & -17.918 & 1283.6459 & 788.42852 & 0.00000 & 0.00000 \\
\hline 3 & 0.95897 & -19.605 & 0.00000 & 0.00000 & 199.98655 & 96.77199 \\
\hline 4 & 0.95040 & -19.952 & 0.00000 & 0.00000 & 129.72921 & 62.77199 \\
\hline 5 & 0.82576 & -25.173 & 0.00000 & 0.00000 & 1297.7161 & 627.68737 \\
\hline 6 & 0.90197 & -21.849 & 0.00000 & 0.00000 & 389.20468 & 188.42460 \\
\hline
\end{tabular}

Total real power at the load end $=2016.6366 \mathrm{kwS}$

Total real power generated $=2220.73902 \mathrm{kws}$

Total reactive power generated $=1359.03474 \mathrm{kvars}$

Now, by Table II capacitor size for partial compensation at the load buses are,

TABLE VIII

PARTIAL COMPENSATION AT THE LOAD BUSES AT PF $=90 \%$

\begin{tabular}{||c|c|c|c|c|}
\hline \hline BUS \# & PRE. PF\% & FIN. PF\% & CORREC. FAC & CAPA. SIZE(kvar) \\
\hline \hline 6 & 92.82 & 95 & 0.07158 & 30.95 \\
\hline 5 & 90.50 & 95 & 0.141 & 203.2582 \\
\hline 4 & 93.99 & 95 & 0.035 & 5.044 \\
\hline 3 & 94.20 & 95 & 0.028 & 6.216 \\
\hline
\end{tabular}

Line Flow From Bus_1 to Bus_6

$$
I_{16}=\left(V_{1}-V_{6}\right) \times Y_{16}
$$

$I_{16}=\left(1.0 e^{-18.099-0.90197} e^{-21.85}\right)(-1.957+j 3.737)$

$I_{16}=(-0.3153+j 0.37459)$

therefore, 
$S_{16}=\left(V_{1}\right) \times I_{16}^{*}$

$S_{16}=\left(1.0 e^{-18.099}\right)(-0.3153-j 0.37459)$

$S_{16}=-0.41607-j 0.2581$

again,

$I_{61}=\left(V_{6}-V_{1}\right) \times Y_{61}$

$I_{61}=-\left(1.0 e^{-18.099}-0.90197 e^{-21.85}\right)(-1.957+j 3.737)$

$I_{61}=-(-0.3153+j 0.37459)$

therefore,

$S_{61}=\left(V_{6}\right) \times I_{61}^{*}$

$S_{61}=-\left(0.90197 e^{-21.84973)(-0.3153-j 0.37459)}\right.$

$S_{61}=0.3897+j 0.2077$

Line loss between bus_1 and bus_6:

$S_{16}+S_{61}=-0.026-j 0.05$

$\underline{\text { Line Flow From Bus_1 to Bus_4 }}$

$$
I_{14}=\left(V_{1}-V_{4}\right) \times Y_{14}
$$

$I_{14}=\left(1.0 e^{-} 18.099-0.9504 e^{-} 19.95\right)(-2.432+j 4.595)$

$I_{14}=(-0.2016+j 0.2295)$

therefore,

$S_{14}=\left(V_{1}\right) \times I_{14}^{*}$

$S_{14}=\left(1.0 e^{-18.099}\right)(-0.2016-j 0.2295)$

$S_{14}=-0.26289-j 0.15553$

again,

$I_{41}=\left(V_{4}-V_{1}\right) \times Y_{41}$ 
$I_{41}=-\left(1.0 e^{\left.-18.099-0.9504 e^{-19.95}\right)(-2.432+j 4.595)}\right.$

$I_{41}=-(-0.2016+j 0.2295)$

therefore,

$S_{41}=\left(V_{4}\right) \times I_{41}^{*}$

$S_{41}=-\left(0.9504 e^{-19.95)(-0.2016-j 0.2295)}\right.$

$S_{41}=0.25449+j 0.13967$

Line loss between bus_1 and bus_4:

$S_{14}+S_{41}=-0.008-j 0.016$

Line Flow From Bus_3 to Bus_4

$$
I_{34}=\left(V_{3}-V_{4}\right) \times Y_{34}
$$

$I_{34}=\left(0.95897 e^{\left.-19.61-0.9504 e^{-19.95}\right)(-1.957+j 3.737)}\right.$

$I_{34}=(-0.02917+j 0.03246)$

therefore,

$S_{34}=\left(V_{3}\right) \times I_{34}^{*}$

$S_{34}=\left(0.95897 e^{-19.61)(-0.02917-j 0.03246)}\right.$

$S_{34}=-0.0368-j 0.01994$

again,

$I_{43}=\left(V_{4}-V_{3}\right) \times Y_{43}$

$I_{43}=-\left(0.95897 e^{\left.-19.61-0.9504 e^{-19.95}\right)(-1.957+j 3.737)}\right.$

$I_{43}=-(-0.02917+j 0.03246)$

therefore,

$S_{43}=\left(V_{4}\right) \times I_{43}^{*}$

$S_{43}=-\left(0.9504 e^{-19.95)(-0.02917-j 0.03246)}\right.$

$S_{43}=0.036593+j 0.01954$ 
Line loss between bus_3 and bus_4:

$S_{34}+S_{43}=-0.000207-j 0.0004$

\section{Line Flow From Bus_4 to Bus_6}

$$
I_{46}=\left(V_{4}-V_{6}\right) \times Y_{46}
$$

$I_{46}=\left(0.9504 e^{\left.-19.95-0.90197 e^{-21.86}\right)(-1.957+j 3.737)}\right.$

$I_{46}=(-0.1525+j 0.1876)$

therefore,

$S_{46}=\left(V_{4}\right) \times I_{46}^{*}$

$S_{46}=\left(0.9504 e^{-19.95)(-0.1525-j 0.1876)}\right.$

$S_{46}=-0.197096-j 0.1182$

again,

$I_{64}=\left(V_{6}-V_{4}\right) \times Y_{64}$

$I_{64}=-\left(0.9504 e^{\left.-19.95-0.90197 e^{-21.86}\right)(-1.957+j 3.737)}\right.$

$I_{64}=-(-0.1525+j 0.1876)$

therefore,

$S_{64}=\left(V_{6}\right) \times I_{64}^{*}$

$S_{64}=-\left(0.90197 e^{-21.84973)(-0.1525-j 0.1876)}\right.$

$S_{64}=0.19066+j 0.10592$

Line loss between bus_ 4 and bus_6:

$S_{46}+S_{64}=-0.0006-j 0.012$

\section{Line Flow From Bus_2 to Bus_3}

$$
I_{23}=\left(V_{2}-V_{3}\right) \times Y_{23}
$$

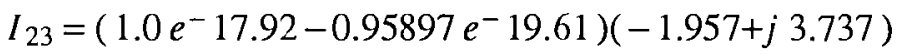

$I_{23}=(-0.1467+j 0.1523)$ 
therefore,

$S_{23}=\left(V_{2}\right) \times I_{23}^{*}$

$S_{23}=\left(1.0 e^{-17.92)(-0.1467-j 0.1523)}\right.$

$S_{23}=-0.1864419-j 0.09972$

again,

$I_{32}=\left(V_{3}-V_{2}\right) \times Y_{32}$

$I_{32}=-\left(1.0 e^{\left.-17.92-0.95897 e^{-19.61}\right)(-1.957+j 3.737)}\right.$

$I_{32}=-(-0.1467+j 0.1523)$

therefore,

$S_{32}=\left(V_{3}\right) \times I_{32}^{*}$

$S_{32}=-\left(0.95897 e^{-19.61)}\right)(-0.1467-j 0.1523)$

$S_{32}=0.1815+j 0.09339$

Line 1oss between bus_2 and bus_3:

$S_{23}+S_{32}=-0.005-j 0.006$

Line Flow From Bus_2 to Bus_5

$$
I_{25}=\left(V_{2}-V_{5}\right) \times Y_{25}
$$

$I_{25}=\left(1.0 e^{\left.-17.92-0.82576 e^{-25.17}\right)(-1.957+j 3.737)}\right.$

$I_{25}=(-0.5623+j 0.6776)$

therefore,

$S_{25}=\left(V_{2}\right) \times I_{25}^{*}$

$S_{25}=\left(1.0 e^{-17.92)(-0.5623-j 0.6776)}\right.$

$S_{25}=-0.7435-j 0.4718$

again, 
$I_{52}=\left(V_{5}-V_{2}\right) \times Y_{52}$

$I_{52}=-\left(1.0 e^{\left.-17.92-0.82576 e^{-25.17}\right)(-1.957+j 3.737)}\right.$

$I_{52}=-(-0.5623+j 0.6776)$

therefore,

$S_{52}=\left(V_{5}\right) \times I_{52}^{*}$

$S_{52}=-\left(0.82576 e^{-25.17}\right)(-0.5623-j 0.6776)$

$S_{52}=0.65823+j 0.30896$

Line loss between bus_2 and bus_5:

$S_{25}+S_{52}=-0.085-j 0.163$

$\underline{\text { Line Flow From Bus } 5 \text { to Bus_6 }}$

$$
I_{56}=\left(V_{5}-V_{6}\right) \times Y_{56}
$$

$I_{56}=\left(0.82576 e^{\left.-25.17-0.90197 e^{-21.85}\right)(-1.957+j 3.737)}\right.$

$I_{56}=(0.2339-j 0.3053)$

therefore,

$S_{56}=\left(V_{5}\right) \times I_{56}^{*}$

$S_{56}=\left(0.82576 e^{-25.17)(0.2339+j 0.3053)}\right.$

$S_{56}=0.28205+j 0.14599$

again,

$I_{65}=\left(V_{6}-V_{5}\right) \times Y_{65}$

$I_{65}=-\left(0.82576 e^{\left.-25.17-0.90197 e^{-21.85}\right)(-1.957+j 3.737)}\right.$

$I_{65}=-(0.2339-j 0.3053)$

therefore,

$S_{65}=\left(V_{6}\right) \times I_{65}^{*}$ 
$S_{65}=-\left(0.90197 e^{-21.84973)(0.2339+j 0.3053)}\right.$

$S_{65}=-0.298322-j 0.17706$

Line loss between bus_5 and bus_6:

$S_{56}+S_{65}=-0.016-j 0.031$

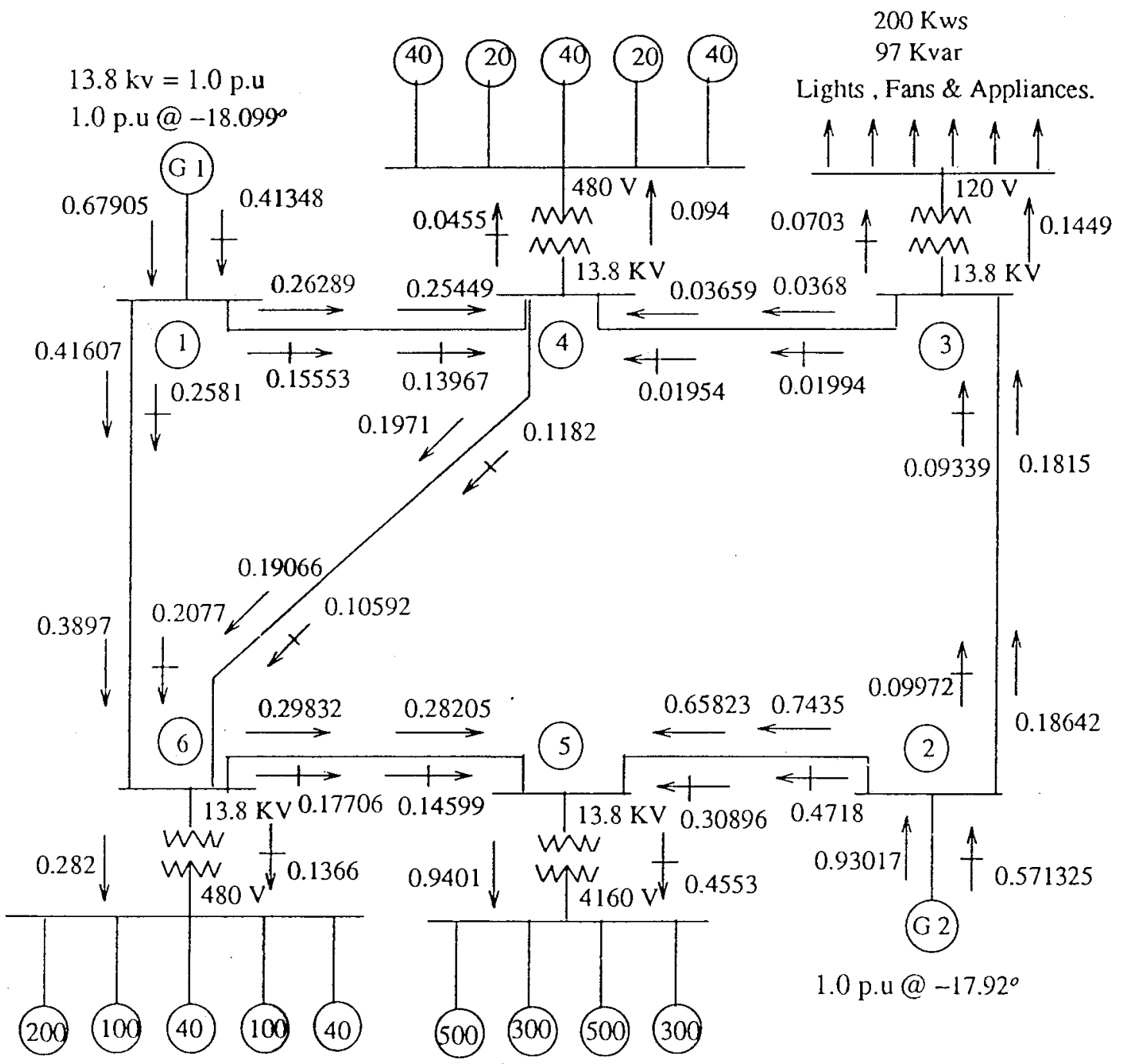

Figure 9. Line flow for $\mathrm{pf}=90 \%$. 
Reactive Power Loss in the Individual Lines Per Mile

Bus_1 to Bus_6 $=(0.2581-0.2077) \times 1380 \div 337=0.206 \mathrm{kvar}$

Bus_1 to Bus_4 $=(0.15553-0.13967) \times 1380 \div 273=0.08 \mathrm{kvar}$

Bus_3 to Bus_4 $=(0.01994-0.01954) \times 1380 \div 337=0.0016 \mathrm{kvar}$

Bus_2 to Bus_3 $=(0.09972-0.09339) \times 1380 \div 337=0.026 \mathrm{kvar}$

Bus_6 to Bus_ $5=(0.17706-0.14599) \times 1380 \div 337=0.13 \mathrm{kvar}$

Bus_2 to Bus_5 $=(0.4718-0.30896) \times 1380 \div 337=0.667 \mathrm{kvar}$

Bus_4 to Bus_6 $=(0.1182-0.10592) \times 1380 \div 337=0.05 \mathrm{kvar}$

Therefore total reactive power losses in the lines $=1.16 \mathrm{kvar}$

Real Power Loss in the Individual Lines Per Mile

Bus_1 to Bus_6 $=(0.41607-0.3892) \times 1380 \div 337=0.11 \mathrm{kw}$

Bus_1 to Bus_4 $=(0.26289-0.25449) \times 1380 \div 273=0.04 \mathrm{kw}$

Bus_3 to Bus_4 $=(0.0368-0.03659) \times 1380 \div 337=0.0008 \mathrm{kw}$

Bus_2 to Bus_3 $=(0.18642-0.1815) \times 1380 \div 337=0.02 \mathrm{kw}$

Bus_6 to Bus_5 $=(0.29832-0.28205) \times 1380 \div 337=0.067 \mathrm{kw}$

Bus_2 to Bus_5 $=(0.7435-0.65823) \times 1380 \div 337=0.35 \mathrm{kw}$

Bus_4 to Bus_6 $=(0.1971-0.19066) \times 1380 \div 337=0.026 \mathrm{kw}$

Therefore total real power losses in the lines $=0.614 \mathrm{kw}$

Total Capacitive Compensation at the Buses

From line flow data of $\mathrm{pf}=90 \%$ and from the reactive line losses we calculate the compensation required at the individual buses:

At Bus_5 $=0.4553 \times 1380+0.667+0.13=629.11 \mathrm{kvar}$

At Bus_6 $=0.1366 \times 1380+0.206+0.05=188.764 \mathrm{kvar}$

At Bus $4=0.0455 \times 1380+0.08+0.0016=62.872 \mathrm{kvar}$ 
At Bus_3 $=0.0703 \times 1380+0.026=97.04 \mathrm{kvar}$

Therefore total bus compensation $=977.786 \mathrm{kvar}$

TABLE IX

COMPENSATION AT BUSES AT PF $=90 \%$

\begin{tabular}{|c|c|c|}
\hline bus \# & generator & capa. size (kvar) \\
\hline \hline 6 & - & 188.764 \\
\hline 5 & - & 629.11 \\
\hline 4 & - & 62.872 \\
\hline 3 & - & 97.04 \\
\hline
\end{tabular}

Cost of energy

From the simulation result we see that,

Tot. $\mathrm{kvar}$ required per hour $=977.0113 \mathrm{kvar} / \mathrm{hr}$

Tot. $\mathrm{kws}$ required per hour $=2017.25 \mathrm{kws} / \mathrm{hr}$

Considering a typical situation where the plant runs for two shifts, 8 hours per shift and 5 days in a week, we find,

Required generation of kvar $/$ month $=977.0113 \times 2 \times 8 \times 20=312643.616 \mathrm{kvar}$

Required generation of kws $/$ month $=2017.25 \times 2 \times 8 \times 20=645520.00 \mathrm{kws}$

Using the formula,

$$
\begin{aligned}
& \text { Average } p f=\frac{T o t k w}{\sqrt{\left(\text { Tot } k w^{2}+\text { Tot } k v a r^{2}\right)}} \\
& p f=\frac{645520.00}{\sqrt{\left(645520.00^{2}+312643.616^{2}\right)}} \\
& p f=90 \%
\end{aligned}
$$

Uncompensated Energy Bill

kva drawn in one month $=\sqrt{(}\left(312643.616^{2}+645520.00^{2}\right)=717246.19276 \mathrm{kva}$

Demand $=\sqrt{ }\left(977.0113^{2}+2017.25^{2}\right)=2241.39435 \mathrm{kva}$

pf penalty of $=(95-90) \times 2=10 \%$ 
Energy $=717246.19276 \mathrm{kws}$

Demand $=2241.39435 \mathrm{kws}$

pf penalty $=2241.39435 \times 0.1=224.1349 \mathrm{kwS}$

The total bill is $=717246.19276 \times 0.02+2241.39435 \times 4.14+224.1349 \times 4.14=24645.03$ dollars

where, the energy charge $=0.02$ dollar $/ \mathrm{kwhr}$

the demand charge $=4.14$ dollar $/ \mathrm{kwh}$, and

pf penalty charge $=4.14$ dollar $/ \mathrm{kwhr}$

\section{Compensated Energy Bill}

By compensating the kvar keeping a pf $=95 \%$ to avoid the power factor penalty, the reactive power that can be drawn safely from the utility without paying a pf penalty can be calculated as,

$$
\begin{gathered}
0.95=\frac{\text { Tot } k w}{\sqrt{\left(\text { Tot } k w^{2}+\text { Tot } k v a r^{2}\right)}} \\
0.95=\frac{645520.00}{\sqrt{\left(645520.00^{2}+\text { Tot } k v a r^{2}\right)}}
\end{gathered}
$$

Tot. kvar (could be drawn safely from the utility) $=212172.16358$ kvar

Therefore, the amount of kvar needs to be compensated is = generated kvar - safe drawn kvar.

kvar to be compensated $=312643.616-212172.16358=100471.4525 \mathrm{kvar} \div 320=313.9733$ $\mathrm{kvar} / \mathrm{hr}$

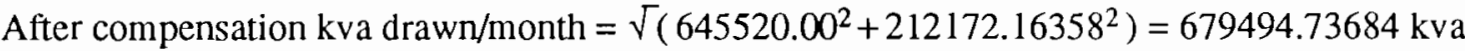

New demand is $=\sqrt{\left(2017.25^{2}+(977.0113-313.9733)^{2}\right.}$

Demand $=2123.42105 \mathrm{kva}$

Energy $=679494.73684 \mathrm{kws}$

Demand $=2123.42105 \mathrm{kws}$ 
The total bill is $=679494.73684 \times 0.02+2123.42105 \times 4.14=22380.86$ dollars .

where, the energy charge $=0.02$ dollar/kwhr, and

the demand charge $=4.14$ dollar $/ \mathrm{kwhr}$

Money saved $/$ month $=$ Uncompensated bill - compensated bill $=24645.03-22380.86=2264.17$

dollars.

\section{Cost of Capacitor Compensation}

From the Table XIII total kvar to be compensated is 977.0113 kvar.

The total compensation cost $=977.0113 \times(6.00+10.00)=15632.18$ dollars .

Dividing compensation cost by monthly excess bill we get,

$15632.0113 \div 2264.17=7$ months.

i.e., the total investment for capacitor compensation is equivalent to 7 months excess bill.

\section{SIMULATION RESULTS AT 85\% POWER FACTOR}

$\underline{\text { Real and Reactive Loads at Load Buses }}$

Given the $\eta, p f$ and the $h p$ of a motor the real and reactive power input of the motor can be calculated as shown below:

Real power input (kw input) $=\frac{h p \times 0.746}{\eta}$

Reactive power input (rkva input) $=k w$ input $\times \tan \left[\cos ^{-1}(p f)\right]$

BUS_6. At bus_6 we have $1 \times 200 \mathrm{hp}, 2 \times 100 \mathrm{hp}$ and $2 \times 40 \mathrm{hp}$ of $\eta=92 \%$.

therefore,

$k w$ input $=480 \times \frac{0.746}{0.92}=389.2174 \mathrm{kw}$

here, $\theta=\tan \left[\cos ^{-1}(0.85)\right]=0.61974$

and, $r k v a$ input $=389.2174 \times 0.61974=241.2153 \mathrm{kvar}$ 
BUS_5. At bus_5 we have $2 \times 500 h p$, and $2 \times 300 h p$ of $\eta=92 \%$.

Calculating the same way as shown above we get,

$k w$ input $=1297.3913 \mathrm{kw}$ and,

rkva input $=804.0509 \mathrm{kvar}$

BUS_4. At bus_4 we have $3 \times 40 \mathrm{hp}$, and $2 \times 20 \mathrm{hp}$ of $\eta=92 \%$.

Calculating the same way as shown above we get,

$k w$ input $=129.7391 \mathrm{kw}$ and,

rkva input $=80.4051 \mathrm{kvar}$

BUS_3. At bus_3 we have lights, fans, computers and other domestic and office usable appliances comprising a load of

$k w$ input $=200 \mathrm{kws}$

rkva input $=97$ kvars

\section{Partial Compensation at the Load Buses}

Results of the load flow simulation at $85 \%$ power factor and the partial compensation required at individual bus levels are shown in the Table $\mathrm{X}$ and Table XI respectively.

TABLE X

LOAD FLOW OUTPUT AT PF $=85 \%$

\begin{tabular}{|c|c|c|c|c|c|c|}
\hline \multirow{2}{*}{$\begin{array}{c}\overline{\text { bus }} \\
\#\end{array}$} & \multirow{2}{*}{$\begin{array}{l}\text { volts } \\
\text { p.u }\end{array}$} & \multirow{2}{*}{$\begin{array}{c}\text { angle } \\
\text { degree }\end{array}$} & \multicolumn{2}{|c|}{ generation } & \multicolumn{2}{|c|}{ load } \\
\hline & & & $\mathrm{P}(\mathrm{kw})$ & Q(kvar) & $\mathrm{P}(\mathrm{kw})$ & Q(kvar) \\
\hline 1 & 1.00000 & -18.099 & 947.22452 & 708.97856 & 0.00000 & 0.00000 \\
\hline 2 & 1.00000 & -17.837 & 1310.9405 & 970.32831 & 0.0000 & 0.00000 \\
\hline 3 & 0.95576 & -19.484 & 0.00000 & 0.00000 & 199.95266 & 97.025689 \\
\hline 4 & 0.94407 & -19.786 & 0.00000 & 0.00000 & 129.71328 & 80.459462 \\
\hline 5 & 0.79812 & -24.651 & 0.00000 & 0.00000 & 1296.97813 & 804.21262 \\
\hline 6 & 0.88749 & -21.528 & 0.00000 & 0.00000 & 389.11633 & 241.25388 \\
\hline
\end{tabular}


It is seen from the Table $X$ that the

Total real power at the load end $=2015.7604 \mathrm{kws}$

Total reactive power at the load end $=1222.95163 \mathrm{kvars}$

Total reactive power generated $=1679.30687 \mathrm{kvars}$

Total real power generated $=2258.16508 \mathrm{kws}$

Now, by Table II capacitor size for partial compensation at the load buses are,

TABLE XI

PARTIAL COMPENSATION AT THE LOAD BUSES AT PF $=85 \%$

\begin{tabular}{|c|c|c|c|c|}
\hline BUS \# & PRE. PF\% & FIN. PF\% & CORREC. FAC & CAPA. SIZE(kvar) \\
\hline \hline 6 & 93.02 & 95 & 0.066 & 30.2173 \\
\hline 5 & 90.88 & 95 & 0.1304 & 198.9393 \\
\hline 4 & 94.09 & 95 & 0.0318 & 4.8616 \\
\hline 3 & 94.27 & 95 & 0.02555 & 5.6785 \\
\hline
\end{tabular}

Line Flow From Bus_1 to Bus_6

$I_{16}=\left(V_{1}-V_{6}\right) \times Y_{16}$

$I_{16}=\left(1.0 e^{-18.099-0.88749} e^{-21.58}\right)(-1.917+j 3.737)$

$I_{16}=(-0.3006+j 0.4375)$

therefore,

$S_{16}=\left(V_{1}\right) \times I_{16}^{*}$

$S_{16}=\left(1.0 e^{-18.099)(-0.3006-j 0.4375)}\right.$

$S_{16}=-0.42165-j 0.3225$

again,

$I_{61}=\left(V_{6}-V_{1}\right) \times Y_{61}$

$I_{61}=-\left(1.0 e^{-18.099-0.88749} e^{-21.58)(-1.917+j 3.737)}\right.$

$I_{61}=-(-0.3006+j 0.4375)$ 
therefore,

$S_{61}=\left(V_{6}\right) \times I_{61}^{*}$

$S_{61}=-\left(0.88749 e^{-21.53)(-0.3006-j 0.4375)}\right.$

$S_{61}=0.39066+j 0.2633$

Line loss between bus_1 and bus_6:

$S_{16}+S_{61}=-0.031-j 0.059$

\section{Line Flow From Bus_1 to Bus_4}

$$
I_{14}=\left(V_{1}-V_{4}\right) \times Y_{14}
$$

$I_{14}=\left(1.0 e^{-18.099}-0.94407 e^{-19.78}\right)(-2.432+j 4.595)$

$I_{14}=(-0.1922+j 0.2641)$

therefore,

$S_{14}=\left(V_{1}\right) \times I_{14}^{*}$

$S_{14}=\left(1.0 e^{-18.099)(-0.1922-j 0.2641)}\right.$

$S_{14}=-0.2647-j 0.19128$

again,

$I_{41}=\left(V_{4}-V_{1}\right) \times Y_{41}$

$I_{14}=-\left(1.0 e^{\left.-18.099-0.94407 e^{-19.78}\right)(-2.432+j 4.595)}\right.$

$I_{41}=-\left(0.94407 e^{\left.-19.78-1.0 e^{-18.099}\right)(-2.432+j 4.595)}\right.$

$I_{41}=-(-0.1922+j 0.2641)$

therefore,

$S_{41}=\left(V_{4}\right) \times I_{41}^{*}$

$S_{41}=-\left(0.94407 e^{-19.78)(-0.1922-j 0.2641)}\right.$

$S_{41}=0.255+j 0.17315$ 
Line loss between bus_1 and bus_4:

$S_{14}+S_{41}=-0.01-j 0.018$

\section{Line Flow From Bus_3 to Bus_4}

$$
I_{34}=\left(V_{3}-V_{4}\right) \times Y_{34}
$$

$I_{34}=\left(0.95576 e^{\left.-19.48-0.94407 e^{-19.78}\right)(-1.937+j 3.737)}\right.$

$I_{34}=(-0.02778+j 0.04589)$

therefore,

$S_{34}=\left(V_{3}\right) \times I_{34}^{*}$

$S_{34}=\left(0.95576 e^{-19.48)}(-0.02778-j 0.04589)\right.$

$S_{34}=-0.03966-j 0.03249$

again,

$I_{43}=\left(V_{4}-V_{3}\right) \times Y_{43}$

$I_{43}=-\left(0.95576 e^{\left.-19.48-0.94407 e^{-19.78}\right)(-1.937+j 3.737)}\right.$

$I_{43}=-(-0.02778+j 0.04589)$

therefore,

$S_{43}=\left(V_{4}\right) \times I_{43}^{*}$

$S_{43}=-\left(0.94407 e^{-19.78)(-0.02778-j 0.04589)}\right.$

$S_{43}=0.03934+j 0.03188$

Line 1 loss between bus__ 3 and bus_4:

$S_{34}+S_{43}=-0.00032-j 0.001$

Line Flow From Bus_4 to Bus_6

$$
I_{46}=\left(V_{4}-V_{6}\right) \times Y_{46}
$$

$I_{46}=\left(0.94407 e^{-19.78-0.88749} e^{-21.53}\right)(-1.947+j 3.737)$

$I_{46}=(-0.1456+j 0.2226)$ 
therefore,

$S_{46}=\left(V_{4}\right) \times I_{46}^{*}$

$S_{46}=\left(0.94407 e^{-19.78)}\right)(-0.1456-j 0.2226)$

$S_{46}=-0.20047-j 0.15121$

again,

$I_{64}=\left(V_{6}-V_{4}\right) \times Y_{64}$

$I_{64}=-\left(0.94407 e^{-19.78}-0.88749 e^{-21.53)(-1.947+j} 3.737\right)$

$I_{64}=-(-0.1456+j 0.2226)$

therefore,

$S_{64}=\left(V_{6}\right) \times I_{64}^{*}$

$S_{64}=-\left(0.88749 e^{-21.53)(-0.1456-j 0.2226)}\right.$

$S_{64}=0.19269+j 0.136358$

Line loss between bus_ 4 and bus_6:

$S_{46}+S_{64}=-0.008-j 0.015$

Line Flow From Bus_2 to Bus_3

$$
I_{23}=\left(V_{2}-V_{3}\right) \times Y_{23}
$$

$I_{23}=\left(1.0 e^{-17.84}-0.95576 e^{-19.48)(-1.927+j 3.737)}\right.$

$I_{23}=-0.1462+j 0.1658$

therefore,

$S_{23}=\left(V_{2}\right) \times I_{23}^{*}$

$S_{23}=\left(1.0 e^{-17.84}\right)(-0.1462-j 0.1650)$

$S_{23}=-0.190005-j 0.11304$

again, 
$I_{32}=\left(V_{3}-V_{2}\right) \times Y_{32}$

$I_{32}=-\left(1.0 e^{\left.-17.84-0.95576 e^{-19.48}\right)(-1.927+j 3.737)}\right.$

$I_{32}=-0.1462+j 0.1658$

therefore,

$S_{32}=\left(V_{3}\right) \times I_{32}^{*}$

$S_{32}=-\left(0.95576 e^{-19.48)(-0.1462-j 0.1658)}\right.$

$S_{32}=0.18463+j 0.10277$

Line loss between bus_2 and bus_3:

$S_{23}+S_{32}=-0.005-j 0.01$

\section{Line. Flow From Bus_2 to Bus_5}

$$
I_{25}=\left(V_{2}-V_{5}\right) \times Y_{25}
$$

$I_{25}=\left(1.0 e^{\left.-17.84-0.79812 e^{-24.65}\right)(-1.927+j 3.737)}\right.$

$I_{25}=(-0.5426+j 0.7946)$

therefore,

$S_{25}=\left(V_{2}\right) \times I_{25}^{*}$

$S_{25}=\left(1.0 e^{-17.84}\right)(-0.5426-j 0.7946)$

$S_{25}=-0.7599-j 0.5902$

again,

$I_{52}=\left(V_{5}-V_{2}\right) \times Y_{52}$

$I_{52}=-\left(1.0 e^{\left.-17.84-0.79812 e^{-24.65}\right)(-1.927+j 3.737)}\right.$

$I_{52}=-(-0.5426+j 0.7946)$

therefore,

$S_{52}=\left(V_{5}\right) \times I_{52}^{*}$ 
$S_{52}=-\left(0.79812 e^{-24.65)(-0.5426-j 0.7946)}\right.$

$S_{52}=0.6581+j 0.39577$

Line loss between bus_2 and bus_5:

$S_{25}+S_{52}=-0.102-j 0.194$

$\underline{\text { Line Flow From Bus_5 to Bus_6 }}$

$$
I_{56}=\left(V_{5}-V_{6}\right) \times Y_{56}
$$

$I_{56}=\left(0.79812 e^{-24.65-0.88749} e^{-21.53)(-1.957+j 3.737)}\right.$

$I_{56}=(0.2229-j 0.3603)$

therefore,

$S_{56}=\left(V_{5}\right) \times I_{56}^{*}$

$S_{56}=\left(0.79812 e^{-24.65)(0.2229+j 0.3603)}\right.$

$S_{56}=0.28169+j 0.18713$

again,

$I_{65}=\left(V_{6}-V_{5}\right) \times Y_{65}$

$I_{65}=-\left(0.79812 e^{-24.65-0.88749} e^{-21.53}\right)(-1.957+j 3.737)$

$I_{65}=-(0.2229-j 0.3603)$

therefore,

$S_{65}=\left(V_{6}\right) \times I_{65}^{*}$

$S_{65}=-\left(0.88749 e^{-21.53)(0.2229+j 0.3603)}\right.$

$S_{65}=-0.30143-j 0.2248$

Line loss between bus_5 and bus_6:

$S_{56}+S_{65}=-0.02-j 0.038$ 


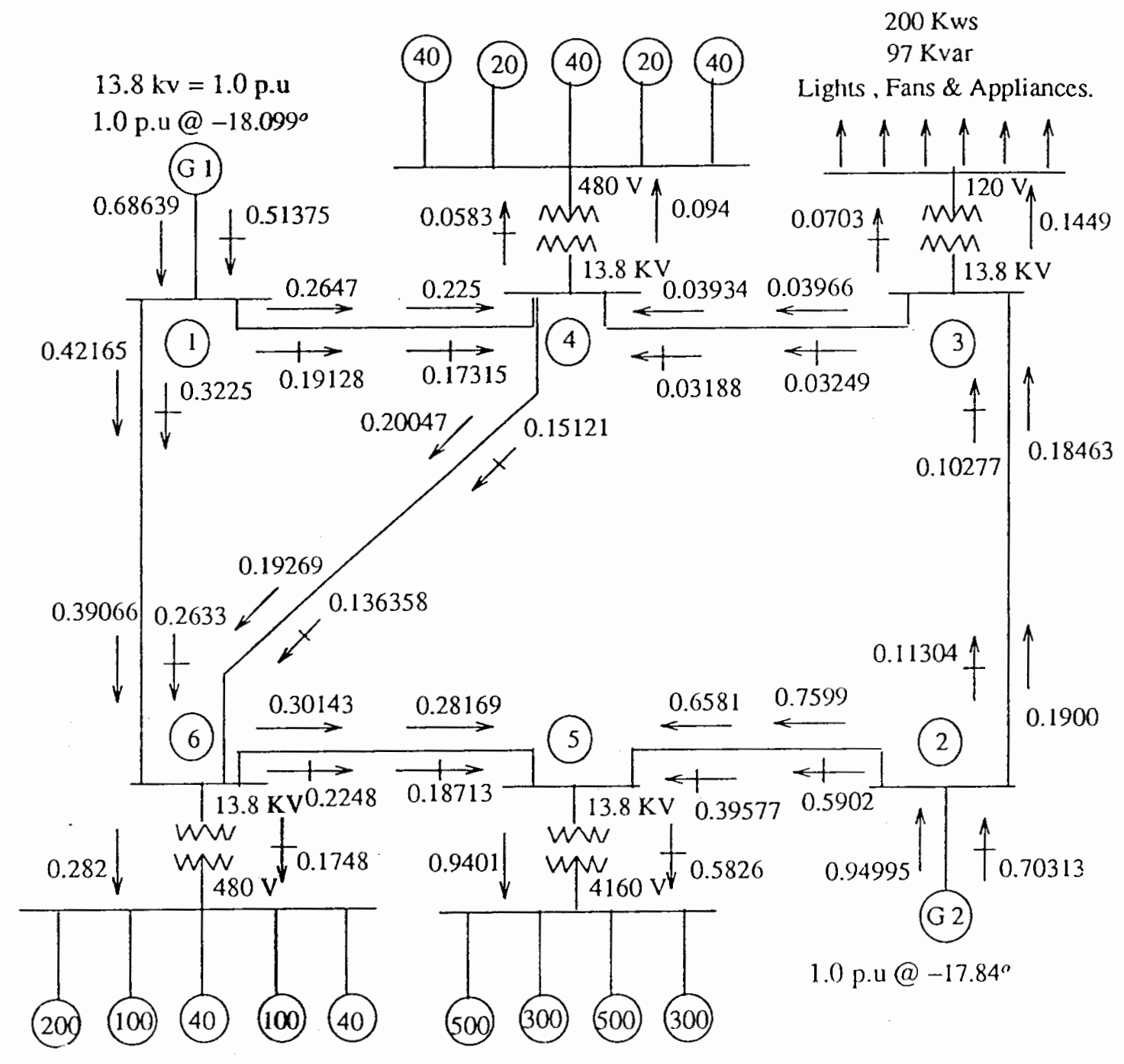

Figure 10. Line flow for $\mathrm{pf}=85 \%$.

Reactive Power Loss in the Individual Lines Per Mile

Bus_1 to Bus_ $6=(0.3225-0.2633) \times 1380 \div 337=0.24 \mathrm{kvar}$

Bus_I to Bus_4 $=(0.19128-0.17315) \times 1380 \div 273=0.09 \mathrm{kvar}$

Bus_3 to Bus_ $4=(0.03249-0.03188) \times 1380 \div 337=0.0025 \mathrm{kvar}$ 
Bus_2 to Bus_3 $=(0.11304-0.10277) \times 1380 \div 337=0.04 \mathrm{kvar}$

Bus_6 to Bus_5 $=(0.2248-0.18713) \times 1380 \div 337=0.15 \mathrm{kvar}$

Bus_2 to Bus_5 $=(0.5902-0.39577) \times 1380 \div 337=0.796 \mathrm{kvar}$

Bus_4 to Bus_6 $=(0.15121-0.136358) \times 1380 \div 337=0.06 \mathrm{kvar}$

Therefore total reactive power losses in the lines $=1.38 \mathrm{kvar}$

$\underline{\text { Real power Loss in the Individual Lines Per Mile }}$

Bus_1 to Bus_6 $=(0.42165-0.39066) \times 1380 \div 337=0.127 \mathrm{kw}$

Bus_1 to Bus_4 $=(0.2647-0.225) \times 1380 \div 273=0.2 \mathrm{kw}$

Bus_3 to Bus_4 $=(0.03966-0.03934) \times 1380 \div 337=0.0013 \mathrm{kw}$

Bus_2 to Bus_3 $=(0.19-0.18463) \times 1380 \div 337=0.04 \mathrm{kw}$

Bus_6 to Bus_5 $=(0.30143-0.28169) \times 1380 \div 337=0.081 \mathrm{kw}$

Bus_2 to Bus_5 $=(0.7599-0.6581) \times 1380 \div 337=0.417 \mathrm{kw}$

Bus_4 to Bus_6 $=(0.20047-0.19269) \times 1380 \div 337=0.0318 \mathrm{kw}$

Therefore total real power losses in the lines $=0.8978 \mathrm{kw}$

Total Capacitive Compensation at the Buses

From line flow data of $\mathrm{pf}=85 \%$ and from the reactive line losses we calculate the compensation required at the individual buses:

At Bus_5 $=0.5826 \times 1380+0.796+0.15=804.934 \mathrm{kvar}$

At Bus_ $6=0.1748 \times 1380+0.24+0.06=241.524 \mathrm{kvar}$

At Bus_4 $=0.0583 \times 1380+0.0025+0.09=80.546 \mathrm{kvar}$

At Bus_3 $=0.0703 \times 1380+0.04=94.054 \mathrm{kvar}$

Therefore total bus compensation $=1224.0593 \mathrm{kvar}$ 
TABLE XII

COMPENSATION AT BUSES AT PF $=85 \%$

\begin{tabular}{|c|c|c|}
\hline bus \# & generator & capa. size (kvar) \\
\hline \hline 6 & - & 241.524 \\
\hline 5 & - & 804.934 \\
\hline 4 & - & 80.546 \\
\hline 3 & - & 94.05 \\
\hline
\end{tabular}

\section{Cost of Energy}

From the simulation result we see that,

Tot. $\mathrm{kvar}$ required per hour $=1224.3316 \mathrm{kvar} / \mathrm{hr}$

Tot. $\mathrm{kws}$ required per hour $=2016.6582 \mathrm{kws} / \mathrm{hr}$

Considering a typical situation where the plant runs for two shifts, 8 hours per shift and 5 days in a week, we find,

Required generation of $\mathrm{kvar} / \mathrm{month}=1224.3316 \times 2 \times 8 \times 20=391786.112 \mathrm{kvar}$

Required generation of kws $/$ month $=2016.6582 \times 2 \times 8 \times 20=645330.624 \mathrm{kws}$

Using the formula,

$$
\begin{aligned}
& \text { Average } p f=\frac{\text { Tot } k w}{\sqrt{\left(\text { Tot } k w^{2}+\text { Tot } k v a r^{2}\right)}} \\
& p f=\frac{645330.624}{\sqrt{\left(645330.624^{2}+391786.112^{2}\right)}} \\
& p f=85.48 \%
\end{aligned}
$$

Uncompensated Energy Bill

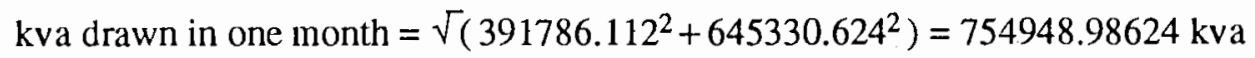

Demand $=\sqrt{(}\left(1224.3316^{2}+2016.6582^{2}\right)=2359.215582 \mathrm{kva}$

pf penalty of $=(95-85.48) \times 2=20 \%$

Energy $=754948.98624 \mathrm{kws}$

demand $=2359.215582 \mathrm{kws}$ 
pf penalty $=2359.1574 \times 0.2=471.843116 \mathrm{kwS}$

The total bill is $=754948.98624 \times 0.02+2359.215582 \times 4.14+471.843116 \times 4.14=26819.56$ dollars

where, the energy charge $=0.02$ dollar $/ \mathrm{kwhr}$

the demand charge $=4.14$ dollar $/ \mathrm{kwhr}$, and

pf penalty charge $=4.14$ dollar $/ \mathrm{kwhr}$

\section{Compensated Energy Bill}

By compensating the kvar keeping a pf $=95 \%$ to avoid the power factor penalty, the reactive power that can be drawn safely from the utility without paying a pf penalty can be calculated as,

$$
\begin{gathered}
0.95=\frac{\text { Tot } k w}{\sqrt{\left(\text { Tot } k w^{2}+\text { Tot } k v a r^{2}\right)}} \\
0.95=\frac{645330.624}{\sqrt{\left(645330.624^{2}+\text { Tot } k v a r^{2}\right)}}
\end{gathered}
$$

The total kvar that could be drawn safely from the utility $=212109.91869 \mathrm{kvar}$ Therefore, the amount of kvar that needs to be compensated is = generated kvar - safe drawn kvar.

The kvar to be compensated $=391786.112-212109.91869=179676.1934 \mathrm{kvar} \div 320=$ $561.4881 \mathrm{kvar} / \mathrm{hr}$

After compensation kva drawn/month $=\sqrt{ }\left(645330.624^{2}+212109.91869^{2}\right)=679295.39368 \mathrm{kva}$ New demand is $=\sqrt{(}\left(2016.6582^{2}+(1224.3316-561.4881)^{2}\right.$

Demand $=2122.79811 \mathrm{kva}$

Energy $=679295.39368 \mathrm{kws}$

demand $=2122.79811 \mathrm{kws}$

The total bill is $=679295.39368 \times 0.02+2122.79811 \times 4.14=22374.29$ dollars. 
where, the energy charge $=0.02$ dollar $/ \mathrm{kwhr}$, and

the demand charge $=4.14$ dollar $/ \mathrm{kwhr}$

Money saved $/$ month $=$ Uncompensated bill - compensated bill $=26819.56-22374.29=4445.27$ dollars.

\section{Cost of Capacitor Compensation}

From the Table XIV total kvar to be compensated is 1224.3316 kvar.

The total compensation cost $=1224.3316 \times(6.00+10.00)=19589.31$ dollars.

Dividing compensation cost by monthly excess bill we get,

$19589.31 \div 4445.27=4.4$ months

i.e., the total investment for capacitor compensation is equivalent to 4.4 months excess bill.

\section{SIMULATION RESULTS AT 80\% POWER FACTOR}

$\underline{\text { Real and Reactive Loads at Load Buses }}$

Given the $\eta, p f$ and the $h p$ of a motor the real and reactive power input of the motor can be calculated as shown below:

Real power input $(\mathrm{kw}$ input $)=\frac{h p \times 0.746}{\eta}$

Reactive power input (rkva input) $=k w$ input $\times \tan \left[\cos ^{-1}(p f)\right]$

\section{$\underline{\text { BUS_6 }}$.}

At bus_ 6 we have $1 \times 200 h p, 2 \times 100 h p$ and $2 \times 40 h p$ of $\eta=92 \%$.

therefore,

$k w$ input $=480 \times \frac{0.746}{0.92}=389.2174 \mathrm{kw}$

here, $\theta=\tan \left[\cos ^{-1}(0.80)\right]=0.7500$

and, $r k v a$ input $=389.2174 \times 0.7500=291.9130 \mathrm{kvar}$ 


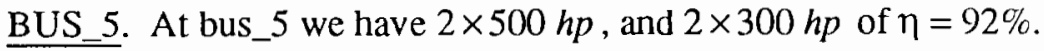

Calculating the same way as shown above we get,

$k w$ input $=1297.3913 \mathrm{kw}$ and,

rkva input $=973.0435 \mathrm{kvar}$

. At bus_4 we have $3 \times 40 \mathrm{hp}$, and $2 \times 20 \mathrm{hp}$ of $\eta=92 \%$.

Calculating the same way as shown above we get,

$k w$ input $=129.7391 \mathrm{kw}$ and,

$r k v a$ input $=97.3045 \mathrm{kvar}$

BUS_3. At bus_3 we have lights, fans, computers and other domestic and office usable appliances comprising a load of

$k w$ input $=200 k w s$

rkva input $=97$ kvars

\section{Partial Compensation at the Load Buses}

Results of the load flow simulation at $80 \%$ power factor and the partial compensation required at individual bus levels are shown in the Table XIII and Table XIV respectively.

It is seen from the Table XIII that the:

Total real power at the load end $=2016.55969 \mathrm{kws}$

Total reactive power at the load end $=1458.73493 \mathrm{kvars}$

Total reactive power generated $=2009.23358$ kvars

Total real power generated $=2308.25645 \mathrm{kws}$

Now, by Table II capacitor size for partial compensation at the load buses are, as shown in the Table XIV. 
TABLE XIII

LOAD FLOW OUTPUT AT PF $=80 \%$

\begin{tabular}{||c||c||c||l|l||l|l||}
\hline \hline \multicolumn{1}{|c||}{ bus } & \multirow{2}{*}{ volts } & angle & \multicolumn{2}{c||}{ generation } & \multicolumn{2}{c||}{ load } \\
\cline { 4 - 7 }$\#$ & & & & & \\
& p.u & degree & $\mathrm{P}(\mathrm{kw})$ & $\mathrm{Q}(\mathrm{kvar})$ & $\mathrm{P}(\mathrm{kw})$ & $\mathrm{Q}(\mathrm{kvar})$ \\
\hline 1 & 1.00000 & -18.099 & 969.44779 & 847.21379 & 0.00000 & 0.00000 \\
\hline 2 & 1.00000 & -17.886 & 1338.8086 & 1162.01979 & 0.0000 & 0.00000 \\
\hline 3 & 0.95246 & -19.452 & 0.00000 & 0.00000 & 199.97583 & 96.987159 \\
\hline 4 & 0.93753 & -19.665 & 0.00000 & 0.00000 & 129.72784 & 97.279559 \\
\hline 5 & 0.76907 & -24.237 & 0.00000 & 0.00000 & 1297.6586 & 972.64805 \\
\hline 6 & 0.87241 & -21.259 & 0.00000 & 0.00000 & 389.19742 & 291.82018 \\
\hline
\end{tabular}

TABLE XIV

PARTIAL COMPENSATION AT THE LOAD BUSES AT PF $=80 \%$

\begin{tabular}{|c|c|c|c|c|}
\hline \hline BUS \# & PRE. PF\% & FIN. PF\% & CORREC. FAC & CAPA. SIZE(kvar) \\
\hline \hline 6 & 93.19 & 95 & 0.0601 & 29.24 \\
\hline 5 & 91.19 & 95 & 0.1213 & 196.714 \\
\hline 4 & 94.17 & 95 & 0.0291 & 4.71 \\
\hline 3 & 94.29 & 95 & 0.02485 & 5.523 \\
\hline
\end{tabular}

$\underline{\text { Line Flow From Bus_1 to Bus_6 }}$

$$
I_{16}=\left(V_{1}-V_{6}\right) \times Y_{16}
$$

$I_{16}=\left(1.0 e^{-18.099-0.87241} e^{-21.26)(-1.917+j 3.737)}\right.$

$I_{16}=(-0.2902+j 0.5027)$

therefore,

$S_{16}=\left(V_{1}\right) \times I_{16}^{*}$

$S_{16}=\left(1.0 e^{-18.099}\right)(-0.2902-j 0.5027)$

$S_{16}=-0.432-j 0.3876$

again, 
$I_{61}=\left(V_{6}-V_{1}\right) \times Y_{61}$

$I_{61}=-\left(1.0 e^{\left.--18.099-0.87241 e^{-21.26}\right)(-1.917+j 3.737)}\right.$

$I_{61}=-(-0.2902+j 0.5027)$

therefore,

$S_{61}=\left(V_{6}\right) \times I_{61}^{*}$

$S_{61}=-\left(0.87241 e^{-}-21.26\right)(-0.2902-j 0.5027)$

$S_{61}=0.39495+j 0.31689$

Line loss between bus_1 and bus_6:

$S_{16}+S_{61}=-0.037-j 0.071$

Line Flow From Bus_1 to Bus_4

$$
I_{14}=\left(V_{1}-V_{4}\right) \times Y_{14}
$$

$I_{14}=\left(1.0 e^{-18.099}-0.93753 e^{-19.67}\right)(-2.432+j 4.595)$

$I_{14}=(-0.1868+j 0.29918)$

therefore,

$S_{14}=\left(V_{1}\right) \times I_{14}^{*}$

$S_{14}=\left(1.0 e^{-18.099)(-0.1866-j 0.29918)}\right.$

$S_{14}=-0.2705-j 0.22634$

again,

$I_{41}=\left(V_{4}-V_{1}\right) \times Y_{41}$

$I_{41}=-\left(1.0 e^{-18.099}-0.93753 e^{-19.67)(-2.432+j 4.595)}\right.$

$I_{41}=-(-0.1868+j 0.29918)$

therefore,

$S_{41}=\left(V_{4}\right) \times I_{41}^{*}$ 
$S_{41}=-\left(0.93753 e^{-19.66)(-0.1866-j 0.29918)}\right.$

$S_{41}=0.2594+j 0.20519$

Line loss between bus_1 and bus_4:

$S_{14}+S_{41}=-0.011-j 0.021$

$\underline{\text { Line Flow From Bus_3 to Bus_4 }}$

$I_{34}=\left(V_{3}-V_{4}\right) \times Y_{34}$

$I_{34}=\left(0.95246 e^{-19.45-0.93753} e^{-19.66)(-1.937+j 3.737)}\right.$

$I_{34}=(-0.0235+j 0.06027)$

therefore,

$S_{34}=\left(V_{3}\right) \times I_{34}^{*}$

$S_{34}=\left(0.95246 e^{-19.45)(-0.0235-j 0.06027)}\right.$

$S_{34}=-0.040246-j 0.04666$

again,

$I_{43}=\left(V_{4}-V_{3}\right) \times Y_{43}$

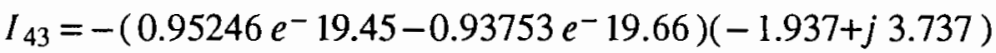

$I_{43}=-(-0.0235+j 0.06027)$

therefore,

$S_{43}=\left(V_{4}\right) \times I_{43}^{*}$

$S_{43}=-\left(0.93753 e^{-19.66)(-0.0235-j 0.06027)}\right.$

$S_{43}=0.03978+j 0.04578$

Line loss between bus_3 and bus_4:

$S_{34}+S_{43}=-0.000466-j 0.001$ 
Line Flow From Bus_4 to Bus_6

$$
\begin{aligned}
& I_{46}=\left(V_{4}-V_{6}\right) \times Y_{46} \\
& I_{46}=\left(0.93753 e^{\left.-19.66-0.87241 e^{-21.26}\right)(-1.947+j 3.737)}\right. \\
& I_{46}=(-0.1396+j 0.2588)
\end{aligned}
$$

therefore,

$S_{46}=\left(V_{4}\right) \times I_{46}^{*}$

$S_{46}=\left(0.93753 e^{-19.66)(-0.1396-j 0.2588)}\right.$

$S_{46}=-0.2049-j 0.1844$

again,

$I_{64}=\left(V_{6}-V_{4}\right) \times Y_{64}$

$I_{64}=-\left(0.93753 e^{\left.-19.66-0.87241 e^{-21.26}\right)(-1.947+j 3.737)}\right.$

$I_{64}=-(-0.1396+j 0.2588)$

therefore,

$S_{64}=\left(V_{6}\right) \times I_{64}^{*}$

$S_{64}=-\left(0.87241 e^{-21.26)(-0.1396-j 0.2588)}\right.$

$S_{64}=0.1954+j 0.16627$

Line loss between bus_ 4 and bus_6:

$S_{46}+S_{64}=-0.01-j 0.018$

\section{Line Flow From Bus_2 to Bus_3}

$$
\begin{aligned}
& \qquad I_{23}=\left(V_{2}-V_{3}\right) \times Y_{23} \\
& I_{23}=\left(1.0 e^{\left.-17.88-0.95246 e^{-19.45}\right)(-1.927+j 3.737)}\right. \\
& I_{23}=(-0.1424+j 0.1805) \\
& \text { therefore, }
\end{aligned}
$$


$S_{23}=\left(V_{2}\right) \times I_{23}^{*}$

$S_{23}=\left(1.0 e^{-17.88)(-0.1424-j 0.1805)}\right.$

$S_{23}=-0.191-j 0.128$

again,

$I_{32}=\left(V_{3}-V_{2}\right) \times Y_{32}$

$I_{32}=-\left(1.0 e^{-17.88}-0.95246 e^{-19.45)(-1.927+j 3.737)}\right.$

$I_{32}=-(-0.1424+j 0.1805)$

therefore,

$S_{32}=\left(V_{3}\right) \times I_{32}^{*}$

$S_{32}=-\left(0.95246 e^{-19.45)(-0.1424-j 0.1805)}\right.$

$S_{32}=0.1851+j 0.1169$

Line loss between bus_2 and bus_3:

$S_{23}+S_{32}=-0.006-j 0.011$

Line Flow From Bus_2 to Bus_5

$$
I_{25}=\left(V_{2}-V_{5}\right) \times Y_{25}
$$

$I_{25}=\left(1.0 e^{-17.88}-0.76907 e^{-24.24}\right)(-1.927+j 3.737)$

$I_{25}=(-0.522+j 0.9189)$

therefore,

$S_{25}=\left(V_{2}\right) \times I_{25}^{*}$

$S_{25}=\left(1.0 e^{-17.88)(-0.522-j 0.9189)}\right.$

$S_{25}=-0.7791-j 0.71414$

again,

$I_{52}=\left(V_{5}-V_{2}\right) \times Y_{52}$ 
$I_{52}=-\left(1.0 e^{-17.88}-0.76907 e^{-24.24}\right)(-1.927+j 3.737)$

$I_{52}=-(-0.522+j 0.9189)$

therefore,

$S_{52}=\left(V_{5}\right) \times I_{52}^{*}$

$S_{52}=-\left(0.76907 e^{-24.24)(-0.522-j 0.9189)}\right.$

$S_{52}=0.656249+j 0.4795568$

Line loss between bus_2 and bus_5:

$S_{25}+S_{52}=-0.123-j 0.235$

Line Flow From Bus_5 to Bus_6

$$
I_{56}=\left(V_{5}-V_{6}\right) \times Y_{56}
$$

$I_{56}=\left(0.76907 e^{\left.-24.24-0.87241 e^{-21.26}\right)(-1.957+j 3.737)}\right.$

$I_{56}=(0.2164-j 0.4188)$

therefore,

$S_{56}=\left(V_{5}\right) \times I_{56}^{*}$

$S_{56}=\left(0.76907 e^{-24.24)}(0.2164+j 0.4188)\right.$

$S_{56}=0.2840+j 0.2254$

again,

$I_{65}=\left(V_{6}-V_{5}\right) \times Y_{65}$

$I_{65}=-\left(0.76907 e^{-24.24}-0.87241 e^{-21.26)(-1.957+j 3.737)}\right.$

$I_{65}=-(0.2164-j 0.4188)$

therefore,

$S_{65}=\left(V_{6}\right) \times I_{65}^{*}$

$S_{65}=-\left(0.87241 e^{-21.26)(0.2164+j 0.4188)}\right.$

$S_{65}=-0.30846-j 0.27208$ 
Line loss between bus_5 and bus_6:

$S_{56}+S_{65}=-0.024-j 0.047$

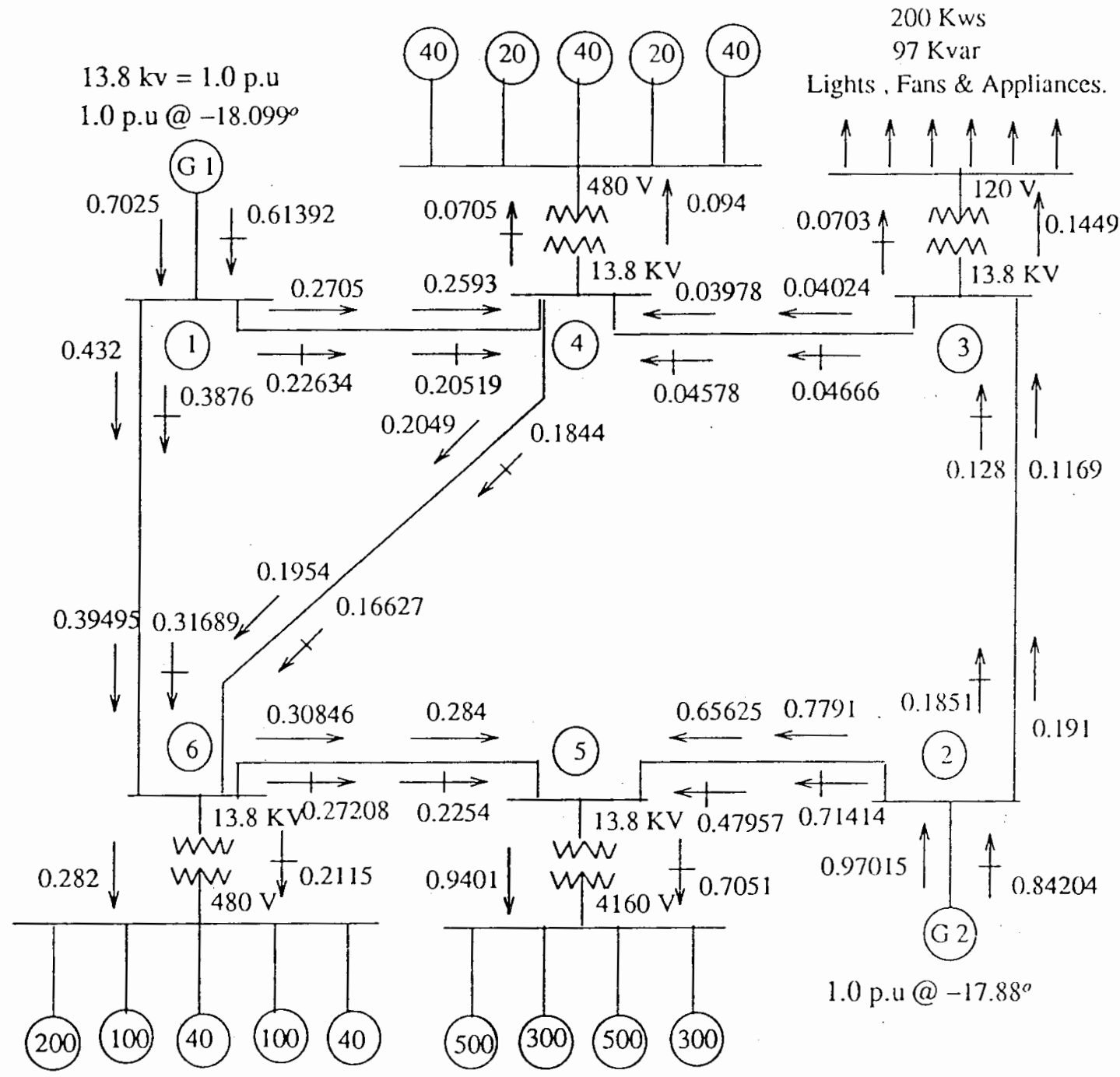

Figure 11. Line flow for $\mathrm{pf}=80 \%$. 
Reactive Power Loss in the Individual Lines Per Mile

Bus_1 to Bus_6 $=(0.3876-0.31689) \times 1380 \div 337=0.29 \mathrm{kvar}$

Bus_1 to Bus_4 $=(0.22634-0.20519) \times 1380 \div 273=0.107 \mathrm{kvar}$

Bus_3 to Bus_4 $=(0.04666-0.04578) \times 1380 \div 337=0.004 \mathrm{kvar}$

Bus_2 to Bus_3 $=(0.1851-0.128) \times 1380 \div 337=0.23 \mathrm{kvar}$

Bus_6 to Bus_5 $=(0.27208-0.2254) \times 1380 \div 337=0.19 \mathrm{kvar}$

Bus_2 to Bus_5 $=(0.71414-0.47957) \times 1380 \div 337=0.96 \mathrm{kvar}$

Bus_4 to Bus_6 $=(0.1844-0.16627) \times 1380 \div 337=0.074 \mathrm{kvar}$

Therefore total reactive power losses in the lines $=1.854 \mathrm{kvar}$

$\underline{\text { Real Power Loss in the Individual Lines Per Mile }}$

Bus_1 to Bus_6 $=(0.432-0.39495) \times 1380 \div 337=0.152 \mathrm{kw}$

Bus_1 to Bus_4 $=(0.2705-0.2593) \times 1380 \div 273=0.0566 \mathrm{kw}$

Bus_3 to Bus_4 $=(0.04024-0.03978) \times 1380 \div 337=0.002 \mathrm{kw}$

Bus_2 to Bus_3 $=(0.191-0.1169) \times 1380 \div 337=0.303 \mathrm{kw}$

Bus_6 to Bus_5 $=(0.30846-0.284) \times 1380 \div 337=0.1 \mathrm{kw}$

Bus_2 to Bus_5 $=(0.7791-0.65625) \times 1380 \div 337=0.5 \mathrm{kw}$

Bus_4 to Bus_6 $=(0.2049-0.1954) \times 1380 \div 337=0.039 \mathrm{kw}$

Therefore total real power losses in the lines $=1.152 \mathrm{kw}$

\section{Total Capacitive Compensation at the Buses}

From line flow data of $\mathrm{pf}=80 \%$ and from the reactive line losses we calculate the compensation required at the individual buses:

At Bus_5 $=0.7051 \times 1380+0.96+0.19=974.188 \mathrm{kvar}$

At Bus_6 $=0.2115 \times 1380+0.29+0.074=292.234 \mathrm{kvar}$

At Bus_ $4=0.0705 \times 1380+0.004+0.107=97.40 \mathrm{kvar}$ 
At Bus_3 $=0.0703 \times 1380+0.23=97.244 \mathrm{kvar}$

Therefore total bus compensation $=1461.06 \mathrm{kvar}$

TABLE XV

COMPENSATION AT BUSES AT PF $=80 \%$

\begin{tabular}{|c|c|c|}
\hline bus \# & generator & capa. size (kvar) \\
\hline \hline 6 & - & 292.234 \\
\hline 5 & - & 974.188 \\
\hline 4 & - & 97.4 \\
\hline 3 & - & 97.244 \\
\hline
\end{tabular}

\section{Cost of Energy}

From the simulation result we see that,

Tot. kvar required per hour $=1460.5889 \mathrm{kvar} / \mathrm{hr}$

Tot. kws required per hour $=2017.7117 \mathrm{kws} / \mathrm{hr}$

Considering a typical situation where the plant runs for two shifts, 8 hours per shift and 5 days in a week, we find,

Required generation of $\mathrm{kvar} / \mathrm{month}=1460.5889 \times 2 \times 8 \times 20=467388.448 \mathrm{kvar}$

Required generation of kws $/$ month $=2017.7117 \times 2 \times 8 \times 20=645667.744 \mathrm{kws}$

Using the formula,

$$
\begin{aligned}
& \text { Average } p f=\frac{\text { Tot } k w}{\sqrt{\left(\text { Tot } k w^{2}+\text { Tot }_{\left.k v a r^{2}\right)}\right.}} \\
& p f=\frac{645667.744}{\sqrt{\left(645667.744^{2}+467388.448^{2}\right)}} \\
& p f=81 \%
\end{aligned}
$$

\section{Uncompensated Energy Bill}

kva drawn in one month $=\sqrt{(}\left(645667.744^{2}+467388.448^{2}\right)=797081.4243 \mathrm{kva}$

Demand $=\sqrt{(}\left(1460.5889^{2}+2017.7117^{2}\right)=2490.87945 \mathrm{kva}$

pf penalty of $=(95-81) \times 2=28 \%$ 
Energy $=797081.4243 \mathrm{kws}$

demand $=2490.87945 \mathrm{kws}$

pf penalty $=2490.87945 \times 0.28=697.44625 \mathrm{kws}$

The total bill is $=797081.4243 \times 0.02+2490.87945 \times 4.14+697.44625 \times 4.14=29141.30$ dollars

where, the energy charge $=0.02$ dollar $/ \mathrm{kwhr}$

the demand charge $=4.14$ dollar $/ \mathrm{kwhr}$, and

pf penalty charge $=4.14$ dollar $/ \mathrm{kwhr}$

\section{Compensated Energy Bill}

By compensating kvar keeping a pf $=95 \%$ to avoid the power factor penalty, the reactive power that can be drawn safely from the utility without paying a pf penalty can be calculated as,

$$
\begin{gathered}
0.95=\frac{\text { Tot } k w}{\sqrt{\left(\text { Tot } k w^{2}+\text { Tot } k v a r^{2}\right)}} \\
0.95=\frac{645667.774}{\sqrt{\left(645667.774^{2}+\text { Tot } k v a r^{2}\right)}}
\end{gathered}
$$

The total kvar that could be drawn safely from the utility $=212220.72468 \mathrm{kvar}$

Therefore, the amount of kvar needs to be compensated is = generated kvar - safe drawn kvar.

The kvar to be compensated $=467388.448-212220.72468$

$$
=255167.7234 \mathrm{kvar} \div 320=797.39914 \mathrm{kvar} / \mathrm{hr}
$$

After compensation kva drawn/month $=\sqrt{ }\left(645667.744^{2}+212220.72468^{2}\right)=679650.25684 \mathrm{kva}$

Now the new demand is $=\sqrt{ }\left(2017.7117^{2}+(1460.5889-797.39914)^{2}\right.$

Demand $=2123.90705 \mathrm{kva}$

Energy $=679650.25684 \mathrm{kws}$

Demand $=2123.90705 \mathrm{kws}$

The total bill is $=679650.25684 \times 0.02+2123.90705 \times 4.14=22385.98$ dollars.

where, the energy charge $=0.02 \mathrm{dollar} / \mathrm{kwhr}$, and 
the demand charge $=4.14$ dollar $/ \mathrm{kwhr}$

Money saved $/$ month $=$ Uncompensated bill - compensated bill $=29141.30-22385.98=6755.32$ dollars.

\section{Cost of Capacitor Compensation}

From the Table XV total kvar to be compensated is $1460.5889 \mathrm{kvar}$.

The total compensation cost $=$

Dividing compensation cost by monthly excess bill we get,

$23369.42 \div 6755.32=3.5$ months

i.e., the total investment for capacitor compensation is equivalent to 3.5 months excess bill.

\section{SUMMARY OF COST OF ENERGY AND TIME OF RECOVERY}

\section{TABLE XVI}

\section{SUMMARY OF COST OF ENERGY}

\begin{tabular}{||l||c||c||c|c||}
\hline \hline $\mathrm{pf}$ & uncompensated & compensated & \multicolumn{2}{|c|}{ dollar saved } \\
\cline { 3 - 5 }$\%$ & bill(monthly) & bill(monthly) & per month & per year \\
\hline 95 & 22571.97 & 22377.34 & 194.63 & 2335.56 \\
\hline 90 & 24645.03 & 22380.86 & 2264.17 & 27170.04 \\
\hline 85 & 26819.56 & 22374.29 & 4445.27 & 53343.24 \\
\hline 80 & 29141.30 & 22385.98 & 6755.32 & 81063.84 \\
\hline
\end{tabular}

From the Table XVII it is evident that the proposed capacitive compensation is highly cost effective and takes short period to recover the capital investment providing long term savings in electrical energy use. 
TABLE XVII

COST EFFECTIVE AND TIME OF RECOVERY

\begin{tabular}{|l||c||c||c||}
\hline $\begin{array}{l}\mathrm{pf} \\
\%\end{array}$ & $\begin{array}{c}\text { excess bill } \\
\text { per month(dollars) }\end{array}$ & $\begin{array}{c}\text { tot. cost of capacitor } \\
\text { compensation(dollars) }\end{array}$ & $\begin{array}{c}\text { recovery time } \\
\text { (months) }\end{array}$ \\
\hline 95 & 194.63 & 11112.96 & 57 \\
\hline 90 & 2264.17 & 15632.18 & 7 \\
\hline 85 & 4445.27 & 19589.31 & 4.4 \\
\hline 80 & 6755.32 & 23369.42 & 3.5 \\
\hline
\end{tabular}




\section{CHAPTER V}

\section{CONCLUSIONS AND FUTURE WORK}

A set of computer programs for analyzing the power cost savings obtainable by improving the power factor of an industrial load have been developed and demonstrated.

The costs, related to the power factor resulting from inductive loads, can be reduced by applying shunt capacitors. The capacitors represent a one time expense that can be paid from the resulting utility bill savings. As the power factor is improved, a point is reached beyond which further correction becomes much less cost effective. The advantage of the method shown here is that the savings can calculated for different amounts of power factor correction and the results can be compared before actually trying one.

For this new method a modified load flow solution was used to provide data for power factor economics studies. This new approach has not been tried before in industrial plants.

The proposed power system model has the advantage of confining faults to individual load centers so that they do not affect the performance of other load centers.

Recent developments in computer technology, such as convenient hardware, compact random access memory, fast central processing units and math coprocessors, have made computing services available in virtually all office and business environments at affordable prices. The programs developed here can be practically executed on a personal computer with $640 \mathrm{~K}$ base memory and a math coprocessor.

Future work for increasing the usefulness of this method could proceed in the direction of combining the programs into a single interactive package with various altematives. Some possible user options might be: 
(1) To find the total line loss

(2) To find the loss for each individual transmission line

(3) To determine the compensation for a particular bus at a specific power factor

(4) To calculate the money saved per month or per year for a particular power factor correction

(5) To find the power factor penalty for a particular load situation

(6) To find the demand charge as a function of the power factor

(7) To find the energy charge as a function of the power factor.

(8) To calculate the time to recover the equipment and installation costs for reaching a particular power factor

The usefulness of the programs for larger installations could be improved by expanding the programs to deal with more than 10 buses.

The actual implementation of the programs will doubtless suggest still other possibilities. 


\section{REFERENCES}

[1] Sueker, Keith H., "High price of low power factor", Plant Engineering, V $41 \mathrm{n} 11 \mathrm{Jan}$ 11,1987 pp. 36-38.

[2] Micheal Boger R. and Manolo E. Juguilon, "Economic benefits of power factor correction at a nuclear facility", IEEE Transactions on Power Apparatus and Systems, July 1984 pp. 81-84.

[3] Hopkinson, R. H., "Economic power factor key to kvar supply", Electrical forum, vol. 6, no. 3,1980 pp. $20-22$.

[4] K. B. Aldrich, The power factor problem, application of corrective equipment, U.S. Dept. of the Interior, BPA., ${ }^{*} 129(\mathrm{BEBT}), 1944$.

[5] King W. C., Power factor in your plant, Comell-Dubilier Electric Corporation, 1940.

[6] Wirgau K. A., "Reactive power coordination", IEEE Milwaukee Symposium on Automatic Computers and Control, April 1976, pp. 37-42.

[7] Del E. Marker, "Electric Energy Management in Industry", The Line, vol. 80, July 1980 pp. 25-37.

[8] Zimmerman R. A., "Economic merits of secondary capacitors", AIEE Transaction, vol. 72, 1953, pp. 694-97.

[9] Gonen, T. and Djavashi F., "Optimum shunt capacitor allocation on primary feeders", IEEE Mexican-80 International conference, Mexico city, Oct. 22-25, 1980.

[10] Schmill, J. V., "Optimum size and location of shunt capacitor on distribution systems", IEEE Transactions on Power Apparatus and Systems, vol. PAS-84, no. 9, sept. 65, pp. 825-32.

[11] McGraw-Edison Company, The ABC of Capacitors, Bulletin R230-90-1, 1968.

[12] Owen R. E., "Distribution System Harmonics, Effects on Equipment and Operation", Pacific Coast Electrical Association Engineering and operating conference, Los Angeles, Calif., March 15-16, 1979.

[13] Gonen T. and A. A. Mahmoud, "Bibliography of power system harmonics", IEEE Transactions on Power Apparatus and Systems, Vol PAS-103, no. 9, Sept. 1984, pp. 2460-2469.

[14] Arrilaga J, Arnola C. P. and Harker B. J., Computer modelling of electrical power systems, John Wiley and sons, 1983. 
[15] Glenn W. Stagg, and Ahmed H. EL-Abiad, Computer methods in power system analysis, McGraw Hill, 1987.

[16] Weedy B. M., Electric power systems John Wiley and Sons, 1987.

[17] Turan Gonen, Electric power distribution system engineering, McGraw Hill, 1986.

[18] Hutcheon W. G, "Power factor in industry", Vector, March 1986, pp. 9-14.

[19] Westing House, Transmission and distribution hand book, 1981

[20] IEEE Industry Applications Society, Recommanded practice for power system analysis, 1983

[21] Willam D. Stevenson. Jr., Elements of power system analysis, McGraw Hill, 1988.

[22] Donald G. Fink and H. Wayne Beaty, Standard handbook for electrical engineers, 12th edition, McGraw Hill, 1987.

[23] IEEE Industry Applications Society, IEEE Recommended practice for electric power systems in commercial buildings, 1983.

[24] IEEE Industry Applications Society, IEEE Recommended practice for electric power distribution for industrial plants, 1986.

[25] G. T. Heydt, Computer analysis methods for power systems, Macmillan Publishing Company, 1986.

[26] Atif S. Debs, Modern power systems control and operation, Kluwer Academic Publishers, 1988

[27] Roy Billinton and Ronald N. Allan, Reliability assesment of large electric power systems, Kluwer Academic Publishers, 1988

[28] R. Bruce Shipley, Introduction to matrices and power systems, John Wiley \& Sons, 1976

[29] E. Palko, "Packaged automatic power factor control centers", Plant Engineering, July 1986, pp.36-41.

[30] W. C. Bloomquist, "Power factor improvement" Industrial Power System Handbook, McGraw Hill, 1969.

[31] E. Palko, "Packaged Automatic Power Factor Control Centers" Plant Engineering, July 24, 1986 pp. 36-41.

[32] Manolo E. Juguilon, R. Micheal Boger, and Walter Dalos, "Economic benefits of power factor correction at a nuclear facility", Proc. IEEE, July 1987 pp. 81-84. 
[33] Irwin Lazar, "Desired power factor improvement and the power factor for a group of loads", Electrical system analysis and design for industrial plants, McGraw Hill, 1980. 
APPENDIX A

THE PROGRAM SOURCE CODE FOR THE CALCULATION OF REAL AND REACTIVE POWER AT THE BUSES 


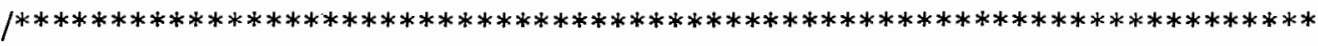

* Pfactor.c

* This program calculates the power factor and total real power and

* total reactive power at a particular bus. It reads power factor

* and bus\# and outputs the bus\#, power factor, total real power and

* total reactive power.

* Input:

* power factor, bus\#

* output:

* bus\#

* power factor

* total kw

$*$ total rkva

$* * * * * * * * * * * * * * * * * * * * * * * * * * * * * * * * * * * * * * * * * * * * * * * * * * * * * * * * * * * * * * * * * * * * * *$

\#include $<$ stdio.h $>$

\#include $<$ math.h $>$

\#define MULFAC $0.81086956 / *$ multiplication factor (0.746/efficiency)*/

\#define BASE $1380.0 \quad$ /* base value */

/* look-up tables for possible bus numbers */

int kwLUT[4][4] $=\{3,0,0,0$,

$4,40,20,0$,

$5,500,300,0$,

$6,200,100,40\}$

int facLUT[4][4] $=\left\{\begin{array}{lll}3,0,0,0, & 0,\end{array}\right.$

$4,3,2,0$,

$5,2,2,0$,

$6,1,2,2\}$;

main()

\{

double pf, tantheta, theta;

double $\mathrm{kw}[3], \operatorname{rkv}[3] ; \quad / *$ kilowatt, reactive kilovolt *I

double kwa, rkva; $\quad / *$ totals */

int busno; $\quad / *$ number of buses */

int $\mathrm{i}, \mathrm{j}$;

$/ *$ input pf and busno values */

printf("Vnenter PF (decimal form) $\Rightarrow$ ");

scanf("\%lf", \&pf);

printf("enter busno (3->6) ==>");

scanf("\%d", \&busno);

$1 *$ search for the busno in the look-up table */

$\mathrm{i}=0$;

while $(\mathrm{i}<4)$

if (busno = = facLUT[i][0])

break;

else

$\mathrm{i}++$; 


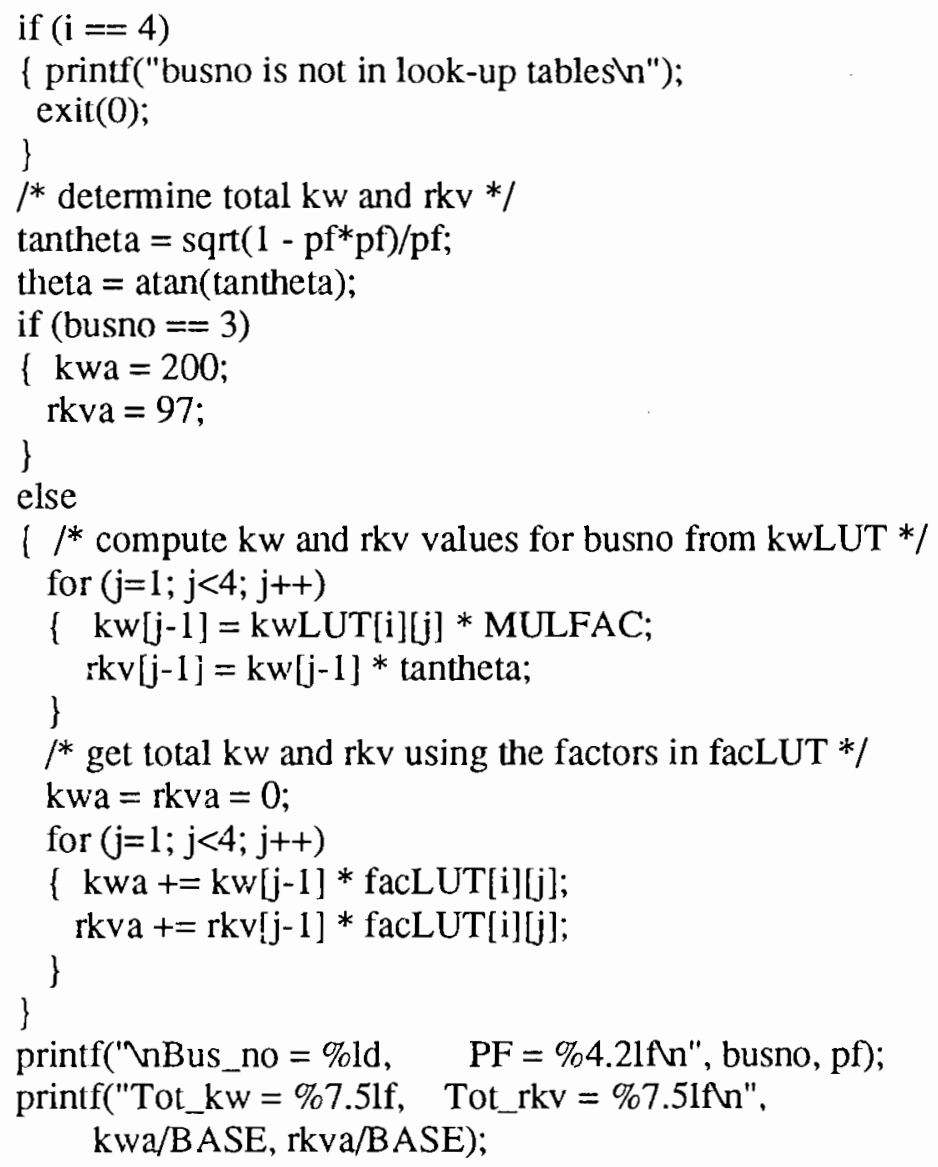


APPENDIX B

THE PROGRAM SOURCE CODE FOR LOAD FLOW

CALCULATION USING THE NEWTON-RAPHSON METHOD 


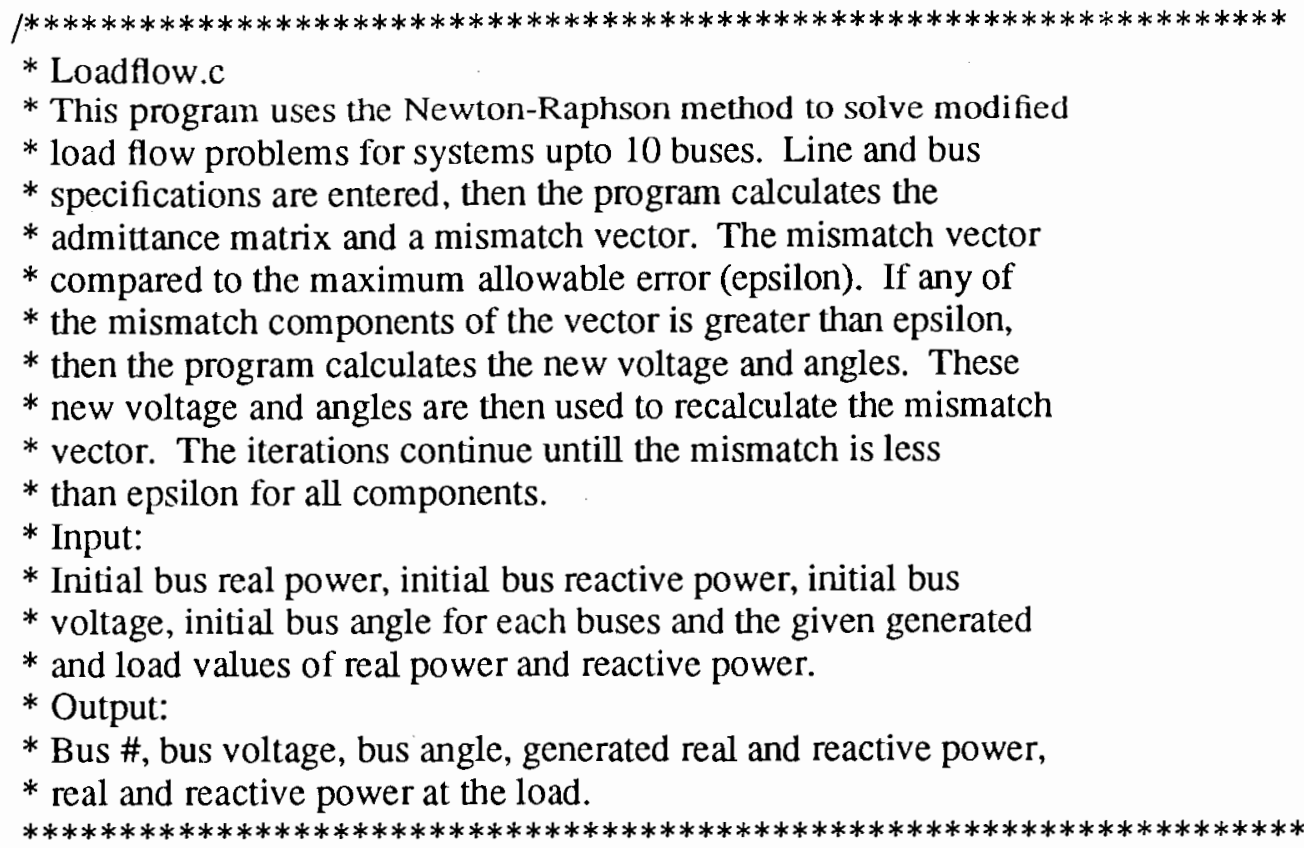

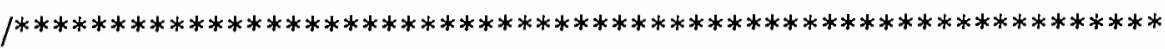

$*$ "EPS"is the error check factor against which all elements

* of the $\triangle P$ and $\Delta Q$ values are checked for proper

* convergence of the linear equations.

* "BASEV" is a multiplier which is 1380 volts.

* "bus" is the number of buses used in this problem.

* "unknown" is the number of unknown quantities or parameters

* of this problem, whose values are to be found out.

* "p[bus]" is the real power at the [bus].

* "Q[bus]" is the reactive power at [bus].

* "G[bus][bus]" is the conductance value bus_bus.

* "B[bus][bus]" is the susceptance value bus_bus.

* "theta[bus]" is the voltage angle at a particular bus.

* "V[bus]" is the voltage at a particular bus.

* "GPQ[unknown]" are the specified (given) values of the P \& Q

$* * * * * * * * * * * * * * * * * * * * * * * * * * * * * * * * * * * * * * * * * * * * * * * * * * * * * * * * * * * * *)$

\#include <stdio.h $>$

\#include <math.h>

\#define PI $\quad 3.14159$

\#define EPS $0.001 \quad / *$ Error check factor */

\#define BASEV $1380 \quad / *$ Multiplier*/

\#define bus $6 \quad / *$ Number of buses*/

\#define unknown $9 \quad / *$ Number of unknown parameters */

double P[bus], Q[bus], G[bus][bus], B[bus][bus],theta[bus];

double V[bus], GPQ[unknown], temp[unknown], delta[unknown], Y[unknown];

double X[unknown], jacob[unknown][unknown], H[bus][bus]; 
double $\mathrm{N}$ [bus][bus], $\mathrm{M}$ [bus][bus], $\mathrm{L}$ [bus][bus], angle[bus];

double P_of_Gen[bus], Q_of_Gen[bus], P_of_Load[bus], Q_of_Load[bus];

int num = 1, check;

\section{/* MAIN FUNCTION */}

main $)$

\{

int $1, \mathrm{~m}, \mathrm{n}, \mathrm{o}, \mathrm{p}, \mathrm{q}$;

GBGEN(); $\quad$ * Generates $\mathrm{G}+\mathrm{jB}$ matrix *

printf(" $n$ Input initial real power for each buses: $n$ ");

for $(\mathrm{m}=1 ; \mathrm{m}<=$ bus; $++\mathrm{m})$

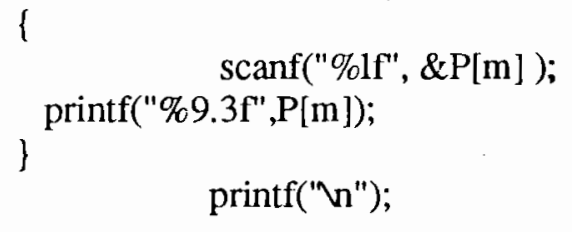

$$
\text { printf(" } n ") \text {; }
$$

printf(" $n$ Input initial reactive power for each buses: $\backslash n$ " );

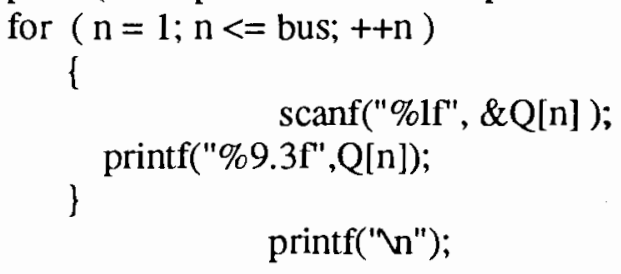

printf('"n Input initial voltage for each buses: $\mathrm{n}$ " );

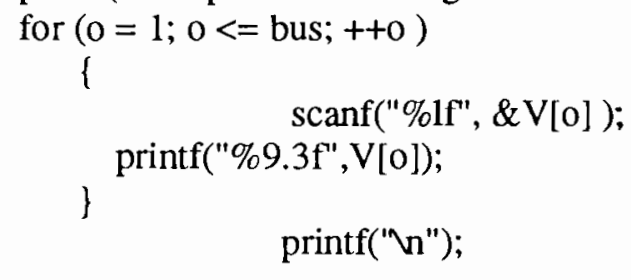

printf(" $\mathrm{n}$ Input initial angle for each buses: $\mathrm{n}$ " );

for $(p=1 ; p<=$ bus; $++p)$

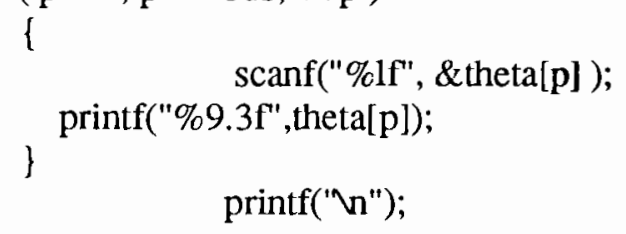

printf(" $\mathrm{n}$ Input the given values for $\mathrm{p}[\mathrm{l}$ and Q[]: $\mathrm{n}$ " );

for $(q=1 ; q<=$ unknown; $++q)$

I

$$
\text { scanf("\%lf", \&GPQ[q] ); }
$$

printf("\%9.3f",GPQ[q]); 
\}

printf("ท");

check $=0$;

while $($ check $==0$ )

1

BDELTPQ(); $\quad / *$ Generate $\Delta P \& \Delta Q$ and check for EPS *

JACOBIAN(); $/ *$ Generates Jacobian matrix

$* 1$

VXY ()$; \quad / *$ L_U decomposition of jacobian matrix \& */

$/ *$ generates new $\theta$ \& new $V$. */

\}

PQ(); $\quad$ * Calculates final values of $\mathrm{P} \& \mathrm{Q} \quad * /$

final $0 ; \quad \quad \quad$ * Prints final values of unknowns */

printf("ทnvin'n" );

)

/* GENERATION OF G[][] AND B[][] MATRIX */

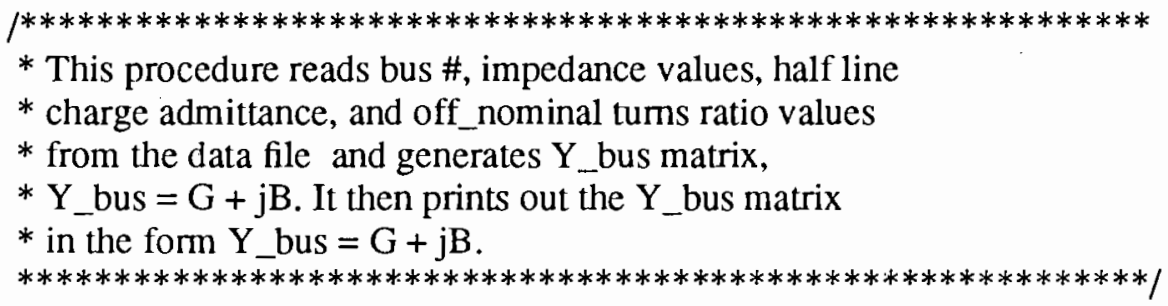

\section{GBGEN()}

f

double zlr, zli, den;

double ylr, yli;

double hych, aline;

double alph;

double cond,sus;

int I,J,K;

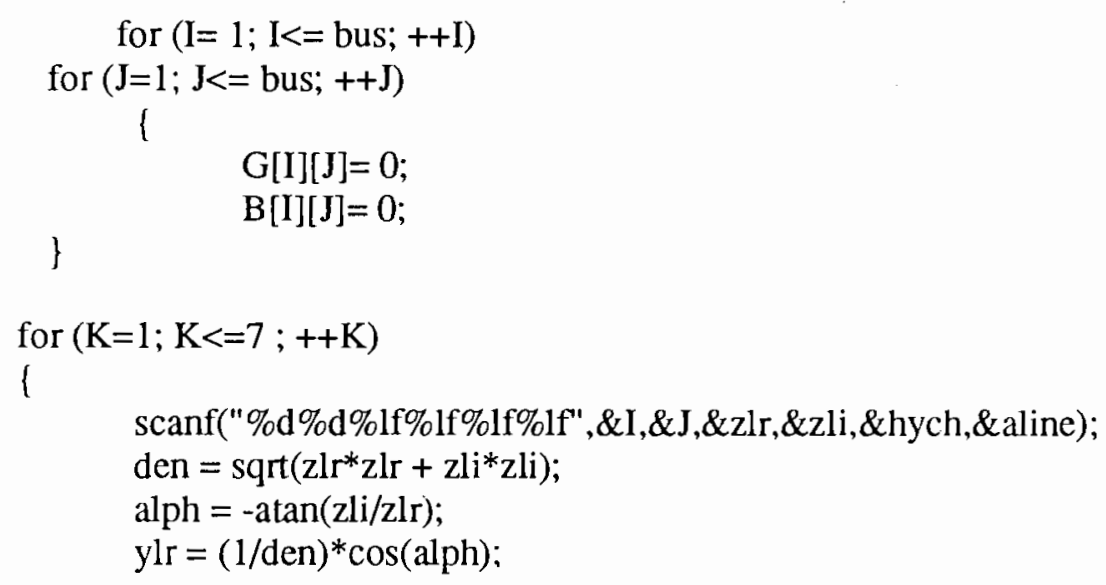




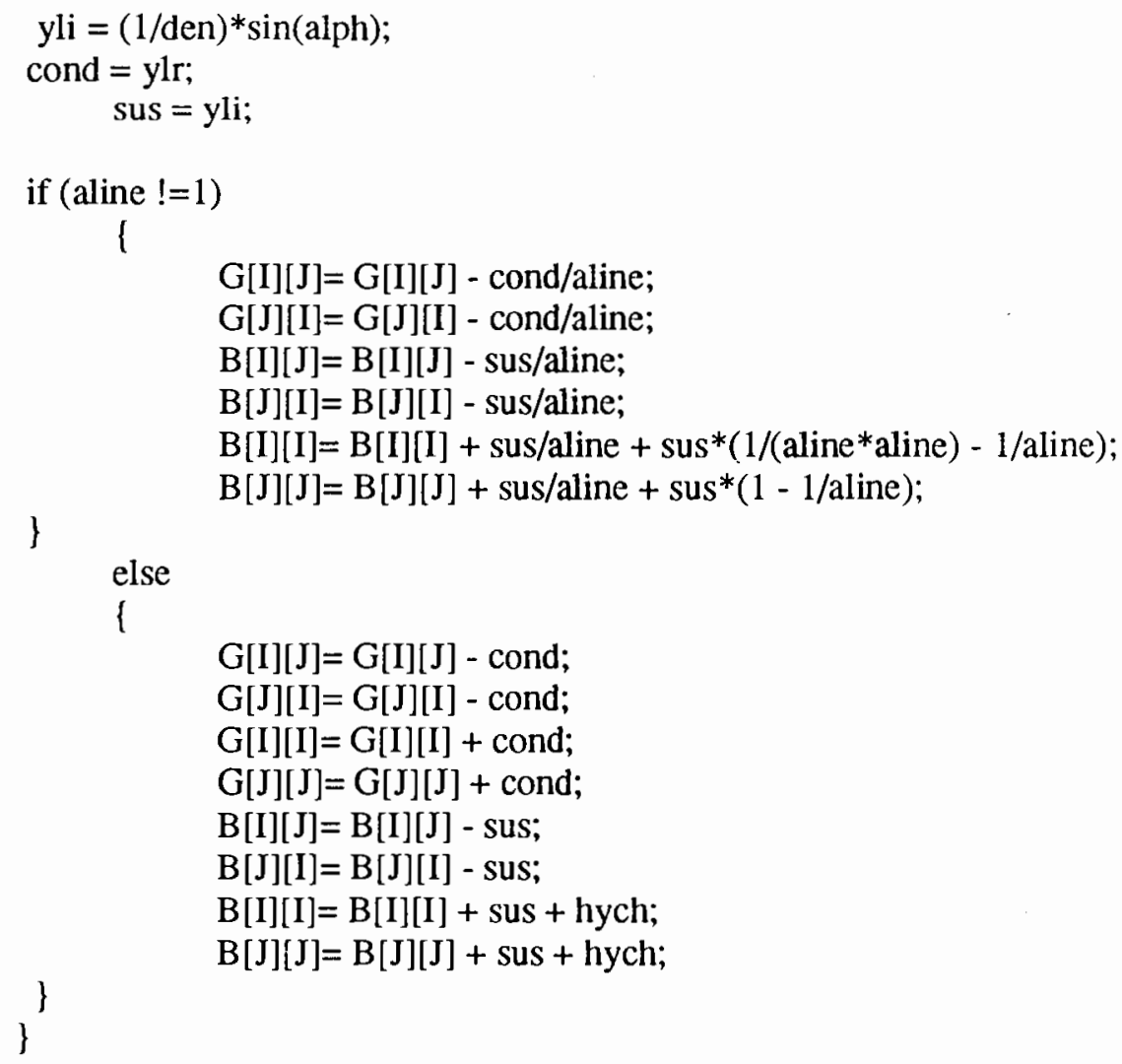

else printf(" $(n$ ");

printf("\%6.3f-j\%5.3f ", G[I][J], fabs(B[I][J])); 
$1 *$ GENERATION OF THE $\Delta P \& \Delta Q * /$

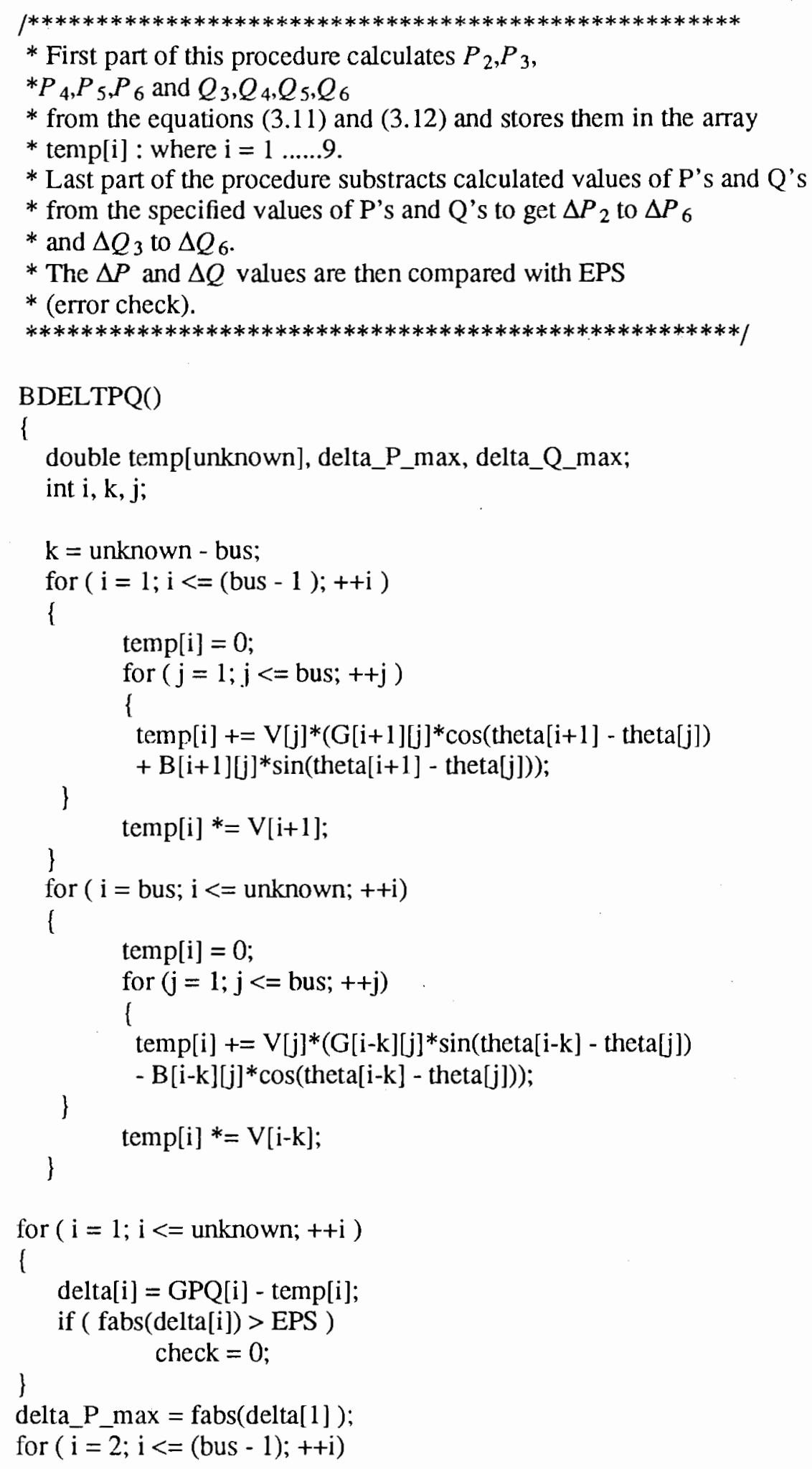




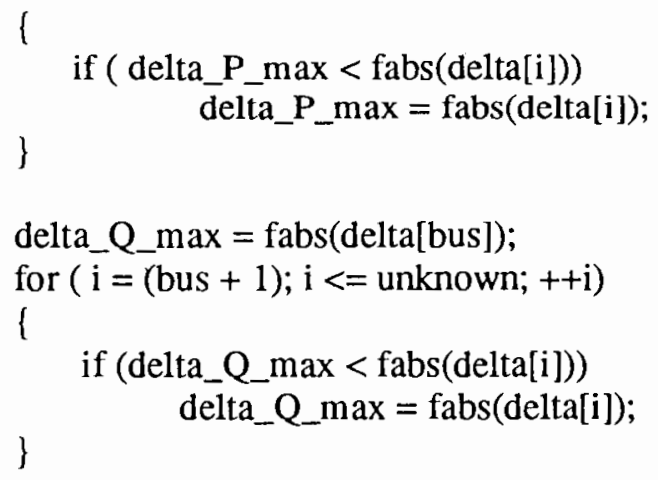

* This procedure creates the H,N,M,L matrices by equations (3.15)

* which are partitions of the partial derivative matrices. The jacobian

* matrix is from the H,N,M,L matrices, with the rows and columns,

* \& neglecting slack bus values. The procedure then does the forward Gauss

* elimination on the jacobian matrix for L_U decomposition.

$* * * * * * * * * * * * * * * * * * * * * * * * * * * * * * * * * * * * * * * * * * * * * * * * * * * * * * * * * * * *)$

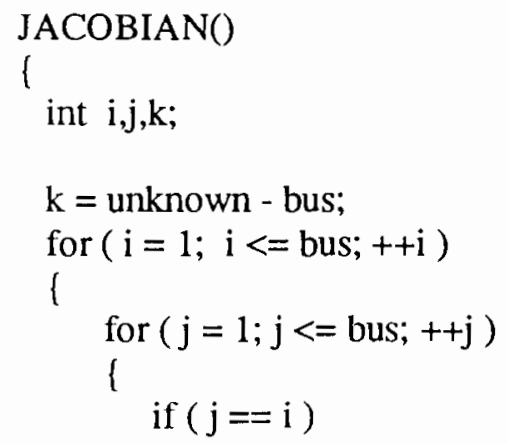




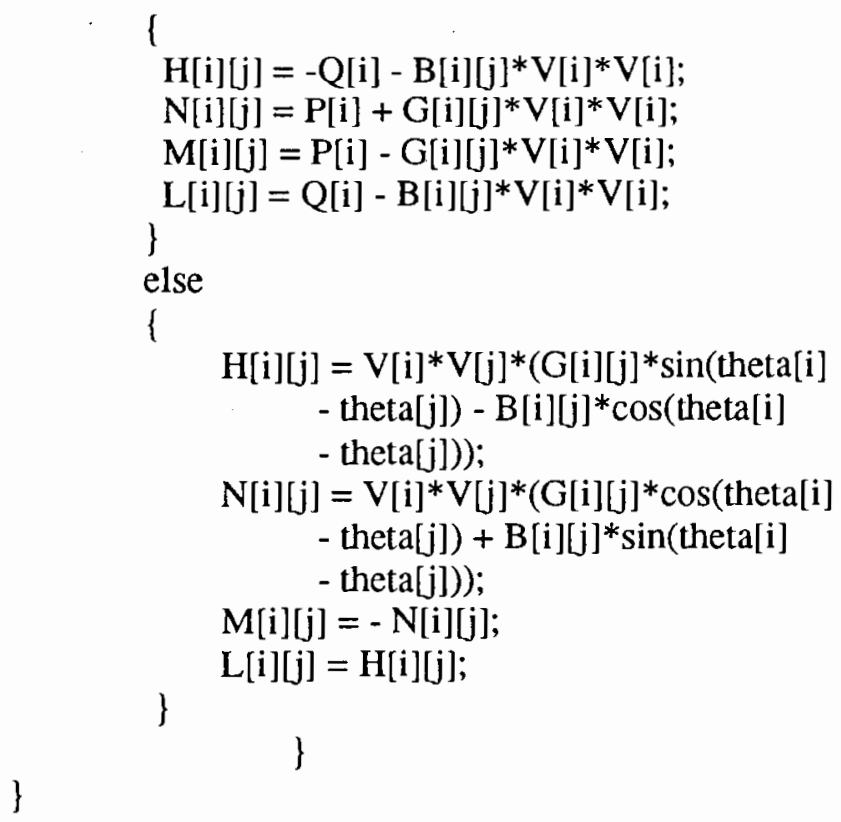

\section{/* GENERATES JACOBIAN MATRIX */}

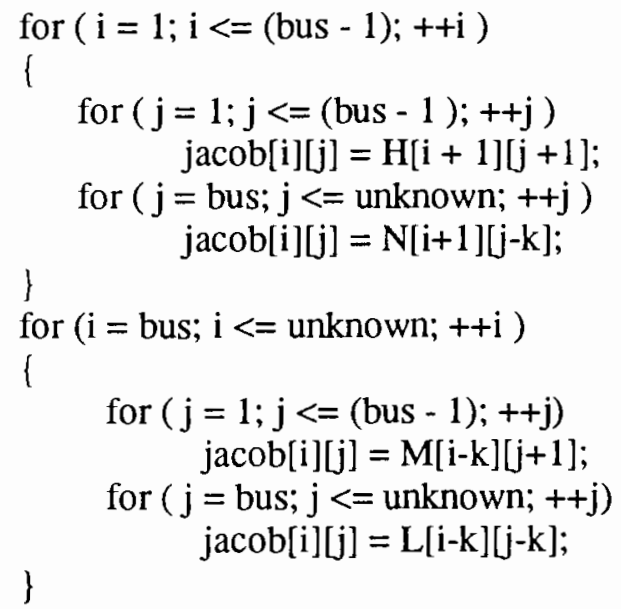

/* L AND U OF THE JACOBIAN MATRIX */

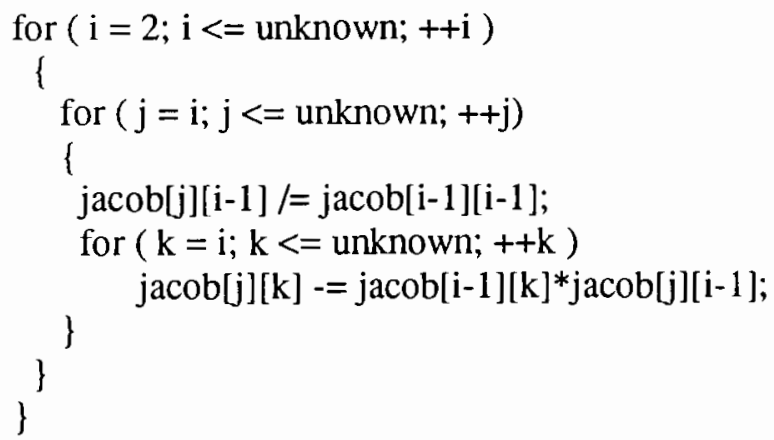


/* CALCULATE V,X,AND Y MATRICES */

* Calculates the Y matrices by back substitution using the

* lower triangular matrix of the modified jacobian matrix \& the

* $\triangle P \& \Delta Q$ are generated in this procedure. The

* matrix is determine by back substitution using the

* triangular matrix of the modified jacobian matrix and the $\mathrm{Y}$

* matrix so generated. The X matrix then corresponds to

$* \Delta \theta^{\prime} s$ and $\Delta V^{\prime} s$ which when added to the

$* \theta^{\prime} s$ and $V^{\prime}$ to give the new set of values for the

* variables. VXY() prints out the values of $\theta^{\prime}$ and

* the values of the $V^{\prime}$ s at the each iteration.

$* * * * * * * * * * * * * * * * * * * * * * * * * * * * * * * * * * * * * * * * * * * * * * * * * * * * * 1$

VXY()

\{

int $\mathrm{i}, \mathrm{j}, \mathrm{k}$;

/* CALCULATE Y MATRIX */

$Y[1]=\operatorname{delta}[1]$;

for $(\mathrm{i}=2 ; \mathrm{i}<=$ unknown; $++\mathrm{i})$

I

$\mathrm{Y}[\mathrm{i}]=\operatorname{delta}[\mathrm{i}]$

for $(\mathrm{j}=1 ; \mathrm{j}<=(\mathrm{i}-1) ;++\mathrm{j})$

$\mathrm{Y}[\mathrm{i}]-=\mathrm{jacob}[\mathrm{i}][\mathrm{j}] * \mathrm{Y}[\mathrm{j}]$;

\}

for $(i=1 ; i<=$ unknown; ++i)

/* CALCULATE X MATRIX */

$\mathrm{X}[$ unknown $]=\mathrm{Y}[$ unknown $] / \mathrm{jacob}[$ unknown][unknown];

$\mathrm{i}=$ unknown - 1 ;

while $(\mathrm{i}>0.0)$

I

$\mathrm{X}[\mathrm{i}]=\mathrm{Y}[\mathrm{i}]$

$\mathrm{j}=$ unknown;

while $(\mathrm{j}>\mathrm{i})$

\{

$\mathrm{X}[\mathrm{i}]-=\mathrm{jacob}[\mathrm{i}][\mathrm{j}] * \mathrm{X}[\mathrm{j}]$;

$\mathrm{j}-=1$;

\}

$\mathrm{X}[\mathrm{i}] /=\mathrm{jacob}[\mathrm{i}][\mathrm{i}]$;

$\mathrm{i}=1$; 
/* CAlCUlate VOLTAGE AND ANGLE */

$\mathrm{k}=$ unknown - bus;

for $(\mathrm{i}=2 ; \mathrm{i}<=$ bus; $++\mathrm{i})$

theta $[\mathrm{i}]+=\mathrm{X}[\mathrm{i}-1]$;

for $(i=3 ; i<=$ bus; $++i)$

$\mathrm{V}[\mathrm{i}]+=\mathrm{X}[\mathrm{i}+\mathrm{k}] * \mathrm{~V}[\mathrm{i}]$;

/* printf VOLTAGES AND ANGLES */

for $(i=1 ; i<=b u s ;++i)$

printf('vn\%4d\%14.5f\% 14.5f', i, theta[i], V[i]);

\}

/* CALCULATE P AND Q OF THE SYSTEM */

* After final iteration i,e, when all the elements of the

* $\triangle P$ and $\triangle Q$ are found less than EPS values, this

* procedure calculates the final values of $P$ and $Q$ by equations (3.11) and (3.12).

$* * * * * * * * * * * * * * * * * * * * * * * * * * * * * * * * * * * * * * * * * * * * * * * * * * * *)$

PQ()

I

int $i, j$;

for $(i=1 ; i<=$ bus; $++i)$

\{

$P[i]=0.0$;

$\mathrm{Q}[\mathrm{i}]=0.0$;

for $(\mathrm{j}=1 ; \mathrm{j}<=$ bus; $++\mathrm{j})$

\{

$P[i]+=V[j]^{*}(G[i][j] * \cos ($ theta $[\mathrm{i}]-$ theta $[\mathrm{j}])$

$+B[i][j] * \sin ($ theta$[i]-$ theta $[j]))$;

$\mathrm{Q}[\mathrm{i}]+=\mathrm{V}[\mathrm{j}] *(\mathrm{G}[\mathrm{i}][\mathrm{j}] * \sin ($ theta$[\mathrm{i}]-$ theta $[\mathrm{j}])$

$-B[i][j]^{*} \cos ($ theta $[\mathrm{i}]-$ theta[j]));

$\begin{aligned} & \} \\ & \mathrm{P}[\mathrm{i}] \\ & \mathrm{Q}\end{aligned} \mathrm{V}^{*} \mathrm{~V}[\mathrm{i}]$
\}

for $(i=1 ; i<=$ bus; $++i)$

I

if $(\mathrm{P}[\mathrm{i}]<0.0)$

\{

P_of_Load $[\mathrm{i}]=\operatorname{fabs}(\mathrm{P}[\mathrm{i}])$;

P_of_Gen[i] $=0.0$; 


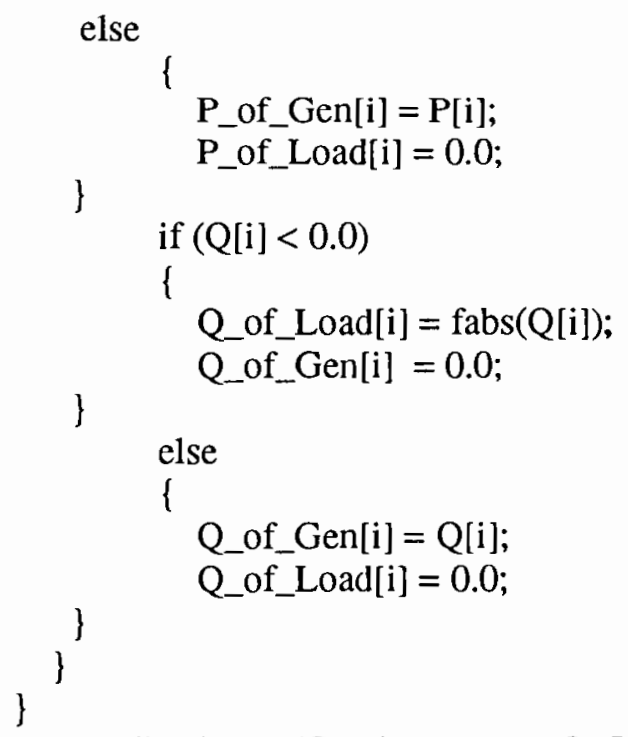

\section{/* SOLUTION OF THE PROBLEM */}

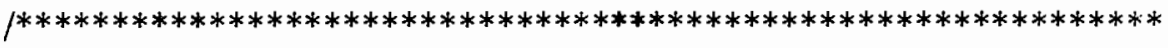

* This procedure converts the per_unit values of $P_{g e n}$,

${ }^{*} Q_{\text {gen }}, P_{\text {load }}, Q_{\text {load }}$ to their actual values by

* multiplying with the multiplier. It also converts the phase

* angle values from radian to degrees and prints the values

* of the final results.

$* * * * * * * * * * * * * * * * * * * * * * * * * * * * * * * * * * * * * * * * * * * * * * * * * * * * * * * * * * * * /$

final()

1

int $\mathrm{i}$;

printf("VIUVIUSSOLUTION TO THE PROBLEM : ");

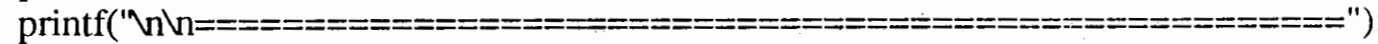

printf("nBUS VOLTS ANGLE GENERATION LOAD");

$\begin{array}{llllll}\text { printf("Vi \# } & \text { (degr) } & \text { p(MW) } & \text { Q(MVAR) } & \text { p(MW) } & \text { Q(MVAR)"); }\end{array}$

printf(" $\mathrm{n}================== \pm==============================\mathrm{h}$ ");

for $(\mathrm{i}=1 ; \mathrm{i}<=$ bus; $++\mathrm{i})$

\{

P_of_Gen[i] ${ }^{*}=$ BASEV;

Q_of_Gen[i] *=BASEV;

P_of_Load [i] * = BASEV;

Q_of_Load[i] ${ }^{*}=$ BASEV;

angle $[\mathrm{i}]=($ theta[i] $* 180.0) / \mathrm{PI}$;

printf("Vn \%d\%9.5f\%11.5f\%11.5f\%11.5f\%11.5f\%10.5f", i, V[i], angle[i], P_of_Gen[i], Q_of_Gen[i],P_of_Load[i], Q_of_Load[i]);

\}

printf(" $n$ (n"); 
APPENDIX C

THE PROGRAM SOURCE CODE

FOR LINE FLOW CALCULATIONS 


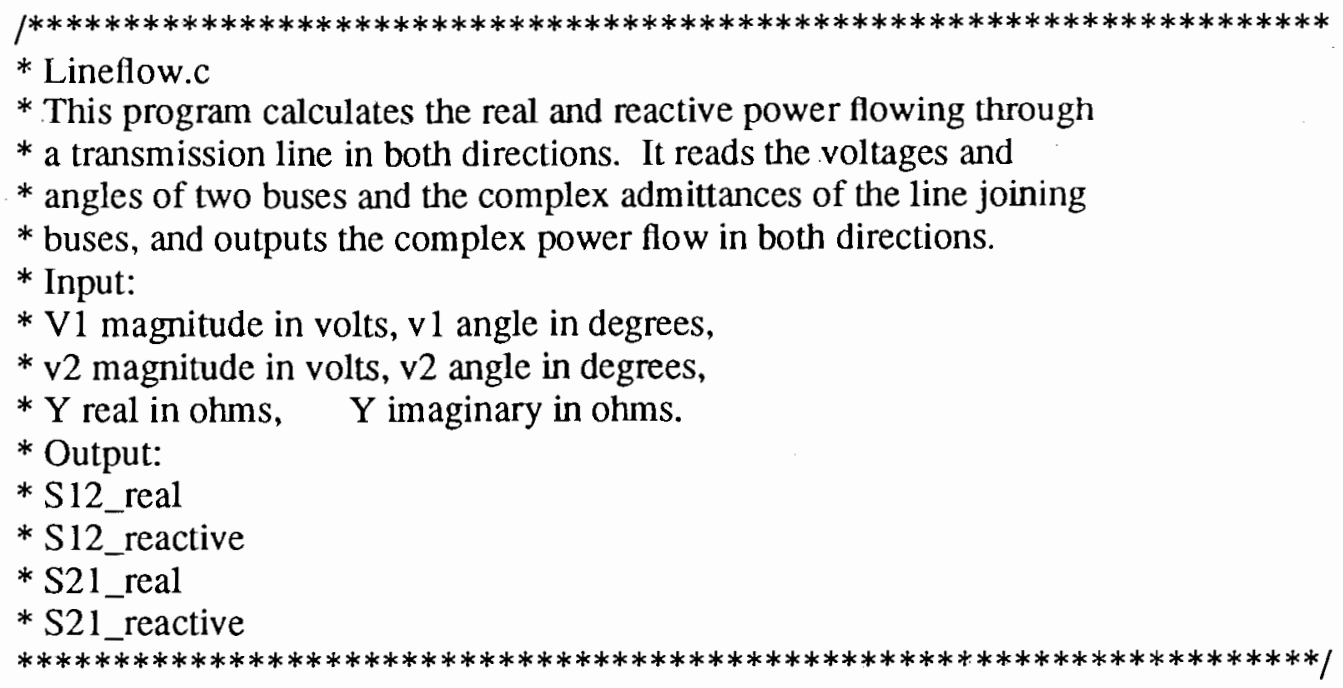

\#include <stdio.h>

\#include <math.h $>$

\#define PI 3.14159

struct element \{

double mag; /* magnitude */

double ang; $/ *$ angle $* /$

\} ;

struct ecomplex \{

double re; $/ *$ real part */

double im; $/ *$ imaginary part */

\}

struct element $v[3] ; /^{*}$ v1, v2 of buses 1,2 respectively */

struct element vL[3], iL[3], yL[3]; /* ?L[1]:1->2, ?L[2]:2->1*/

struct ecomplex y, sC[3]; /* complex admittance, powers of line */

main 0

\{ double templ, temp2;

int $\mathrm{j}$;

$l^{*}$ input magnitudes and angles of $v 1, \mathrm{v} 2 * /$

printf( " $\mathrm{nEnter}$ magnitudes and angles(degrees) of: $\mathrm{n} n$ ");

for $(j=1 ; j<3 ; j++)$

$\{$ printf(" $\vee \%$ Id $==>", j)$;

scanf("\%lf\%lf", \&temp1, \&temp2);

$v[j] . m a g=$ temp 1 ;

\}

$\mathrm{v}[\mathrm{j}]$.ang $=$ temp2 $* \mathrm{PI} / 180 ; \quad / *$ radians $* /$

/****

printf( " $n$ ");

for $(j=1 ; j<3 ; j++)$

printf("v[\%ld].elem: (\%8.31f,\%8.31f) $\mathrm{kn}$ 
j, v[j].mag, v[j].ang * 180/PI);

$1 *$ input real and imaginary parts of the complex admittance $y * /$

printf("Enter real and imaginary parts of $\mathrm{y}==>$ ");

scanf("\%lf\%lf", \&temp1, \& temp2);

y.re $=$ temp $1 ;$ y.im = temp2;

$1 *$ Get the magnitudes and angles of $y 12=y L[1], y 21=y L[2] * /$

GetMagni(y.re, y.im ,\&temp1 );

yL[1].mag $=y L[2] \cdot m a g=t e m p 1 ;$

GetAngle(y.re, y.im, \&temp2);

yL[1].ang = yL[2].ang = temp2; $/ *$ degrees *

/****

printf("ทny.comp: $\quad(\% 8.31 f, \% 8.31 f) \backslash n "$, y.re, y.im);

for $(j=1 ; j<3 ; j++)$

printf("y121[\%1d].elem: (\%8.31f,\%8.31f) $\mathrm{n"}$

j, yL[j].mag, yL[j].ang);

$* * * * 1$

$/ *$ Get magnitudes and angies of $\mathrm{v} 12=\mathrm{vL}[1], \mathrm{v} 21=\mathrm{vL}[2] * /$

GetvL();

$|* * * *|$

for $(\mathrm{j}=1 ; \mathrm{j}<3 ; \mathrm{j}++)$

printf("v121[\%1d].elem: (\%8.31f,\%8.31f)ทn",

$1 * * * * 1$

$\mathrm{j}, \mathrm{vL}[\mathrm{j}]$.mag, vL[j].ang);

$/ *$ Get magnitudes and angles of i12=iL[1], i21=iL[2] */

iL[1].mag $=$ iL[2].mag $=$ vL[1].mag $*$ yL[1].mag;

iL[1].ang $=(v L[1]$. ang $+y L[1]$. ang $) * \mathrm{PI} / 180 ; \quad / *$ radians $* /$

iL[2].ang $=(v L[2]$. ang $+y L[2]$.ang $) * P L / 180$;

/****/

for $(j=1 ; j<3 ; j++)$

printf("i121[\%1d].elem: (\%8.3lf,\%8.31f) $n "$ ", j,iL[j].mag,iL[j].ang *180/PI);

$|* * * *|$

$/ *$ Get the complex powers $\mathrm{s} 12=\mathrm{sC}[1], \mathrm{s} 21=\mathrm{sC}[2] * /$

GetsC();

/* Print the components of the complex powers */

printf(" real reactive $\mathrm{n} "$ ");

printf("s12: \%10.5lf \%10.5lfn", sC[1].re, sC[1].im);

printf("s21: \%10.5lf \%10.51fn", sC[2].re, sC[2].im);

\} $/ *$ end main */

$/ *++++++++++++++++++++++++++++++++++++++++++++++++++++++$

${ }^{*}$ GetMagni $(0$ : retums the magnitude given the complex components/

*++++++++++++++++++++++++++++++++++++++++++++++++++++++++++*/

GetMagni $(\mathrm{x}, \mathrm{y}, \mathrm{z})$

double $x, y,{ }^{*} z$

\{

$*^{*} \mathrm{z}=\operatorname{sqrt}\left(\mathrm{x}^{*} \mathrm{x}+\mathrm{y}{ }^{*} \mathrm{y}\right)$

\} $/ *$ end GetMagni */ 
$/ *++++++++++++++++++++++++++++++++++++++++++++++++++++++$

* GetAngle() : determines the angle and its sign according to its

* quadrant, given the complex components. Returns the value of

* the angle in degrees.

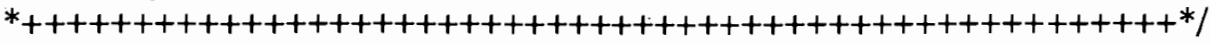

GetAngle $(x, y, z)$

double $\mathrm{x}, \mathrm{y},{ }^{*} \mathrm{z}$

\{

if $(\mathrm{x}==0) *_{\mathrm{Z}}=90$;

else

$\left\{{ }^{*} \mathrm{Z}=\operatorname{atan}(\mathrm{fabs}(\mathrm{y}) / \mathrm{fabs}(\mathrm{x})) * 180 / \mathrm{PI} ; / *\right.$ angle in degrees $*$ /

if $((\mathrm{x}>0) \& \&(\mathrm{y}<0)) \quad *_{\mathrm{z}}=-1 *^{*} \mathrm{z}$;

else if $((x<0) \& \&(y>0)) \quad *_{z}=180-*^{*} z$

else if $((\mathrm{x}<0) \& \&(\mathrm{y}<0)) \quad *_{\mathrm{z}}=*_{\mathrm{z}}-180$;

$1^{*}$ else if $((\mathrm{x}>0) \& \&(\mathrm{y}>0)) \quad \mathrm{z}=\mathrm{z}^{*} /$

\}

\} ${ }^{*}$ end GetAngle */

$/ *++++++++++++++++++++++++++++++++++++++++++++++++++++++++$

* GetvL() : determines the magnitudes, angles of $v 12, v 21$ given $v 1, v 2$

* $++++++++++++++++++++++++++++++++++++++++++++++++++++* 1$

GetvL()

\{ struct ecomplex $v \mathrm{C}[3] ; / *$ complex components of $\mathrm{v} 1, \mathrm{v} 2, \mathrm{v} 12, \mathrm{v} 21 *$ /

double temp;

int $\mathrm{j}$;

int 1;

* Get the complex components of $\mathrm{v} 1=\mathrm{vC}[1], \mathrm{v} 2=\mathrm{vC}[2] * /$

for $(1=1 ; 1<3 ; 1++)$

GetComplex (v[1].mag, v[1].ang, \&vC[1]);

j****

for $(j=1 ; j<3 ; j++)$

printf("v[\%1d].comp: $\quad(\% 8.31 \mathrm{l}, \% 8.31 \mathrm{f}) \mathrm{nn}$,

j,vC[j].re, vClj].im;

$* * * * /$

$I^{*}$ use $\mathrm{vC}[1], \mathrm{vC}[2]$ for the complex components of $\mathrm{v} 12$ and $\mathrm{v} 21 * /$

vC[1].re $=$ vC[1].re $-\mathrm{vC}[2] . r e ; \quad / * v 12 \mathrm{re}=\mathrm{v} 1 \mathrm{re}-\mathrm{v} 2 \mathrm{re} * /$

vC[1].im $=v C[1] . \mathrm{im}-\mathrm{vC}[2] . \mathrm{im} ; \quad / * v 12 \mathrm{im}=\mathrm{v} 1 \mathrm{im}-\mathrm{v} 2 \mathrm{im} * /$

$\mathrm{vC}[2] . \mathrm{re}=-1 * \mathrm{vC}[1] . \mathrm{re} ; \quad / * \mathrm{v} 21 \mathrm{re}=-\mathrm{v} 12 \mathrm{re} \quad * /$

$\mathrm{vC}[2] . \mathrm{im}=-1 * \mathrm{vC}[1] . \mathrm{im} ; \quad / * \mathrm{v} 21 \mathrm{im}=-\mathrm{v} 2 \mathrm{lim} \quad *$ I

/****1

for $(j=1 ; j<3 ; j++)$

printf("v121[\% ld].comp: (\%8.31f,\%8.31f) $\backslash n "$, j, vC[j].re, vC[j].im);

j****/

$/ *$ find magnitudes,angles of $\mathrm{v} 12, \mathrm{v} 21$ from complex components */

GetMagni(vC[1].re, vC[1].im, \&temp);

$\mathrm{vL}[1] \cdot \mathrm{mag}=\mathrm{vL}[2] \cdot \mathrm{mag}=$ temp;

GetAngle(vC[1].re, vC[1].im, \&vL[1].ang); $/ *$ degrees */ 
GetAngle(vC[2].re, vC[2].im, \&vL[2].ang);

\} /* end GetvL */

$/ *+++++++++++++++++++++++++++++++++++++++++++++++++++++++++++$

* GetComplex () : determines the complex components z.re, z.im given

* the magnitude and angl(radians)

* $++++++++++++++++++++++++++++++++++++++++++++++++++++++++++* 1$

GetComplex(magni, angle, $\mathrm{z}$ )

double magni, angle;

struct ecomplex ${ }^{*} z$;

\{

z->re $=$ magni $* \cos ($ angle $)$;

$\mathrm{z}->\mathrm{im}=\operatorname{magni} * \sin ($ angle $)$;

\} $/ *$ end GetComplex */

$/ *++++++++++++++++++++++++++++++++++++++++++++++++++++++++++$

* GetsL() : determines the complex components of the power that

* flows in the line in both directions

GetsCO

\{ struct ecomplex iC; /* complex components of i12,i21,i12c,i21 $\mathrm{c}^{*}$ \}

struct element iCL, sL; /* mag, angles of i12C,i21C, s12,s21 */

int $\mathrm{j}$;

for $(j=1 ; j<3 ; j++)$

\{ GetComplex(iL[j].mag, iL[j].ang, \&iC);

$|* * * *|$

printf("i121 [\%1d].comp: (\%8.31f,\%8.31f)v", j, iC.re,iC.im);

$1 * * * * /$

${ }^{*}$ use iC to hold the complex components of i12c, i21 $\mathrm{c}^{*} /$

$/ * \mathrm{iC}=\mathrm{i} 12 \mathrm{c} . \mathrm{re}(\mathrm{j}=1), \mathrm{iC}=\mathrm{i} 21$.re $(\mathrm{j}=2) * /$

$\mathrm{iC} . \mathrm{im}=-1 * \mathrm{iC} . \mathrm{im} ; / * \mathrm{i} 12 \mathrm{c} . \mathrm{im}=-\mathrm{i} 12 . \mathrm{im}, \mathrm{i} 21 \mathrm{c} . \mathrm{im}=-\mathrm{i} 21 . \mathrm{im} * /$

$|* * * *|$

printf("i121c[\% [d].comp:(\%8.31f,\%8.31f)\n", j, iC.re,iC.im);

|****|

GetMagni(iC.re, iC.im, \&iCL.mag);

GetAngle(iC.re, iC.im, \&iCL.ang); $/ *$ degrees */

$|* * * *|$

printf("i121c[\%1d].elem:(\%8.31f,\%8.31f) \n",

j, iCL.mag, iCL.ang);

$|* * * *|$

$$
\text { j, iCL.mag, iCL.ang); }
$$

sL.mag $=v[j] . m a g * i C L . m a g ;$

sL.ang $=v[j]$.ang $+(\mathrm{iCL}$. ang $* \mathrm{PI} / 180) ; / *$ radians */

$1 * * * *$

printf("s121[\%1d].elem: (\%8.31f,\%8.31f) $\mathrm{nn",}$

$* * * * 1$

j, sL.mag, sL.ang *180/PI);

$/ *$ get complex components of powers s 12=sC[1], s21=sC $[2] * /$

GetComplex(sL.mag, sL.ang, \&sC[j]); 
\}

$1^{*}$ end GetsC $*$ I

$/ * * * * * * * * * * * * * * * * * * * * * * * * *$ end lineflow.c $* * * * * * * * * * * * * * * * * * * * * * * * *)$ 
APPENDIX D

THE PROGRAM SOURCE CODE

FOR COST CALCULATION 
/*******************************************************************

$*$ CostCalc.c

* This program calculates monthly energy bill for compensated

* reactive power and uncompensated reactive power in a plant.

* Input:

* days/month, shifts/day, hours/shift

* pf, rkva drawn/hr, kw drawn/hr

* output:

* -No_compensation power cost-

$*$ pf penalty $=$

* energy/month, energy charge $=$

* demand, demand charge $=$

$*$ pf penalty, penalty charge $=$

$*$ total cost $=$

* -Compensation power cost-

$*$ pf penalty $=$

* energy/month, energy charge $=$

$*$ demand, demand charge $=$

$*$ pf penalty, penalty charge $=$

$*$ total cost $=$

* safely drawn rkva =

* monthly savings $=$

\#include $<$ stdio.h $>$

\#include <math.h $>$

\#define DCOST $4.14 / *$ unit cost for demand charges */

\#define ECOST $0.02 \quad l^{*}$ unit cost for energy charges */

main()

$\{$ double pf, avepf; $/ *$ power facter and average in a month *\} double hrkva, hkw; /* power drawn per hour */

double days, shifts, hours; /* days/mo, shifts/day, hrs/shift */

double mhrs, mrkva, mkw, mkva; /* hrs,kw,rkva,kva. for a month */

int pfpenalty; $\quad / * \%$ penalty in terms of $\%$ of $\mathrm{pf} * 1$

double demandch; $/ *$ power subjected to demand charge */

double bill; $\quad / *$ total power cost for no-compensation */

double saferkva, comrkva; /* rkva with compensated power */

double tempd; $\quad I^{*}$ temporary variable for doubles $* /$

/* input data for power consumption determination */ printf("Vnenter days/mo, shifts/day, hours/shift ==> "); scanf("\%lf\%lf\%lf", \&days, \&shifts, \&hours);

printf('venter pf, and rkva, kw drawn per hour ==>"); scanf("\%lf\%lf\%lf", \&pf, \&hrkva, \&hkw);

mhrs $=$ days $*$ shifts $*$ hours; $/ *$ total hours in one month */ $|* * * *|$

printf("Vndays/month $=\% 5.21 \mathrm{f}, "$, days);

printf("shifts/day = \%3.2lf, ", shifts); 
printf("hours/shift = \%5.21N", hours);

printf("total hours/month $=\% 5.21 \mathrm{fn} "$, mhrs);

printf('vnf $=\% 4.21 \mathrm{f}, \mathrm{rkva} / \mathrm{hr}=\% 10.5 \mathrm{lf}, \mathrm{kw} / \mathrm{hr}=\% 10.5 \mathrm{lfN} "$ ",

$1 * * * * /$

pf, hrkva, hkw);

$/ *$ determine power drawn in one month $* /$

mrkva $=$ hrkva $*$ mhrs;

$\mathrm{mkw}=\mathrm{hkw}{ }^{*} \mathrm{mhrs}$

mkva $=\operatorname{sqrt}\left(m k w^{*} m k w+m r k v a * m r k v a\right) ;$

${ }^{*}$ determine avarage pf in a month $* /$

avepf $=\mathrm{mkw} / \mathrm{mkva} * 100$;

printf("vaverage plant power factor $=\% 6.21 \mathrm{fn}$ ", avepf);

$I^{* * * *}$ No-compensation power cost determination $* * * *$ /

printf(" $\mathrm{n} * * * *$ No-compensation power $\operatorname{cost} * * * * \mathrm{n} n$ ");

${ }^{*}$ determine $\%$ pf penalty $* /$

tempd $=(0.95 * 100-\text { avepf })^{*} 2$;

if (tempd $>$ (double)(int)tempd)

pfpenalty $=($ int $)$ tempd +1 ;

else

pfpenalty = (int)tempd;

printf("power factor penalty = \%6.21fn", (double)pfpenalty);

${ }^{*}$ power charges in kwhrs: energych=mkva, demandch, penaltych*/

demandch $=$ sqrt $(h k w * h k w+$ hrkva*hrkva $)$;

TabulateCharges(mkva, demandch, demandch*pfpenalty/100, \&bill);

/**** Compensated power cost determination $* * * * /$

printf(" $\vee n^{* * * *}$ Compensated power cost $\left.* * * * n "\right)$;

/* rkva that may be drawn safeily from the utility */

tempd $=\mathrm{mkw} / 0.95$;

saferkva $=\operatorname{sqrt}\left(\right.$ tempd ${ }^{*}$ tempd $\left.-\mathrm{mkw}^{*} \mathrm{mkw}\right)$;

printf("rkva that may be drawn safely $=\% 10.51 \mathrm{fn}$ ", saferkva);

$/ *$ rkva to be compensated to avvoid pf penalty in rkva/hr */

comrkva $=($ mrkva - saferkva $) /$ mhrs;

/* kva drawn per month after compensation */

$\mathrm{mkva}=\operatorname{sqrt}\left(\mathrm{mkw} \mathrm{w}^{*} \mathrm{mkw}+\right.$ saferkva*saferkva $)$

${ }^{*}$ power charges in kwhrs: energych $=m k v a$, demandch, penaltych $=0 * /$

tempd = hrkva - comrkva;

demandch $=\operatorname{sqrt}\left(h_{k w} * h k w+\right.$ tempd*tempd $)$;

TabulateCharges(mkva, demandch, 0.0, \& tempd);

/* monthly savings with compensation */

printf("vMMonthly savings $=\% 8.21 \mathrm{f} n$ ", bill - tempd);

\} $/ *$ end main *I

/*+++++++++++++++++++++++++++++++++++++++++++++++++++++++++++

* TabulateCharges () : tabulates the kwh charges incurred, the

* corresponding costs and the total power cost (bill)

$*++++++++++++++++++++++++++++++++++++++++++++++++++++++++++* /$

TabulateCharges(energy, demand, penalty, totalcost)

double energy, demand, penalty, *totalcost; 
1

printf(" $\mathrm{n} \quad \mathrm{kw}-\mathrm{hr} \quad$ dollarsh");

printf("energy charge : \%13.51f : \%10.21fn", energy, energy*ECOST);

printf("demand charge : \% 13.51f : \% 10.21fun", demand, demand*DCOST);

printf("penalty charge: \%13.5lf : \%10.21fn", penalty, penalty*DCOST);

$*$ totalcost $=$ energy $* E C O S T+($ demand + penalty $) * D C O S T$;

printf("TOTAL COST :\%10.2lfn", *totalcost);

\} $1 *$ end TabulateCharges *1

$/ * * * * * * * * * * * * * * * * * * * * * * * * * * * *$ end CostCalc 